\title{
The Longevity of Famous People from Hammurabi to Einstein*
}

\author{
David de la Croix \\ IRES and CORE, Université catholique de Louvain
}

\author{
Omar Licandro \\ IAE-CSIC and Barcelona GSE
}

April 24, 2015

\begin{abstract}
We build a new sample of 300,000 famous people born between Hammurabi's epoch and Einstein's cohort, including their vital dates, occupations, and locations from the Index Bio-bibliographicus Notorum Hominum. We discuss and control for selection and composition biases. We show using this long-running consistent database that there was no trend in mortality during most of human history, confirming the existence of a Malthusian epoch; we date the beginning of the steady improvements in longevity to the cohort born in 1640-9, clearly preceding the Industrial Revolution, lending credence to the hypothesis that human capital may have played a significant role in the take-off to modern growth; we find that this timing of improvements in longevity concerns most countries in Europe and most skilled occupations.
\end{abstract}

JEL Classification Numbers: J11, I12, N30, I20, J24.

Keywords: Longevity, Notoriety, Malthus, Elite, Compensation Effect of Mortality, Enlightenment, Europe.

${ }^{*}$ The authors thank Manuel Arellano, Raouf Boucekkine, Leah Boustan, Elise Brezis, Georgi Kocharkov, Oded Galor, Ana Rute, Frans van Poppel, Sébastien Van Belleghem, Jan Luiten van Zanden, Nico Voigtlaender, Joachim Voth, John Wilmoth and participants at seminars (CEMFI, CIREC-McGill, DemographyUCLouvain, GREQAM-Marseilles, Max Planck Institute for Demographic Research-Rostock, PUC-Rio de Janeiro, UdelaR-Montevideo, University San Andrés-Buenos Aires, University of São Paulo, University of Southern Denmark, University of Zurich, UCLA economic history group), and conferences (2012: REDgMadrid, Sixth Low Countries Conference-Antwerp, Sustainability of Population Changes-Louvain-la-Neuve, Towards Sustainable Economic Growth-Barcelona, Cologne Workshop on Macroeconomics, SAEe; 2013: ASSA-San Diego, Deep Determinants of International Comparative Development-Brown, LACEA-Mexico) for their comments. Laura Cozma has provided highly valuable research assistance. Omar Licandro acknowledges the financial support of the Spanish Ministry of Economy and Competitiveness (ECO2010-17943 and ECO2013-48884-C3-1-P). We finally thank Zeller Verlag and Mrs Suzanna Wand, for allowing us to publish online the part of their commercial database we used for the empirical analysis (except for the title of the sources linked to each famous person). 


\section{Introduction}

Having gathered estimations on adult life expectancy from various times and places, Clark (2007) (Tables 5.2 and 5.3) argues that there was no trend in adult longevity during the Malthusian stagnation era, i.e. until about the industrial revolution. There is, moreover, extensive evidence showing that adult life expectancy has increased markedly and continuously since the beginning of the 19th century. The importance of the economic growth process in fostering such improvements has been stressed by Fogel (1994). Country wide statistics for Sweden, England and France show the emergence of a trend for generations born in the nineteenth century, although little information is available for those born earlier. ${ }^{1}$ The earliest evidence of improved adult life expectancy is provided by Wrigley et al. (1997). They reported an important reduction in adult mortality in the English population in the middle of the eighteenth century. On top of that, some authors who looked at small prominent groups of households, such as the English aristocrats (Hollingsworth 1977), identify the beginning of the change one century earlier for these groups than for the overall population.

The question of the timing of the rise in longevity finds a nice echo in what the contemporaries of the industrial revolution wrote about the history and prospects of life expectancy. Malthus (1798) believed that "With regard to the duration of human life, there does not appear to have existed from the earliest ages of the world to the present moment the smallest permanent symptom or indication of increasing prolongation." Writing a few years before Malthus, Condorcet (1795), instead, anticipated the emergence of large improvements in longevity: "One feels that transmissible diseases will slowly disappear with the progresses of medicine, which becomes more effective through the progress of reason and social order, ... and that a time will come where death will only be the consequence of extraordinary accidents, or of the increasingly slower destruction of vital forces."

In this paper, we aim to document the long stagnation period and identify the time at which longevity, defined as the average lifespan of individuals of a given cohort, started to increase above its plateau mean. To this aim, we built a new dataset of around 300,000 famous people born between the 24th century BCE (Hammurabi, king of Babylonia, is among the first) and $1879 \mathrm{CE}$, the year of Albert Einstein's birth. Vital dates were taken from the Index Bio-bibliographicus Notorum Hominum (IBN), which also contains information on multiple individual characteristics, including place of birth and death, occupation, nationality, religion and gender, among others. This very comprehensive tool, covering 3000 biographical

\footnotetext{
${ }^{1}$ From the Human Mortality Database (HMD), cohort life expectancy at age 20 (males) started to increase in 1810-19 for Sweden, 1850-59 for France, and 1840-49 for England and Wales. For the latter, 1840-49 is the first decade of observation. An overview on the HMD is at http://www . mortality.org/Public/Overview. php.
} 
sources from all countries and historical periods, enables us to go beyond the current state of knowledge and to provide a global picture. Existing estimations are local and start, at best, in the 16 th century. ${ }^{2}$

The main contribution of this paper is fourfold. First, it documents, using a worldwide, longrunning, consistent database, that there was no trend in adult longevity until the second half of the 17th century, longevity of famous people being at about 60 years during this period. This finding is important as it provides a reliable confirmation to conjectures that life expectancy was rather stable for most of human history and establishes the existence of a Malthusian epoch. Indeed, the existing literature tends to show that technical advancements has not generated an increase in the standard of living over the years 1, 1000 and 1500 (using the GDP per capita of Maddison (2010)). This view is confirmed and extended by our study as indeed, standards of living, as measured by longevity, had not changed over nearly 4000 years within the period that is conventionally viewed as the Malthusian epoch.

Second, it shows that permanent improvements in longevity preceded the Industrial Revolution by at least one century. The longevity of famous people started to steadily increase for generations born around 1650, reaching a total gain of around nine years for Einstein's cohort. The rise in longevity among the educated segment of society hence preceded industrialization, lending credence to the hypothesis that human capital may have played a significant role in the process of industrialization and the take-off to modern growth.

Third, using information about locations and occupations available in the database, we also found that the increase in longevity did not occur only in the leading countries of the 17th-18th century, but almost everywhere in Europe, and was not dominated by mortality reductions in any particular occupation. Hence, the results found in the existing literature about some local groups of nobles generalize to the whole class of elite people, including writers, scientists, artists, master craftsmen, etc.

Fourth, the rise in longevity is associated primarily with the recanalization of age specific mortality rates, not with a change in the characteristic length of life as measured by the lifespan. This suggests that the rise in longevity we observe in the 17th-19th century does not reflect changes in the biological lifespan of humans but rather improvements in its environment.

People in the IBN belonged to the upper classes of human societies, including the richest,

\footnotetext{
${ }^{2}$ Before the Fourth Lateran Council in 1215, which recommended parishes to hold Status Animarum books covering baptisms, marriages and burials, and took centuries to be adopted over Europe, no systematic register of individual life spans existed in Europe. Graunt (1661) produced the first life table using London data collected by Cromwell in 1535, and the first full-fledged life table was developed by Halley (1693) using data from Breslau (today Wroclav in Poland) for 1687-88.
} 
most powerful and influential individuals, with the highest human capital. In this sense, the observed break occurred around 1650 can be seen as a tipping point in the longevity of the upper classes. Since, as in most studies in economics history, the IBN is not a random sample, we were concerned with the several selection and composition biases that may affect our results. As individuals need to have acquired some reputation to be recorded in the IBN, the sample suffers from a form of selection bias that we refer to as the notoriety bias. People with the potentials to become famous but dying young are excluded and, inversely, only those that are old enough to become famous are included. In addition, there are other biases related to changes in the composition of the sample, in terms of gender, occupation and location. To deal with the different types of selection and composition biases faced by the IBN, we created a measure of conditional longevity that controls for all observed individual characteristics, including occupation dummies, reflecting differences in the notoriety bias across occupations. As additional robustness, we interacted the nine large occupational categories with the time dummies to take into account for possible unobservable changes in standard that may affect the selection bias. Finally, we also documented some of these biases by comparing our results with existing data from different times and places.

The notoriety bias is related to the well-known problem in statistics of left truncation. Most people in the IBN did not get notoriety from birth, but after reaching some status (as for example, a military rank, a political responsibility, or any hierarchical position in a public or private organization) or accomplishing some important achievement (writing a book, painting a picture, making a scientific discovery, founding a city). To compute age specific death rates and life expectancy, one needs to know for all ages the population at risk, i.e. the population of already famous people susceptible of dying. Since the IBN is silent about the age at which people became famous, we cannot estimate life expectancy. For this reason, we used the alternative measure of longevity, equal to the mean lifetime of all observed famous people, and only requires their vital dates. As far as the standards for being famous have not significantly changed over the sample period, we should expect that longevity and life expectancy co-move, longevity being systematically larger.

However, over such a long period, these standards might likely have changed. The introduction of the printing press, for example, has multiplied the number of published biographies, likely making the standards to be famous less strict. If it were the case, changes in longevity may be associated to unobservable changes in the definition of being famous, totally uncorrelated with changes in life expectancy. To deal with this problem we made the following out-of-sample test. For the population of cardinals of the Catholic Church and the population of knights of the Golden Fleece, whose nomination dates are available, we have computed both longevity and life expectancy at age 25 . We found in both population that longevity 
and life expectancy co-move and show a break at the second half of the 17th century, consistently with the behavior of the IBN famous people longevity. This establishes that, even in cases where the conditions to be included into the sample changed dramatically over time (for example the age at elevation of catholic cardinals rose from 40 in the sixteenth century to 50 in the middle of the nineteenth century), the tipping points in longevity and life expectancy are the same.

Famous people are those with a high level of human capital. The community of European famous people, such as scientists, artists, and entrepreneurs, is seen by Mokyr (2011) as being at the root of the Industrial Revolution. The early increase in their longevity has a specific relevance for economic growth, and may support the hypothesis that improvements in longevity were one cause of the industrial revolution. One mechanism for this effect could be through facilitating knowledge accumulation (see Lucas (2009) and Bar and Leukhina (2010)). For Lucas, "a productive idea needs to be in use by a living person to be acquired by someone else, so what one person learns is available to others only as long as he remains alive. If lives are too short or too dull, sustained growth at a positive rate is impossible." Another possible mechanism relates to the provision of incentives for investment in human capital (see Galor and Weil (1999), Boucekkine, de la Croix, and Licandro (2002), Soares (2005), Cervellati and Sunde (2014) and de la Croix and Licandro (2013)). For Galor and Weil, "Changes in mortality can serve as the basis for a unified model that describes the complete transition from the Malthusian Regime to the Modern Growth Regime. Consider the effect of an initial reduction in mortality (due to an exogenous shock to health technology or to standards of living). The effect of lower mortality in raising the expected rate of return to human capital investments will nonetheless be present, leading to more schooling and eventually to a higher rate of technological progress. This will in turn raise income and further lower mortality...".

Famous people were also very much living in cities. We know that cities were unhealthy places, with higher mortality rates. It therefore appears remarkable that despite the increase in population density in the course of urbanization, longevity first remained relatively stable, then started to increase, suggesting perhaps that there was a gradual improvement in the capacity of individuals to live a longer life. Or perhaps that literate people (who are being sampled) had learned how to cope with the hazard of an increase in population density in cities.

The paper is organized as follows. In Section 2, we describe the data and measure the unconditional longevity of famous people. Section 3 defines the universe from which the sample is drawn, reports a list of potential composition and selection biases, discusses the gap between longevity and life expectancy, and provides the out-of-sample test. In Section 4, 
we provide an estimation of famous people conditional longevity, after controlling for the reported biases. We also study whether changes in longevity were general to all locations and occupations. An analytical description of the observed changes is provided in Section 5 through the lenses of the Gompertz-Makeham survival law and the Compensation Effect of Mortality. In Section 6, we compare, for some specific geographical locations and time periods, the longevity of IBN famous people with existing case studies. Finally, in Section 7, we suggest a set of criteria that any good interpretation of these events should meet, advance some possible explanations and conclude.

\section{Sample and Descriptive Statistics}

Our database is built from the Index Biobibliographicus Notorum Hominum (IBN), which is aimed to help researchers around the world to easily access existing biographical sources. The information in the IBN was compiled from around 3000 biographical sources (mainly dictionaries and encyclopedias) covering almost all countries and historical periods; Europeans are clearly overrepresented.

FAmous PEOPle: For people included in the IBN, we have name, year (and often place) of birth and death, a statement about the individual including some broad information on occupation and nationality, and the list of biographical sources in which he (rarely she) is mentioned. Data in the IBN may be coded in different languages (English, German and French are the most frequent) and basically contain the type of information reported in the two examples below (we only report one source per person, but many sources may be associated with the same person):

- Hammurapi; 1792-1750 (1728-1686) ante chr.;3 ... ; Babylonischer könig aus der dynastie der Amoräer; Internationale Bibliographie de Zeitschriftenliteratur aus allen Gebieten des Wissens.

- Einstein, Albert; 1879-1955; Ulm (Germany) - Princeton (N.J.); German physicist, professor and scientific writer, Nobel Prize winner (1921), Swiss and American citizen; Internationale Personal Bibliographie 1800-1943.

The digital version of the IBN used in this paper contains around one million famous people whose last names begin with the letters $\mathrm{A}$ to $\mathrm{L}$, since those from $\mathrm{M}$ to $\mathrm{Z}$ were not yet available in electronic format when we received the data. However, this criterion is not expected to introduce any selection bias in the estimation of longevity changes.

\footnotetext{
${ }^{3}$ Notice that two different years of birth are reported for Hammurabi (Hammurapi in German), but a unique lifespan. The places of birth and death are not reported.
} 


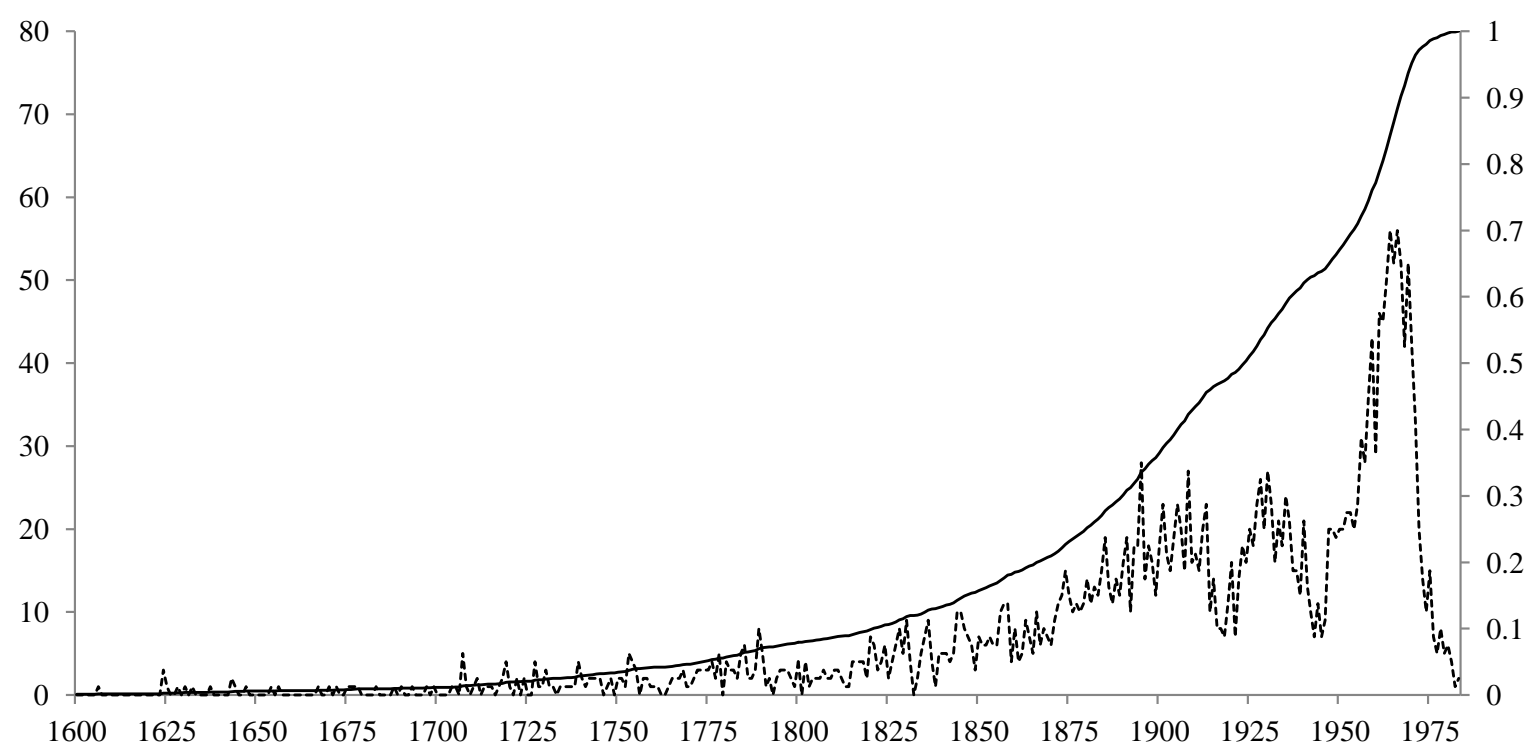

Figure 1: Time Distribution of Biographical Sources. Frequency (dashed line, left axis), cumulative (solid line, right axis)

The retained database includes 297,651 individuals extracted from the IBN following three steps. First, for reasons that we will make explicit below, we restricted the sample to people born before 1880. Second, only people with known years of both birth and death were retained, allowing us to measure their lifespan. ${ }^{4}$ Third, individuals with lifespan less than 15 or larger than 100 years, 729 and 872 respectively, were excluded. Note that the IBN reports information on very few people dying during childhood, and most centenarians in the database are likely to be measurement errors.

Biographical Sources: We identified 2,781 biographical sources in the IBN for which a publication year was observed. To illustrate the nature of the famous people in the database, these are four haphazard examples of sources written in the English language:

- A Dictionary of Actors and of Other Persons Associated with the Public Representation of Plays in England before 1642. London: Humphrey Milford / Oxford, New Haven, New York, 1929.

- A Biographical Dictionary of Freethinkers of all Ages and Nations. London: Progressive Publishing Company, 1889.

- Portraits of Eminent Mathematicians with Brief Biographical Sketches. New York: Scripta-Mathematica, 1936.

\footnotetext{
${ }^{4}$ When the date of death is not reported, it can either be because it is unknown, or because the person was still alive at the time of the publication of the source. Unfortunately, we cannot identify which case is relevant for each observation, preventing us from using a duration model.
} 
- Who Was Who in America. Historical volume (1607-1896). A complement volume of Who's Who in American History. Chicago: The A. N. Marquis Company, 1963.

Figure 1 plots the distribution of the years of publication (in case of multiple publication years, we retained the most recent date); they concentrate heavily in the 19th and 20th Century.

Using the information reported in the IBN, we created the following variables.

LIFESPAN: The lifespan is the year of death minus the year of birth.

PRECISION: In some cases, the lifespan is imprecise. The IBN adds the indications "c.", for circa, or "?" to the vital dates when the years of birth or death are not known with certainty. It may also be that more than one date is reported. We retained all the imprecise observations (taking the mean if there was more than one date), but created a discrete variable called precision, allocating a value of one when the lifespan was imprecise, zero otherwise. Appendix A gives some information on the evolution of precision, and also reports heaping indexes calculated on dates of birth and death.

Place of Birth AND DeATh: In order to locate individuals in specific cities, we used the places of birth and death cells. Among the 297,651 individuals in the database, a place of birth or death was missing for 60,637 (20\% of the sample). For the remaining 237,014 individuals, we first counted words using the Hermetic Word Frequency Counter $1089 t$ and identified 56,574 birth places and 35,852 death places; we took into account the fact that some cities have composed names, such as New York. We then translated city names for birth (resp. death) places with at least 30 (resp. 20) observations into 22 languages, ${ }^{5}$ and searched again to identify all individuals who were born or died in the same city. We also checked for historical names for these cities (if possible) using Wikipedia. ${ }^{6}$ This procedure identified 584 and 603 birth and death cities, respectively. After translation, the number of observations more than doubled for some cities. We finally retained 77 cities with at least 300 observations as either birth or death place (see Table 2). For the statistical analysis below, we created a dummy for each of the 77 cities. $^{7}$ They are set equal to one if someone lived in one of those cities, i.e. was born there, or died there. We have also created a large

\footnotetext{
${ }^{5}$ For this, we used Nice Translator -http://nicetranslator.com/. The list of languages included were Bulgarian, Catalan, Czech, Danish, Dutch, English, Estonian, Finnish, French, German, Greek, Hungarian, Italian, Latvian, Lithuanian, Norwegian, Polish, Portuguese, Romanian, Slovak, Slovenian, Spanish, Swedish and Turkish.

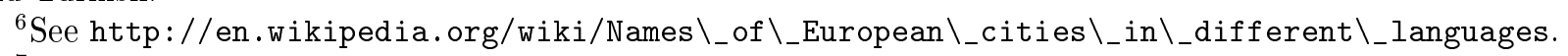

${ }^{7}$ It is important to notice that some cells in the IBN are empty, and when complete some contain useless information, implying that the variables here created contain missing values. Of course, by construction, this is not the case for the year of birth and the individual lifespan. When creating dummies, the missing values systematically adopt the value zero. It does imply that we tend to underestimate the dummy coefficients, since the excluded group may include individuals belonging to the control group.
} 
cities dummy that takes value one if an individual was born or dead in at least one of the 77 selected cities, zero otherwise.

Migration: For all individuals with observed birth and death places, we created a migration dummy that took value one if the places of birth and death were different.

OCCUPATiOn, NATionality AND Religion: Information in the statement cells is more complex. Only 1,274 observations had an empty statement cell. We identified 81,078 unique words using the Hermetic Word Frequency Counter 1089t, and retained those words with at least 200 observations that could be associated with any type of occupation, nationality or religion. We then translated them into the same 22 languages as we used for the cities, and merged all observations corresponding to the same occupation, nationality or religion. The words collapsed into 171 occupations, 65 nationalities and 10 religions. Using these categories, 278,084 individuals had at least one occupation (94.4\% of the sample) and 207,049 had more than one; 218,530 have at least one nationality (73.4\%) and 11,929 have more than one. Finally, we retained all relevant words with at least 300 observations; this allowed us to identify 33 nationalities, 7 religions, and 148 occupations (see Appendix 2). In addition, occupations were grouped into nine categories: Arts and métiers, business, religious, education, humanities, law and government, military, nobility, and sciences (see Appendix C). There were six other repeated words that we also used as controls. ${ }^{8}$

GENDER ( $1=$ female, $0=$ male or unknown) was coded automatically on the basis of most frequent female names, using www.namepedia.org, which is a name database. We have identified 9,362 individuals as females, but one should be aware that this classification is highly imperfect, essentially because the mapping between names and gender is far from univocal.

Age at Publication. Finally, the source cells were used to single out for each individual the publication year of the biographical source citing her/him. We identified this year for 290,528 individuals, $99.9 \%$ of total observations. ${ }^{9}$ Then, we measured for each individual the age of her/his cohort at the publication of the source in the following way. When the individual's death year was before the publication year of the source, we took the difference between the publication year and the individual's birth year. The resulting post-mortem age at publication is then larger than the individual lifespan. Otherwise, we assume it is missing.

\footnotetext{
${ }^{8}$ Chief, bengali, founder, landowner, servant and unionist. We include bengali in this group, because most were British soldiers in the Bengal war from the book "List of the officers of the Bengal army, 1758-1834. Alphabetically arranged and annotated with biographical and genealogical notices", who seem to have had particularly short lives.

${ }^{9}$ Unfortunately, because of the way data are organized in the IBN, when an individual was cited by more than one source, we could only identify one of these sources automatically, not necessarily the most recent. In particular, for 42,600 observations, the year of publication preceded the year of death, which we take as evidence of the existence of another source published later.
} 


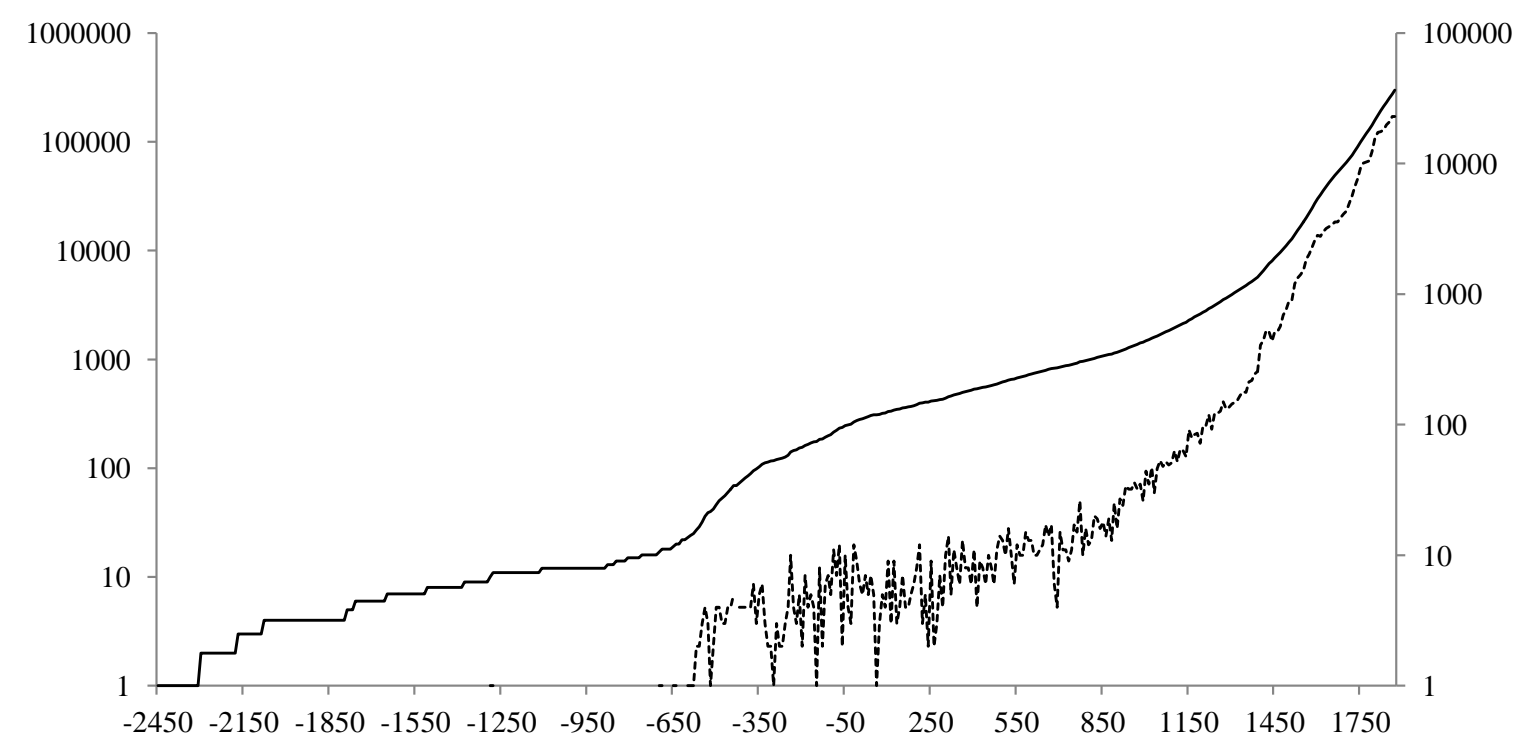

Figure 2: Number of Observations by Decade. Density (dots) and cumulative (solid line)

Finally, we created eight "age at publication" dummies for ages $\{15-29,30-39, \ldots, 90-99\}$. The dummies were allocated a value of one for individuals for whom the age at publication of the source was in the age group, zero otherwise. These dummies will be used to control for the source bias (see Section 3.3).

To describe the sample, let us before represent unconditional longevity by grouping individuals into ten-year cohorts and averaging their lifespan. In Section 3 we will discuss the biases in this estimation and in Section 4 we will provide an estimation that controls for individual characteristics (conditional longevity).

We concentrate on cohort longevity, and not on period longevity, which is subject to tempo effects when mortality changes over time (Bongaarts and Feeney 2003). Individuals in the database were grouped into cohorts by year of birth. As can be observed in Figure 2, at the beginning of the sample, the size of these cohorts is very small; there were only 274 individuals born before Christ, 400 individuals before $230 \mathrm{CE}$, and 1600 before $1040 \mathrm{CE}$. The data only really becomes rich for cohorts born after 1400. Since these cohorts have small size at the beginning of the sample, when representing the data, we apply a simple adaptive rule

$$
\lambda_{t}= \begin{cases}\left(n_{t} / x\right) l_{t}+\left(1-n_{t} / x\right) \lambda_{t-1} & \text { if } n_{t}<x \\ l_{t} & \text { otherwise }\end{cases}
$$

where $l_{t}$ and $\lambda_{t}$ are actual and smoothed longevities, $n_{t}$ represents the actual cohort size, and $x$ is an arbitrary representative size. The choice of $x$ is based on the idea that if the lifespans of people in the sample were random draws from a Normal distribution, the 


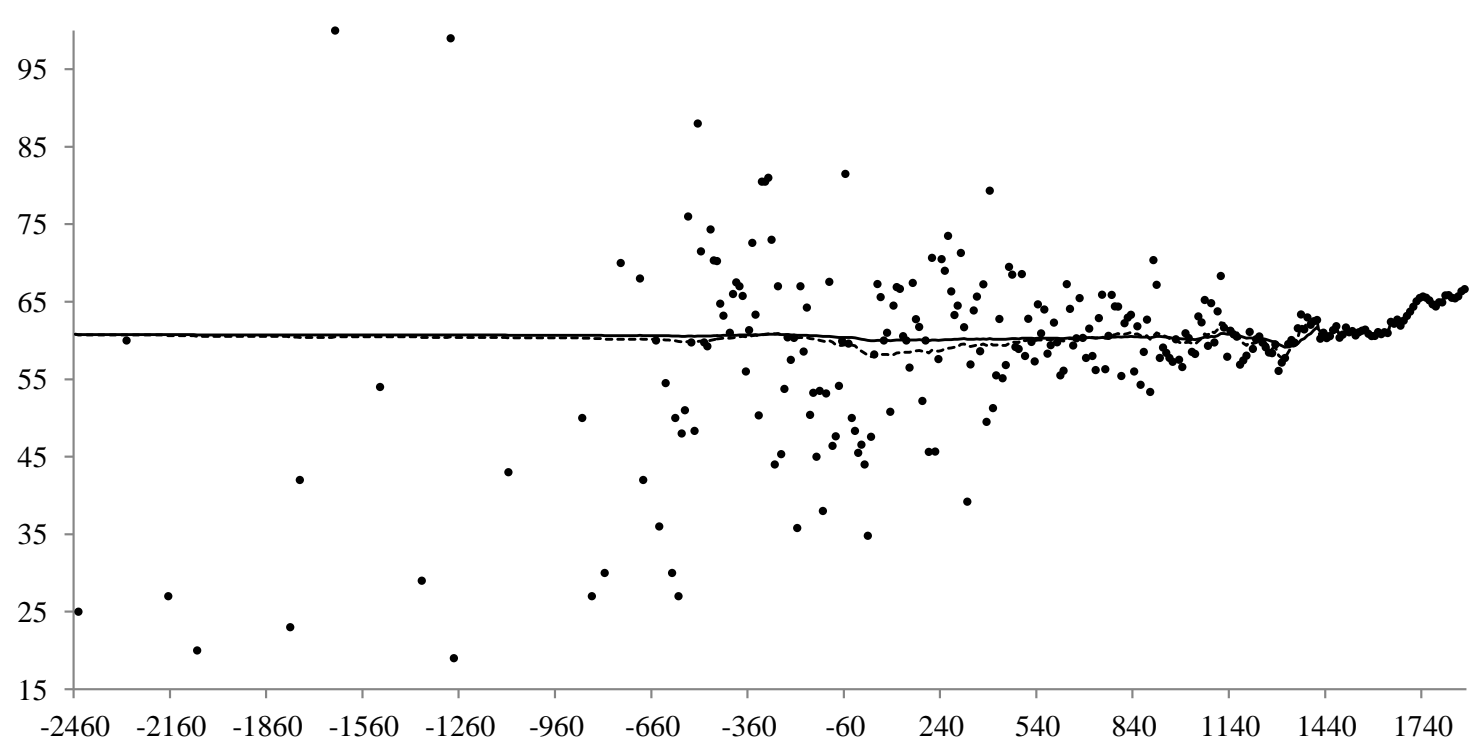

Figure 3: Unconditional Longevity. Data (dots), smoothing with $x=400$ (dotted line), smoothing with $x=1600$ (solid line)

standard deviation of the observed cohort longevity would be $\sigma / \sqrt{x}$, where $\sigma$ is the standard deviation of the population and $x$ is the cohort size. Since $\sigma=15$ for famous people born before 1640, we need $x=400$ (respectively 1600) for the observed longevity to be within a $95 \%$ confidence interval $\pm 1.5( \pm 0.75)$.

As an initial condition we used $\lambda_{-\infty}=60.8$, taken from Clark (2007) for the huntergatherers. ${ }^{10}$ The adaptive rule adds past information $\lambda_{t-1}$ when the actual size of the sample $n_{t}$ is smaller than its representative size $x$. Current and past information, $l_{t}$ and $\lambda_{t-1}$, are weighted by the relative size $n_{t} / x$, when $n_{t}<x$, and its complement, respectively. When the cohort size is large enough, actual and smoothed longevities are identical.

Figure 3 shows the actual longevity (dots) and the corrected longevity of ten-year cohorts for $x=400$ and $x=1600$. Actual longevity fluctuates dramatically around 60.9 until the 14th Century, because of the small size of the cohorts. Smoothed longevity, however, moves around the mean with very small fluctuations until the Black Death (cohorts born just before 1340-1350); then, it moves again around the mean until it starts to increase with the cohort born 1640-1649.

\footnotetext{
${ }^{10}$ This number is very close to the sample mean (60.9) for individuals born before 1640 .
} 


\section{Biases in Sampling}

This section describes the universe from which famous people in the IBN have been drawn from, some sampling issues and the way we took care of them.

\section{$3.1 \quad$ Universe}

According to Malanima (2009), the ancien régime society can be schematically depicted as a two-class society, respectively made up of gentlemen and those who were not. He estimated the high-society (nobles, rich landowners, professional men, important tradesmen) to be $10 \%$ of the European population on average over 1500-1700, the nobility accounting only for $3 \%$ of the same total. Consistent with this estimation, Vauban, engineer and general under Louis XIV, classified the French population as follows: 10\% rich, 50\% very poor, 30\% near beggars, 10\% beggars (Cipolla 1993, p. 9).

Our study is based on a group of people who has done something special to be kept in the records, because they were rulers, members of different clergies, rich merchants, important statesman, authors of books, professors at university, artists, artisans, etc. Most of them belonged to the top $10 \%$ of the society, and were among the richest, most powerful and influential individuals, likely with the highest human capital. ${ }^{11}$ In this sense, the $10 \%$ elite group represents the universe from which the present sample has been drawn.

Table 1 shows the composition of our sample in terms of the occupations described in Section 2. It shows that, contrary to most existing studies on elite groups (see Cummins (2014) for the most recent one), our sample contains much more than just nobles or religious dignitaries. The decline of religion and nobility is very sharp over the period, as well as the rise of humanities, science, and business. ${ }^{12}$

There are several reasons why studying the longevity of this group of famous people is valuable. First, as we stressed in the introduction, famous people are those with a high level of human capital. It is therefore of special importance for studying whether improvements in longevity were one cause of the industrial revolution. Remember that Mokyr (2011) saw the community of European famous people formed during the Enlightenments as being at

\footnotetext{
${ }^{11}$ As stressed by van Poppel, van de Kaa, and Bijwaard (2013) who studied Dutch and Belgian artists, "the data on these groups reflect the experience of populations which were, in all likelihood, better nourished and better housed than the general population."

${ }^{12}$ Let us also remark that the ratio of occupations per person is around 1.5 for all periods. This means, that, often, one person had several occupations. For example, Pieter Huidekoper (1798-1852), was not only Mennonite deacon, but also Dutch politician, mayor of Amsterdam, banker, and merchant. Table 1 also reports the very low but increasing percentage of women in the sample.
} 


\begin{tabular}{lrrrrrrr}
\hline \hline & $<1550$ & $1550-1649$ & $1650-1699$ & $1700-1749$ & $1750-1799$ & $1800-1849$ & $1850-1879$ \\
\hline Religion & $16.7 \%$ & $22.3 \%$ & $20.8 \%$ & $15.6 \%$ & $9.3 \%$ & $7.4 \%$ & $4.9 \%$ \\
Army & $3.4 \%$ & $5.3 \%$ & $7.1 \%$ & $8.7 \%$ & $12.1 \%$ & $7.5 \%$ & $4.4 \%$ \\
Education & $18.7 \%$ & $24.0 \%$ & $23.0 \%$ & $22.6 \%$ & $20.9 \%$ & $23.4 \%$ & $26.5 \%$ \\
Art & $10.9 \%$ & $11.7 \%$ & $11.2 \%$ & $11.5 \%$ & $10.9 \%$ & $13.2 \%$ & $14.5 \%$ \\
Law & $12.4 \%$ & $12.8 \%$ & $12.1 \%$ & $14.1 \%$ & $16.6 \%$ & $14.2 \%$ & $12.7 \%$ \\
Humanities & $4.6 \%$ & $3.6 \%$ & $3.4 \%$ & $3.6 \%$ & $4.0 \%$ & $6.7 \%$ & $8.7 \%$ \\
Science & $4.8 \%$ & $4.2 \%$ & $4.7 \%$ & $6.2 \%$ & $7.8 \%$ & $10.2 \%$ & $12.3 \%$ \\
Business & $2.8 \%$ & $3.3 \%$ & $4.5 \%$ & $6.0 \%$ & $7.6 \%$ & $9.7 \%$ & $10.0 \%$ \\
Nobility & $11.0 \%$ & $4.9 \%$ & $4.2 \%$ & $3.2 \%$ & $2.5 \%$ & $1.0 \%$ & $0.4 \%$ \\
Unknown & $14.7 \%$ & $8.2 \%$ & $9.0 \%$ & $8.6 \%$ & $8.2 \%$ & $6.7 \%$ & $5.7 \%$ \\
\hline Women & $1.4 \%$ & $2.2 \%$ & $2.5 \%$ & $2.5 \%$ & $3.3 \%$ & $3.4 \%$ & $4.0 \%$ \\
\hline \hline
\end{tabular}

Table 1: Occupational and Gender Composition of Our Sample of Famous People

the root of the Industrial Revolution. Upper tail knowledge is nowadays more and more recognized to be central to the development process (see Mokyr (2005a) and Squicciarini and Voigtländer (2014)).

Second, our sample forms a coherent whole in terms of social position. It is however quite heterogeneous compared to previous studies in historical demography in terms of ethnicity/nationality. To limit the presence of unobserved heterogeneity, having a sample with social position homogeneity might be more important than with nationality homogeneity. ${ }^{13}$ Indeed, there might be less diversity across elites of different countries than between the elite and ordinary people within each country. Reading Mokyr (2005b) again, one feels that there was even probably more in common between Hume and Kant, than between Hume and the average farmer in England.

Finally, an important strength of our study is the use of a large number of observations, which allows to measure empirical moments with more accuracy than the typical study in historical demography (1000 to 2000 observations per period in Perrenoud (1978), 100 to 6000 by 50-year birth cohort in van Poppel, van de Kaa, and Bijwaard (2013), a few hundreds per period in Vandenbroucke (1985)).

\subsection{Notoriety Bias, and Longevity vs Life Expectancy}

The analysis of famous people longevity in our sample may suffer from several biases. In the following, we detail them and discuss solutions. We start with the notoriety bias, a particular form of selection bias.

\footnotetext{
${ }^{13}$ Desmet, Ortuño-Ortín, and Wacziarg (2014) found that ethnicity has a low explanatory power in accounting for cultural norms.
} 
An individual has to acquire some reputation or social status to be recorded in the IBN. This generates a form of selection bias as the IBN does not include those who died too soon to become famous. We refer to it as the notoriety bias. In most cases, the probability of obtaining such a status increases with age, implying that mortality rates of famous people tend to be underestimated, particularly at young ages. In addition, there might be unobservable changes in standards that modify the age at which a person becomes famous, making the notoriety bias to change over time. The introduction of the printing press, for example, rendered easier to write and publish biographies, which likely reduced the requirements for being in the IBN and made people became famous at younger ages.

To control for the notoriety bias, we included in our regression analysis the set of occupational dummies described in Section 2. The associated coefficients reflect differences in the notoriety bias across occupations. In Section 4.3, as robustness tests, we interacted the nine large occupational categories with the cohort dummies to take into account for possible unobservable changes in standard that may affect the notoriety bias. We also performed out-of-sample tests that we now describe.

The notoriety bias is related to the well-known problem in statistics of left truncation. Most people in the IBN did not get notoriety from birth, but after reaching some status. To deal with left truncation and compute the mortality rate of famous people at any age, we have to include in the population only those that were alive and have already achieved notoriety at this age. The population defined this way is referred as population at risk, since it only includes all members of the population whose death is susceptible to be observed. The left truncation is then related to the fact that a particular person is not part of the population of famous people until he/she does achieve notoriety. For populations like those in the IBN, the age at which people become famous is not usually known, making it impossible to measure the population at risk at any age. More fundamentally, even if accurate information about individual achievements (and the time of their occurrence) were available, in most cases it will be very difficult to determine the exact age at which they became famous. It would be easy in the case of European kings or US Presidents, but very difficult for Dutch painters, for example. ${ }^{14}$

This poses a fundamental problem for the measurement of life expectancy, problem that is shared by most populations of famous people. Since we do not have information on the age at which our famous people got notoriety, we cannot compute the population at risk and the corresponding death rates, and we cannot then measure life expectancy. We use the

\footnotetext{
${ }^{14}$ For many of these occupations, indeed, identifying the age at which the event or achievement that made individuals famous is highly difficult. When did van Gogh become famous enough to be recorded as a famous painter from the point of view of a book's editor? The degree of notoriety varies of course from occupation to occupation and from book to book.
} 

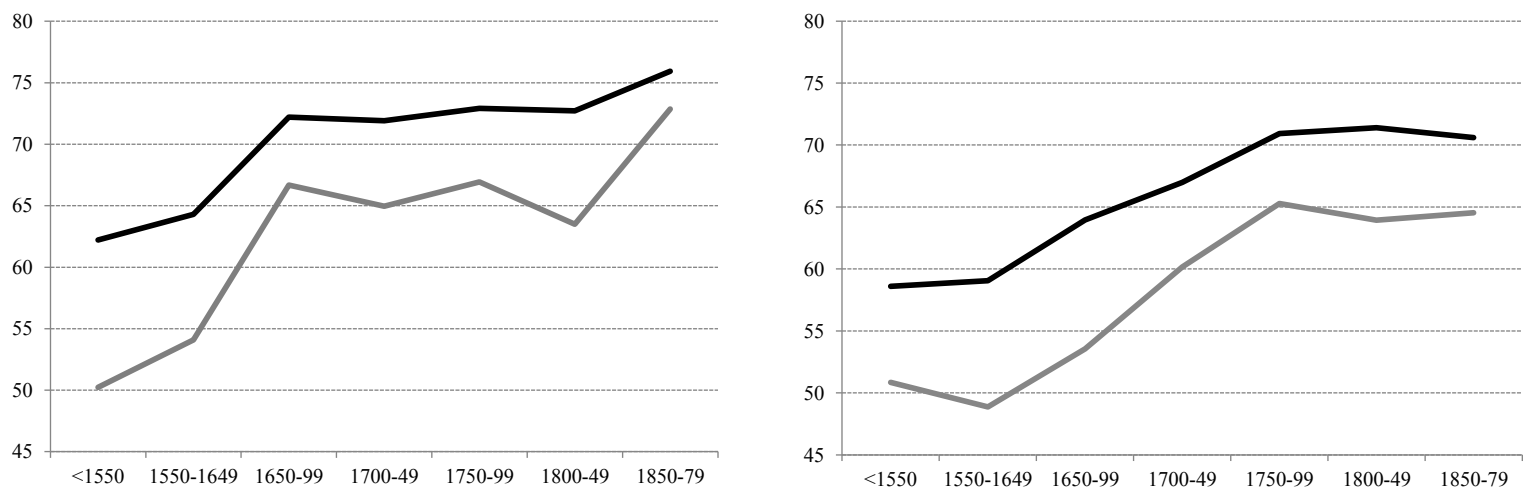

Figure 4: Longevity at 25 (black) and Life expectancy at 25 (gray) of cardinals (left) and of Knights of the Golden Fleece (right)

alternative measure of longevity: the average age at death of a particular population. As for life expectancy, it can be measured conditional on a minimum age $a$. Implicitly, dead rates are computed using the total number of famous people alive at a particular age irrespective of the fact that at these age they were or not famous. Of course, when we observe all individuals of a particular population at birth, life expectancy and longevity are the same measure. In general, however, longevity is larger than life expectancy. Appendix B shows that the gap between the two measures depend on the process leading people to enter the population at risk.

This paper aims to identify the exact time in human history when famous people mortality started improving. Since we cannot measure life expectancy and we have to rely on longevity, as defined above, we would like to be sure that these two measures at least share a common trend. There are two particular groups for which we can compute both, the cardinals of the Catholic Church and the knights of the Golden Fleece.

For the 2179 cardinals of the Catholic Church born before 1880 (Fornasin, Breschi, and Manfredini 2010), we know the designation date in addition to their vital dates. ${ }^{15}$ It was then possible to compute the population at risk and then life expectancy. Figure 4 (left) shows the join evolution of their life expectancy at 25 and their longevity at $25 .{ }^{16}$ As expected, longevity is larger than life expectancy. More importantly, both move in parallel with an important improvement in both series during the second half of the 17th century. If anything, for the second half of the 17th century, longevity tends to underestimate the

\footnotetext{
${ }^{15}$ Among them, 1296 have a family name between A and L. We were able to identify 537 of them in the IBN, around $40 \%$ of those with family names between A and L.

${ }^{16}$ In order to make these two measures directly comparable, we report as life expectancy the standard life expectancy at 25 plus 25 .
} 
improvement in life expectancy. ${ }^{17}$

The second sample for which we can compare both measures over time contains the knights of the Golden Fleece. The Order consists of a highly select group of noblemen, starting with dukes and princes of Burgundy and continuing with the Hapsburg rulers and the kings of Spain, the Austrian emperors of the Holy Roman Empire, and the Bourbons (Vandenbroucke 1985). For each knight, we know the year of nomination to the Order, the year of birth, and the year of death. Figure 4 (right) shows longevity and life expectancy for this sample. Again here, the two measures move together, start raising in the second half to the 17th century, and the rise in longevity underestimate the rise in life expectancy over the sample period.

From these two out-of-sample examples, we are confident that longevity is informative about life expectancy, and that both measures move in the same direction showing a common tipping point at the second half of the 17th century, despite changes in the standards to enter the sample.

\subsection{Composition and Other Biases}

In addition to the notoriety/selection bias referred to in the previous section, the IBN may suffer from different types of composition biases, related to occupation, location and gender.

Occupation Bias. Fame has not always been related to the same human achievements, implying that the weight of some occupations may have changed substantially over time. This is the case, for example, for the nobility and for religious occupations. The case of martyrs, although less frequent, is more striking, because they lived short lives, by definition, and were concentrated in particular periods of human history. For this reason, changes in the occupational composition of the sample may generate artificial changes in longevity. Occupation dummies were also used to control for this potential occupation bias. ${ }^{18}$

Location Bias. Another form of potential composition bias is related to changes over time in the location of individuals in the sample, in relation for example with the changes in the

\footnotetext{
${ }^{17}$ The difference between longevity and life expectancy at age 25 does not show any particular pattern even if the average age at elevation (age at which cardinals were appointed) grew steadily from the second half of the 17th century. See Fornasin, Breschi, and Manfredini (2010) for an explanation of the reasons for the behavior of the cardinals' life expectancy.

${ }^{18}$ It may also be that occupational categories change their risk profile over time. For example, the aristocracy in most European countries went from being in the business of war to a bunch of leisure-seeking activities. Changes in the risk profile cannot be control for a time-invariant dummy. Unfortunately, we do not have enough data to estimate changes over time in the mortality risk of all occupations together. However, the robustness exercise performed in Section 4.3 does also control for possible changes in the risk profile.
} 
primacy of nations over time. City dummies and nationality dummies were used to control for the location bias.

Gender Bias. Such a bias may arise if famous females live on average longer (or shorter) than famous males and their proportion in the sample varies over time. The gender dummy, identified from people's first names, is used to control for this bias.

Migration Bias. Since the probability of migrating is positively correlated with the individual lifespan, we expect that migrants on average have a larger lifespan than non-migrants. If the propensity to migrate changed over time, a bias is introduced in the estimation of longevity. We refer to this effect as the migration bias. As the IBN provides information on the city of birth and the city of death for most individuals, we can control for the migration bias using the migration dummy which takes the value of one when the place of birth and death are different.

Finally, we have identified two other controls that we include in the regression analysis below. Source Bias. As explained above, our database only includes famous people for whom the years of birth and death were reported. For this reason, celebrities in the IBN still alive at the time they were cited in a biographical dictionary or encyclopedia were excluded from our database, since their year of death was not known at the time of publication. This is another form of selection bias, this time related to right truncation. Consequently, our sample may underestimate the longevity of famous people, in particular for cohorts for which the average time between birth dates and publication dates was short. We call this phenomenon the source bias. As most biographical sources were published during the 19th and 20th centuries (see Figure 1), we have decided to exclude people born after 1880 to limit the scope of this bias. Moreover, we included in the regression the eight dummies "age at publication", for (post-mortem) ages $\{15-29,30,39, \ldots, 90-99\}$, as described previously. These dummies capture the abnormally low longevity of those whose date of birth is close to the issuing of the source citing them. Another, less efficient, way to control for this bias is to exclude from the sample all the people born close to the publication of the source. This method will be used to validate the correction with the "age at publication" dummies.

Precision Bias. The increase in the precision of the data documented in Appendix A may hide trends that could affect our estimates. Including a precision dummy which takes value one when the vital dates are imprecise (when a vital date has "c.", or "?", or when more than one date is reported, for either the birth or the death date) should take care of this bias. 


\section{Conditional Longevity of Famous People}

\subsection{Estimation}

We estimate conditional longevities of famous people cohorts using the following regression:

$$
m_{i, t}=m+d_{t}+\alpha x_{i, t}+\varepsilon_{i, t}
$$

where $m_{i, t}$ is the lifespan of individual $i$ belonging to cohort $t$, the constant term $m$ measures the conditional longevity of the excluded cohort dummy -for a representative individual without retained city, nationality or occupation (because those are either unknown or below our 300 observations threshold); $d_{t}$ is a cohort fixed effect which measures the difference between the conditional longevity of cohort $t$ and the conditional longevity of the excluded cohort; $x_{i, t}$ is a vector of individual controls including city, occupation and nationality dummies, gender, precision and migration dummies, and age at publication dummies; $\alpha$ is a vector of parameters; and $\varepsilon_{i, t}$ is an error term measuring individual's $i$ idiosyncratic lifespan circumstances. Equation (2) was estimated using Ordinary Least Squares. ${ }^{19}$ The detailed results are in Table 2.

Because our main objective was to identify the precise cohort after which the longevity of famous people started to increase, and we had few observations per decade before the fifteenth century, we created cohort dummies by decade starting in 1430-1439, the first decade with more than 300 observations. The conditional longevity of all previous cohorts, consistent with the observation in Figure 3, was assumed constant. ${ }^{20}$ Figure 5 shows estimates, and the corresponding $95 \%$ confidence intervals, for all cohort dummies. As can be observed, the longevity of cohorts born between 1430 and 1640 was not significantly different from the longevity of celebrities born before 1430, which implies that there was no significant gradual increase of longevity during 1550-1649. Indeed, the longevity of celebrities started to increase with the cohort born in 1640-49, gaining nine years over around two and a half centuries. This figure establishes the conclusion that longevity improvements for celebrities started well before the Industrial Revolution.

\footnotetext{
${ }^{19}$ Remember that the OLS estimators are weighted sums of random variables, the central limit theorem applies, and the OLS estimators are in any case asymptotically normal. All test statistics relying on asymptotic distribution results are typically valid with large samples such as ours.

${ }^{20}$ Including cohort dummies before 1430 allows to capture the dip due to the Black Death, but estimations are very imprecise.
} 


\begin{tabular}{|c|c|c|c|c|c|}
\hline & \# obs & Coef. & Std. Err. & $\mathrm{t}$ & $\mathbf{P}>|\mathbf{t}|$ \\
\hline Constant term & 297,651 & 59.669 & 0.192 & 310.22 & 0 \\
\hline \multicolumn{6}{|l|}{ Decade } \\
\hline 1430 & 511 & -0.042 & 0.656 & -0.06 & 0.949 \\
\hline 1440 & 436 & -0.683 & 0.707 & -0.97 & 0.334 \\
\hline 1450 & 508 & -0.505 & 0.658 & -0.77 & 0.443 \\
\hline 1460 & 516 & 0.341 & 0.653 & 0.52 & 0.602 \\
\hline 1470 & 567 & 0.902 & 0.625 & 1.44 & 0.149 \\
\hline 1480 & 690 & -0.888 & 0.572 & -1.55 & 0.121 \\
\hline 1490 & 758 & -0.522 & 0.549 & -0.95 & 0.341 \\
\hline 1500 & 883 & 0.680 & 0.512 & 1.33 & 0.185 \\
\hline 1510 & 896 & -0.119 & 0.509 & -0.23 & 0.815 \\
\hline 1520 & 1,200 & 0.284 & 0.450 & 0.63 & 0.528 \\
\hline 1530 & 1,333 & -0.005 & 0.430 & -0.01 & 0.991 \\
\hline 1540 & 1,405 & 0.373 & 0.421 & 0.89 & 0.376 \\
\hline 1550 & 1,525 & 0.436 & 0.408 & 1.07 & 0.285 \\
\hline 1560 & 1,852 & 0.597 & 0.378 & 1.58 & 0.114 \\
\hline 1570 & 2,020 & 0.120 & 0.366 & 0.33 & 0.744 \\
\hline 1580 & 2,294 & -0.333 & 0.349 & -0.96 & 0.339 \\
\hline 1590 & 2,559 & -0.104 & 0.336 & -0.31 & 0.757 \\
\hline 1600 & 2,818 & 0.316 & 0.325 & 0.97 & 0.331 \\
\hline 1610 & 2,773 & -0.009 & 0.327 & -0.03 & 0.979 \\
\hline 1620 & 3,016 & 0.146 & 0.317 & 0.46 & 0.646 \\
\hline 1630 & 3,182 & 0.045 & 0.312 & 0.15 & 0.884 \\
\hline 1640 & 3,281 & 1.559 & 0.309 & 5.05 & 0 \\
\hline 1650 & 3,394 & 1.411 & 0.305 & 4.62 & 0 \\
\hline 1660 & 3,572 & 2.008 & 0.301 & 6.68 & 0 \\
\hline 1670 & 3,576 & 1.271 & 0.301 & 4.23 & 0 \\
\hline 1680 & 3,849 & 1.975 & 0.294 & 6.71 & 0 \\
\hline 1690 & 4,120 & 2.577 & 0.289 & 8.93 & 0 \\
\hline 1700 & 4,337 & 3.018 & 0.284 & 10.63 & 0 \\
\hline 1710 & 4,986 & 3.676 & 0.273 & 13.44 & 0 \\
\hline \multirow[t]{2}{*}{1720} & 5,704 & 4.250 & 0.264 & 16.13 & 0 \\
\hline & & & & \multicolumn{2}{|c|}{ continued on next page } \\
\hline
\end{tabular}




\begin{tabular}{lrrrrr}
\hline \hline & \# obs & Coef. & Std. Err. & $\mathbf{t}$ & $\mathbf{P}>|\mathbf{t}|$ \\
\hline 1730 & 6,621 & 4.653 & 0.254 & 18.29 & 0 \\
1740 & 7,619 & 4.679 & 0.247 & 18.96 & 0 \\
1750 & 9,233 & 4.887 & 0.237 & 20.59 & 0 \\
1760 & 10,118 & 4.832 & 0.233 & 20.7 & 0 \\
1770 & 10,313 & 4.249 & 0.233 & 18.24 & 0 \\
1780 & 10,486 & 4.144 & 0.233 & 17.78 & 0 \\
1790 & 12,338 & 4.443 & 0.227 & 19.58 & 0 \\
1800 & 15,630 & 4.681 & 0.220 & 21.31 & 0 \\
1810 & 17,335 & 5.703 & 0.218 & 26.21 & 0 \\
1820 & 17,609 & 6.041 & 0.218 & 27.76 & 0 \\
1830 & 18,120 & 5.971 & 0.218 & 27.44 & 0 \\
1840 & 19,867 & 5.938 & 0.216 & 27.52 & 0 \\
1850 & 20,831 & 6.341 & 0.216 & 29.36 & 0 \\
1860 & 22,960 & 7.530 & 0.215 & 34.95 & 0 \\
1870 & 22,932 & 8.853 & 0.217 & 40.8 & 0 \\
Availability of information & & & & & \\
city & 101,955 & 0.311 & 0.189 & 1.65 & 0.099 \\
nationality & 206,421 & -0.258 & 0.247 & -1.04 & 0.297 \\
precision & 43,158 & -0.812 & 0.080 & -10.18 & 0 \\
Additional biases & & & & & \\
female & 9,362 & 1.088 & 0.156 & 6.97 & 0 \\
migration & 135,759 & 0.464 & 0.059 & 7.89 & 0 \\
Cities & & & & & \\
Amsterdam & 2,194 & -0.752 & 0.366 & -2.06 & 0.04 \\
Antwerpen & 1,159 & -0.887 & 0.462 & -1.92 & 0.055 \\
Augsburg & 544 & -0.463 & 0.635 & -0.73 & 0.466 \\
Barcelona & 627 & -2.042 & 0.622 & -3.28 & 0.001 \\
Basel & 560 & -1.137 & 0.634 & -1.79 & 0.073 \\
Berlin & 4,777 & -0.458 & 0.267 & -1.71 & 0.087 \\
Bern & 579 & -0.833 & 0.627 & -1.33 & 0.184 \\
Bologna & 592 & 1.060 & 0.614 & 1.73 & 0.084 \\
Bordeaux & 946 & 0.750 & 0.493 & 1.52 & 0.129 \\
\hline \hline
\end{tabular}




\begin{tabular}{|c|c|c|c|c|c|}
\hline & \# obs & Coef. & Std. Err. & $\mathrm{t}$ & $P>|t|$ \\
\hline Boston & 724 & -0.191 & 0.565 & -0.34 & 0.735 \\
\hline Bremen & 619 & -0.881 & 0.600 & -1.47 & 0.142 \\
\hline Breslau & 1,234 & -1.640 & 0.438 & -3.74 & 0 \\
\hline Brno & 550 & -0.356 & 0.632 & -0.56 & 0.573 \\
\hline Bruxelles & 1,614 & 0.811 & 0.404 & 2.01 & 0.044 \\
\hline Budapest & 3,757 & 0.421 & 0.338 & 1.24 & 0.213 \\
\hline Buenos Aires & 1,279 & 0.609 & 0.550 & 1.11 & 0.268 \\
\hline Chicago & 434 & 0.046 & 0.711 & 0.06 & 0.949 \\
\hline Cologne & 918 & 0.159 & 0.501 & 0.32 & 0.751 \\
\hline Copenhagen & 2,781 & -1.270 & 0.369 & -3.44 & 0.001 \\
\hline Denhaag & 1,492 & 2.210 & 0.422 & 5.23 & 0 \\
\hline Dresden & 1,700 & -0.631 & 0.384 & -1.65 & 0.1 \\
\hline Dublin & 696 & -0.460 & 0.619 & -0.74 & 0.457 \\
\hline Edinburgh & 806 & -0.312 & 0.538 & -0.58 & 0.561 \\
\hline Florence & 1,050 & 0.152 & 0.475 & 0.32 & 0.749 \\
\hline Frankfurt & 1,058 & -0.748 & 0.468 & -1.6 & 0.11 \\
\hline Frederiksberg & 362 & 4.034 & 0.782 & 5.16 & 0 \\
\hline Freiburg & 451 & 0.172 & 0.693 & 0.25 & 0.804 \\
\hline Gdansk & 577 & -1.516 & 0.616 & -2.46 & 0.014 \\
\hline Geneve & 1,651 & -0.266 & 0.400 & -0.67 & 0.505 \\
\hline Genoa & 452 & 0.477 & 0.694 & 0.69 & 0.491 \\
\hline Ghent & 690 & 0.489 & 0.582 & 0.84 & 0.401 \\
\hline Graz & 880 & -0.883 & 0.518 & -1.7 & 0.088 \\
\hline Hamburg & 1,699 & -1.364 & 0.383 & -3.57 & 0 \\
\hline Hannover & 640 & 1.446 & 0.588 & 2.46 & 0.014 \\
\hline Helsinki & 553 & -0.431 & 0.693 & -0.62 & 0.534 \\
\hline Kaliningrad & 812 & -1.349 & 0.527 & -2.56 & 0.01 \\
\hline Krakow & 1,036 & -0.008 & 0.497 & -0.02 & 0.988 \\
\hline Leiden & 582 & -1.963 & 0.620 & -3.16 & 0.002 \\
\hline Leipzig & 1,384 & -2.574 & 0.419 & -6.14 & 0 \\
\hline Liege & 778 & 0.437 & 0.549 & 0.8 & 0.426 \\
\hline Lisbon & 755 & -0.008 & 0.627 & -0.01 & 0.99 \\
\hline
\end{tabular}




\begin{tabular}{|c|c|c|c|c|c|}
\hline & \# obs & Coef. & Std. Err. & $\mathrm{t}$ & $\mathbf{P}>|\mathbf{t}|$ \\
\hline London & 6,381 & 0.435 & 0.260 & 1.67 & 0.094 \\
\hline Lviv & 705 & -0.501 & 0.574 & -0.87 & 0.383 \\
\hline Lyon & 1,319 & -1.732 & 0.426 & -4.07 & 0 \\
\hline Madrid & 1,587 & -1.896 & 0.435 & -4.36 & 0 \\
\hline Marseille & 528 & 1.375 & 0.642 & 2.14 & 0.032 \\
\hline Metz & 441 & 1.235 & 0.697 & 1.77 & 0.076 \\
\hline Milan & 834 & -0.210 & 0.525 & -0.4 & 0.69 \\
\hline Montreal & 444 & -0.115 & 0.717 & -0.16 & 0.873 \\
\hline Moscow & 1,102 & 1.101 & 0.478 & 2.3 & 0.021 \\
\hline Munich & 2,107 & 0.011 & 0.354 & 0.03 & 0.976 \\
\hline Napoli & 1,046 & -0.649 & 0.478 & -1.36 & 0.174 \\
\hline New York & 2,379 & 0.332 & 0.345 & 0.96 & 0.336 \\
\hline Nuremberg & 1,112 & -2.410 & 0.463 & -5.2 & 0 \\
\hline Oslo & 734 & 0.601 & 0.641 & 0.94 & 0.348 \\
\hline Paris & 13,693 & -0.018 & 0.215 & -0.08 & 0.934 \\
\hline Philadelphia & 973 & -1.267 & 0.496 & -2.55 & 0.011 \\
\hline Prag & 2,747 & -1.444 & 0.346 & -4.17 & 0 \\
\hline Riga & 689 & -3.177 & 0.570 & -5.57 & 0 \\
\hline Rio de Janeiro & 669 & 1.014 & 0.688 & 1.47 & 0.141 \\
\hline Roma & 2,442 & -0.324 & 0.337 & -0.96 & 0.336 \\
\hline Rotterdam & 697 & -0.109 & 0.574 & -0.19 & 0.849 \\
\hline Rouen & 835 & 0.838 & 0.520 & 1.61 & 0.107 \\
\hline Saint Petersburg & 1,897 & -1.021 & 0.387 & -2.64 & 0.008 \\
\hline Stockholm & 3,373 & -0.486 & 0.332 & -1.46 & 0.143 \\
\hline Strasbourg & 1,584 & -1.235 & 0.398 & -3.1 & 0.002 \\
\hline Stuttgart & 871 & 0.632 & 0.514 & 1.23 & 0.219 \\
\hline Toulouse & 510 & 1.883 & 0.653 & 2.88 & 0.004 \\
\hline Turin & 539 & -0.341 & 0.641 & -0.53 & 0.595 \\
\hline Utrecht & 681 & 0.064 & 0.581 & 0.11 & 0.913 \\
\hline Venezia & 886 & -0.233 & 0.512 & -0.45 & 0.649 \\
\hline Versailles & 545 & 1.532 & 0.629 & 2.44 & 0.015 \\
\hline Warsaw & 1,974 & -0.987 & 0.398 & -2.48 & 0.013 \\
\hline \multicolumn{6}{|c|}{ continued on next page } \\
\hline
\end{tabular}




\begin{tabular}{lrrrrr}
\hline \hline & \# obs & Coef. & Std. Err. & $\mathbf{t}$ & $\mathbf{P}>|\mathbf{t}|$ \\
\hline Washington & 654 & -0.661 & 0.596 & -1.11 & 0.267 \\
Wien & 6,352 & -1.066 & 0.266 & -4.01 & 0 \\
Wiesbaden & 438 & 2.114 & 0.703 & 3.01 & 0.003 \\
Zurich & 813 & -1.980 & 0.543 & -3.65 & 0
\end{tabular}

Occupation categories

Arts and métiers

$\begin{array}{rrrrr}56,657 & -1.393 & 0.202 & -6.91 & 0 \\ 35,003 & 1.151 & 0.263 & 4.38 & 0 \\ 105,582 & 0.738 & 0.137 & 5.38 & 0 \\ 26,223 & 0.486 & 0.325 & 1.49 & 0.135 \\ 62,961 & 1.356 & 0.137 & 9.9 & 0 \\ 32,826 & -3.024 & 0.217 & -13.94 & 0 \\ 11,037 & -0.265 & 0.393 & -0.67 & 0.5 \\ 48,230 & -0.029 & 0.189 & -0.16 & 0.877 \\ 39,232 & 1.407 & 0.267 & 5.27 & 0\end{array}$

Occupations

Business

Education

Humanities

Law and government

Military

Nobility

Religious

Sciences

abbot

academician

actor

administrator

admiral

adviser

agronomist

ambassador

antiquary

archaeologist

archbishop

archdeacon

architect

artist

astronomer

author

$$
1,430
$$

3.443

$675 \quad 3.216$

0.406

8.47

0.558

5.76

0.282

$-1.26$

0.454

4.22

$0.442 \quad 18.58$

0.326

0.8

0.602

2.79

0.478

1.15

0.640

1.96

0.489

3.38

0.434

7.99

0.638

3.74

0.332

3.6

0.292

1.79

0.509

$-1.15$

0.123

5.87

0.496

$\begin{array}{ll}-0.7 & 0.485\end{array}$ 


\begin{tabular}{lrrrrr}
\hline \hline & \# obs & Coef. & Std. Err. & $\mathbf{t}$ & $\mathbf{P}>|\mathbf{t}|$ \\
\hline banker & 1,728 & 3.560 & 0.400 & 8.9 & 0 \\
baron & 479 & 1.948 & 0.726 & 2.68 & 0.007 \\
beamter & 4,979 & 0.562 & 0.231 & 2.43 & 0.015 \\
benedictine & 1,841 & 0.555 & 0.368 & 1.51 & 0.132 \\
bishop & 4,855 & 3.873 & 0.244 & 15.9 & 0 \\
bookseller & 1,472 & 0.518 & 0.443 & 1.17 & 0.242 \\
botanist & 2,090 & 0.384 & 0.366 & 1.05 & 0.294 \\
brigadier_general & 593 & -3.938 & 0.615 & -6.4 & 0 \\
builder & 773 & 1.458 & 0.556 & 2.62 & 0.009 \\
businessman & 4,934 & 1.393 & 0.303 & 4.61 & 0 \\
cantor & 643 & 1.768 & 0.581 & 3.04 & 0.002 \\
captain & 3,049 & -0.773 & 0.303 & -2.55 & 0.011 \\
capuchin & 928 & 2.120 & 0.493 & 4.3 & 0 \\
cardinal & 727 & 1.580 & 0.564 & 2.8 & 0.005 \\
cartographer & 614 & -0.219 & 0.613 & -0.36 & 0.721 \\
chamberlain & 604 & 2.113 & 0.655 & 3.22 & 0.001 \\
chemist & 1,897 & 0.056 & 0.391 & 0.14 & 0.887 \\
classicist & 495 & 0.818 & 0.703 & 1.16 & 0.245 \\
clergyman & 6,455 & 1.164 & 0.244 & 4.78 & 0 \\
collector & 1,130 & 4.359 & 0.458 & 9.52 & 0 \\
colonel & 3,747 & 4.326 & 0.291 & 14.87 & 0 \\
commander & 1,018 & 0.729 & 0.459 & 1.59 & 0.112 \\
composer & 6,489 & 1.013 & 0.255 & 3.97 & 0 \\
congressman & 2,276 & -0.970 & 0.336 & -2.88 & 0.004 \\
consul & 701 & -0.347 & 0.553 & -0.63 & 0.531 \\
councillor & 5,166 & 0.895 & 0.291 & 3.08 & 0.002 \\
deacon & 653 & -4.975 & 0.576 & -8.64 & 0 \\
dean & 1,036 & 4.065 & 0.453 & 8.98 & 0 \\
deputy & 5,367 & 1.478 & 0.220 & 6.71 & 0 \\
designer & 652 & -0.224 & 0.573 & -0.39 & 0.696 \\
diplomat & 2,278 & 1.553 & 0.317 & 4.9 & 0 \\
director & 8,694 & 1.690 & 0.292 & 5.78 & 0 \\
\hline \hline & & & $c o n t i n u e d$ & on \\
next page \\
\hline \hline
\end{tabular}




\begin{tabular}{|c|c|c|c|c|c|}
\hline & \# obs & Coef. & Std. Err. & $\mathrm{t}$ & $\mathbf{P}>|\mathbf{t}|$ \\
\hline doctor & 15,384 & -2.204 & 0.273 & -8.08 & 0 \\
\hline dramatist & 1,604 & 0.328 & 0.382 & 0.86 & 0.391 \\
\hline duke & 1,283 & -4.721 & 0.472 & -9.99 & 0 \\
\hline earl & 1,243 & -2.159 & 0.490 & -4.4 & 0 \\
\hline economist & 796 & 0.872 & 0.584 & 1.49 & 0.135 \\
\hline editor & 5,362 & 0.050 & 0.293 & 0.17 & 0.865 \\
\hline engineer & 4,799 & 0.448 & 0.307 & 1.46 & 0.144 \\
\hline engraver & 2,976 & 0.593 & 0.290 & 2.05 & 0.041 \\
\hline farmer & 2,302 & 2.876 & 0.385 & 7.47 & 0 \\
\hline fighter & 915 & -4.230 & 0.519 & -8.15 & 0 \\
\hline franciscan & 1,063 & 1.456 & 0.462 & 3.15 & 0.002 \\
\hline general & 12,503 & 7.044 & 0.221 & 31.88 & 0 \\
\hline geograph & 668 & 1.001 & 0.588 & 1.7 & 0.089 \\
\hline geologist & 861 & 1.324 & 0.528 & 2.51 & 0.012 \\
\hline goldsmith & 1,178 & 0.200 & 0.464 & 0.43 & 0.666 \\
\hline governor & 2,915 & 0.808 & 0.283 & 2.85 & 0.004 \\
\hline historian & 7,562 & 2.243 & 0.320 & 7.02 & 0 \\
\hline illustrator & 1,224 & 2.286 & 0.421 & 5.43 & 0 \\
\hline industrialist & 2,066 & 3.391 & 0.394 & 8.61 & 0 \\
\hline inspector & 1,813 & 0.053 & 0.357 & 0.15 & 0.883 \\
\hline inventor & 865 & 1.851 & 0.520 & 3.56 & 0 \\
\hline jesuit & 7,201 & -2.822 & 0.238 & -11.84 & 0 \\
\hline journalist & 6,056 & -1.988 & 0.351 & -5.67 & 0 \\
\hline judge & 3,494 & 2.168 & 0.257 & 8.44 & 0 \\
\hline jurist & 15,660 & -0.682 & 0.149 & -4.56 & 0 \\
\hline kapellmeister & 804 & 1.369 & 0.534 & 2.56 & 0.01 \\
\hline king & 2,300 & -1.900 & 0.434 & -4.38 & 0 \\
\hline knight & 746 & 0.414 & 0.614 & 0.67 & 0.501 \\
\hline lawyer & 10,242 & -0.355 & 0.168 & -2.11 & 0.035 \\
\hline lecturer & 1,685 & -0.864 & 0.355 & -2.43 & 0.015 \\
\hline librarian & 1,769 & 1.019 & 0.413 & 2.46 & 0.014 \\
\hline lieutenant & 4,927 & -1.231 & 0.241 & -5.1 & 0 \\
\hline \multicolumn{6}{|c|}{ continued on next page } \\
\hline
\end{tabular}




\begin{tabular}{|c|c|c|c|c|c|}
\hline & \# obs & Coef. & Std. Err. & $\mathrm{t}$ & $\mathbf{P}>|\mathbf{t}|$ \\
\hline lieutenant_colonel & 457 & -0.738 & 0.740 & -1 & 0.318 \\
\hline lithograph & 1,241 & 0.666 & 0.419 & 1.59 & 0.112 \\
\hline lord & 1,546 & 1.844 & 0.466 & 3.95 & 0 \\
\hline magistrato & 1,753 & 2.338 & 0.354 & 6.6 & 0 \\
\hline major & 2,696 & 2.174 & 0.433 & 5.02 & 0 \\
\hline major_general & 1,479 & -2.877 & 0.594 & -4.84 & 0 \\
\hline manufacturer & 1,649 & 3.061 & 0.417 & 7.34 & 0 \\
\hline marshal & 1,707 & 6.744 & 0.377 & 17.88 & 0 \\
\hline martyr & 532 & -14.623 & 0.631 & -23.17 & 0 \\
\hline mathematician & 2,018 & -0.104 & 0.381 & -0.27 & 0.785 \\
\hline mayor & 4,488 & 2.756 & 0.230 & 11.99 & 0 \\
\hline merchant & 4,008 & 0.967 & 0.342 & 2.83 & 0.005 \\
\hline military & 3,431 & -0.542 & 0.279 & -1.94 & 0.052 \\
\hline minister & 5,417 & 1.109 & 0.222 & 4.99 & 0 \\
\hline missionary & 2,801 & -1.257 & 0.291 & -4.31 & 0 \\
\hline musician & 6,644 & 1.174 & 0.255 & 4.61 & 0 \\
\hline naturalist & 1,016 & -0.817 & 0.480 & -1.7 & 0.089 \\
\hline noble & 3,635 & -2.274 & 0.395 & -5.76 & 0 \\
\hline notary & 1,217 & 1.016 & 0.419 & 2.43 & 0.015 \\
\hline officer & 13,787 & 0.962 & 0.191 & 5.03 & 0 \\
\hline organist & 1,777 & 1.411 & 0.374 & 3.78 & 0 \\
\hline orientalist & 611 & -0.448 & 0.631 & -0.71 & 0.477 \\
\hline painter & 19,293 & 1.974 & 0.203 & 9.72 & 0 \\
\hline pastor & 9,800 & 0.822 & 0.204 & 4.03 & 0 \\
\hline pedagogue & 3,806 & 1.777 & 0.369 & 4.82 & 0 \\
\hline pewterer & 448 & 0.867 & 0.707 & 1.23 & 0.22 \\
\hline pharmacist & 1,192 & 0.022 & 0.463 & 0.05 & 0.962 \\
\hline philologe & 2,976 & -0.733 & 0.379 & -1.93 & 0.053 \\
\hline philosopher & 1,966 & 0.007 & 0.428 & 0.02 & 0.986 \\
\hline physician & 2,990 & -0.566 & 0.359 & -1.58 & 0.114 \\
\hline physicist & 989 & 0.828 & 0.493 & 1.68 & 0.093 \\
\hline pianist & 979 & -0.899 & 0.486 & -1.85 & 0.064 \\
\hline \multicolumn{6}{|c|}{ continued on next page } \\
\hline
\end{tabular}




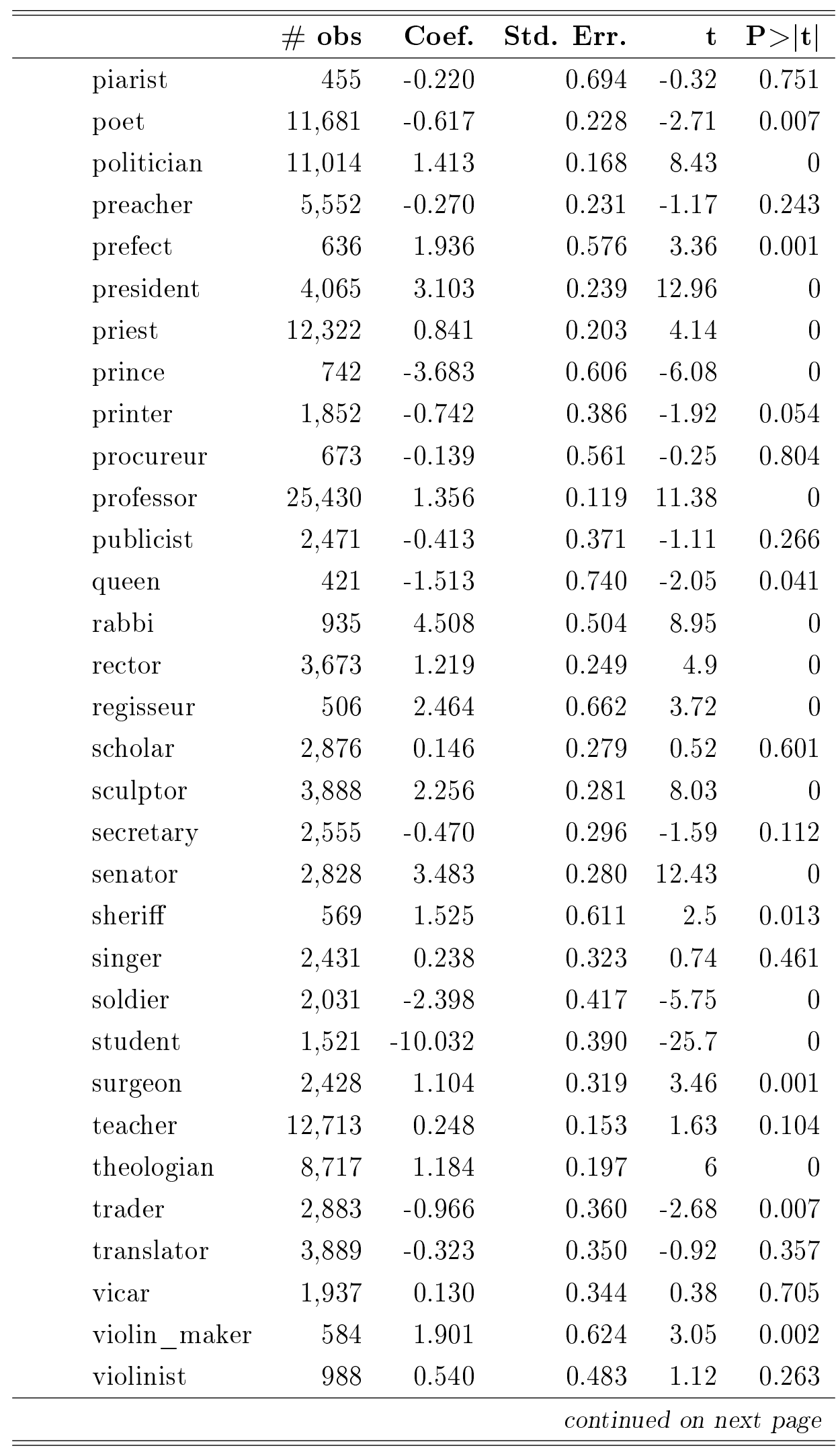




\begin{tabular}{lrrrrr}
\hline \hline & \# obs & Coef. & Std. Err. & $\mathbf{t}$ & $\mathbf{P}>|\mathbf{t}|$ \\
\hline wholesaler & 438 & 0.568 & 0.766 & 0.74 & 0.458 \\
writer & 24,391 & 0.946 & 0.142 & 6.69 & 0 \\
zoologist & 535 & 1.005 & 0.652 & 1.54 & 0.123
\end{tabular}

Nationalities

\begin{tabular}{|c|c|c|c|c|c|}
\hline American & 18,261 & 2.307 & 0.266 & 8.66 & 0 \\
\hline Argentinian & 1,438 & -2.901 & 0.551 & -5.27 & 0 \\
\hline Australian & 556 & 4.648 & 0.650 & 7.14 & 0 \\
\hline Austrian & 8,282 & 0.508 & 0.303 & 1.68 & 0.094 \\
\hline Belgian & 4,325 & -0.808 & 0.344 & -2.35 & 0.019 \\
\hline Brazilian & 1,461 & -5.057 & 0.515 & -9.82 & 0 \\
\hline British & 21,857 & 1.239 & 0.261 & 4.75 & 0 \\
\hline Canadian & 1,150 & 2.862 & 0.485 & 5.9 & 0 \\
\hline Chinese & 1,029 & 0.723 & 0.513 & 1.41 & 0.159 \\
\hline Croatian & 587 & -1.240 & 0.633 & -1.96 & 0.05 \\
\hline Czech & 2,755 & 0.340 & 0.384 & 0.89 & 0.376 \\
\hline Danish & 6,329 & 0.074 & 0.323 & 0.23 & 0.819 \\
\hline Dutch & 8,516 & -0.236 & 0.310 & -0.76 & 0.447 \\
\hline Finnish & 1,524 & -1.027 & 0.468 & -2.19 & 0.028 \\
\hline French & 21,408 & 1.190 & 0.260 & 4.57 & 0 \\
\hline German & 41,401 & -0.560 & 0.250 & -2.24 & 0.025 \\
\hline Greek & 744 & 2.096 & 0.550 & 3.81 & 0 \\
\hline Hungarian & 8,992 & -1.618 & 0.303 & -5.34 & 0 \\
\hline Icelandic & 2,058 & 0.651 & 0.400 & 1.63 & 0.104 \\
\hline Indian & 460 & -1.550 & 0.695 & -2.23 & 0.026 \\
\hline Irish & 1,303 & 1.110 & 0.490 & 2.27 & 0.023 \\
\hline Italian & 7,958 & 1.397 & 0.292 & 4.79 & 0 \\
\hline Japanese & 554 & 1.421 & 0.653 & 2.18 & 0.029 \\
\hline Norwegian & 2,239 & -0.721 & 0.424 & -1.7 & 0.089 \\
\hline Polish & 6,744 & -1.099 & 0.309 & -3.56 & 0 \\
\hline Portuguese & 1,330 & 0.519 & 0.511 & 1.01 & 0.31 \\
\hline Roman & 968 & -0.703 & 0.476 & -1.48 & 0.14 \\
\hline Russian & 7,467 & -3.973 & 0.293 & -13.55 & 0 \\
\hline
\end{tabular}




\begin{tabular}{|c|c|c|c|c|c|}
\hline & \# obs & Coef. & Std. Err. & $\mathrm{t}$ & $\mathbf{P}>|\mathbf{t}|$ \\
\hline Slovak & 387 & 0.738 & 0.762 & 0.97 & 0.333 \\
\hline Slovenian & 543 & -2.215 & 0.654 & -3.38 & 0.001 \\
\hline Spanish & 5,554 & 0.011 & 0.326 & 0.03 & 0.972 \\
\hline Swedish & 13,914 & 0.896 & 0.276 & 3.24 & 0.001 \\
\hline Swiss & 8,327 & 0.823 & 0.293 & 2.81 & 0.005 \\
\hline \multicolumn{6}{|l|}{ Religions } \\
\hline Baptist & 595 & 0.139 & 0.597 & 0.23 & 0.816 \\
\hline Catholic & 2,016 & 0.976 & 0.331 & 2.94 & 0.003 \\
\hline Lutheran & 552 & -2.438 & 0.619 & -3.94 & 0 \\
\hline Mennonite & 521 & 5.445 & 0.638 & 8.53 & 0 \\
\hline Methodist & 415 & -0.041 & 0.717 & -0.06 & 0.954 \\
\hline Protestant & 1,647 & -0.170 & 0.371 & -0.46 & 0.647 \\
\hline Reformed & 1,292 & 1.599 & 0.419 & 3.81 & 0 \\
\hline \multicolumn{6}{|l|}{ Various } \\
\hline Bengali & 1,459 & -13.402 & 0.483 & -27.77 & 0 \\
\hline chief & 2,178 & 1.151 & 0.310 & 3.71 & 0 \\
\hline founder & 2,942 & 3.012 & 0.266 & 11.3 & 0 \\
\hline Jewish & 606 & 0.252 & 0.586 & 0.43 & 0.668 \\
\hline landowner & 1,081 & 3.211 & 0.439 & 7.32 & 0 \\
\hline servant & 405 & 2.068 & 0.715 & 2.89 & 0.004 \\
\hline unionist & 383 & 4.102 & 0.737 & 5.57 & 0 \\
\hline \multicolumn{6}{|c|}{ Age at publication } \\
\hline 15 & 27 & -39.379 & 2.753 & -14.3 & 0 \\
\hline 30 & 205 & -35.641 & 1.000 & -35.64 & 0 \\
\hline 40 & 834 & -29.274 & 0.497 & -58.86 & 0 \\
\hline 50 & 2,681 & -22.729 & 0.280 & -81.31 & 0 \\
\hline 60 & 6,313 & -15.478 & 0.185 & -83.75 & 0 \\
\hline 70 & 13,232 & -8.914 & 0.132 & -67.56 & 0 \\
\hline 80 & 19,829 & -4.480 & 0.111 & -40.38 & 0 \\
\hline 90 & 22,634 & -2.869 & 0.104 & -27.45 & 0 \\
\hline R-squared & 0.1342 & & & & \\
\hline
\end{tabular}

Table 2: Detailed Regression Results 


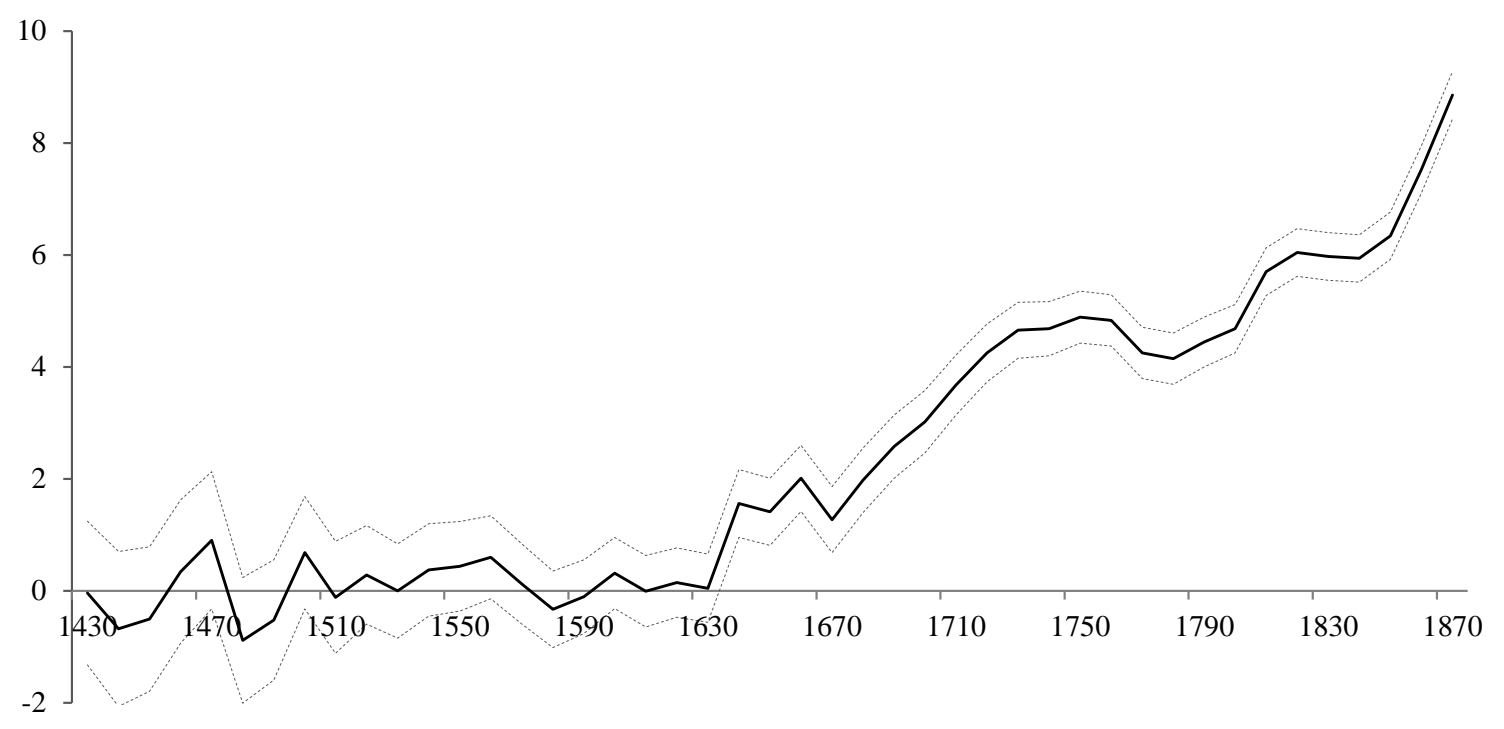

Figure 5: Conditional Longevity. Cohort dummies and 95\% confidence interval

The estimated constant term was 59.67 years, which is slightly smaller than the 60.46 years of the unconditional mean before 1430 -the standard deviation is 0.19 , implying that it is estimated with high precision. The difference has to be attributed to the omitted control dummies, because the constant term measures the age of the mean male celebrity born before 1430 with a precise lifespan, non-migrating and without an identified city, nationality, occupation or religion. The precision dummy was estimated at -0.81 years, which is small but significantly different from zero -the standard deviation was 0.08 . The negative sign is fundamentally due to the fact that imprecise observations occurred more frequently before 1640. Consequently, controlling for imprecise reported lifespans, if anything, reduces the gains in longevity observed after 1640 .

The estimation also provides evidence that the other dummies effectively controlled for the different biases referred to in Section 3. From our estimation, a person living in one of the 77 retained cities had on average no survival advantage with respect to the rest of the population, since the estimated coefficient of the large cities dummy was small, 0.31 years, and not significantly different from zero -the standard deviation was $0.19 .{ }^{21}$ Even if the 77 city dummies were estimated with relatively high precision -their standard deviations are in the interval $(0.21,0.79)$, for $2 / 3$ of them zero is in the $95 \%$ confidence interval. A few cities have longevity 2.5 years larger (Frederiksberg) or smaller (Leipzig and Riga) than the mean.

\footnotetext{
${ }^{21}$ We have also created a control variable urban, taking value one if the place of birth or the place of death were mentioned in GeoDataSource. We decided not to retain it, since the estimated coefficient was non significant.
} 
Details for cities are in Appendix 2.

The estimated coefficient for the group of large nationalities - a dummy grouping all individuals with at least one among the 33 retained nationalities- is non significantly different from zero: -0.26 years with a standard deviation of 0.24 . Australians had the largest positive estimated coefficients and Brazilians, in the other extreme, had the lowest, 4.64 years and 5.06 years above and below the mean, respectively. Details for nationalities are also in Appendix 2.

The estimated coefficients of the occupation categories are shown in Figure A.3, in the appendix, with the corresponding $95 \%$ confidence intervals. These results illustrate that the regression effectively controlled for occupational composition bias. The difference in longevity between an average military occupation and an average science occupation was slightly larger than four years. Among the 148 estimated occupation dummies, 1/3 are not significantly different from zero and $73 \%$ of the estimated coefficients are in the interval $(-2,2)$. A few occupations had large negative dummies, in some cases larger than 10 years (martyrs and students). Details for occupations are also in Appendix 2.

As Table 3 illustrates for religious, military and education occupations, seniority is one of the main causes of the notoriety bias referred to in Section $3 .^{22}$ High ranks in the three occupational groups had larger dummies than low ranks, since some seniority is required to climb up the rank ladder. Particularly interesting is the case of martyrs and students, which had a highly significant negative dummy. This observation likely reflects the fact that these people became famous because they died young.

The migration dummy was estimated at 0.46 years, with standard error 0.06 , reflecting the migration bias that some potential emigrants died before migrating. The gain is relatively small since migration and being famous are likely to be highly correlated. ${ }^{23}$ The female dummy was estimated at 1.09 years (sd. 0.15), reflecting the fact that females live on average longer than males.

To control for the source bias, we included in the regression eight age at publication dummies (15-29,30-39,...,90-99). All coefficients, as reported in Table 2, are negative, sizable and statistically significant - the dotted lines correspond to the $95 \%$ confidence interval. As expected, the coefficient of the dummy decreased in absolute value with the age at publication, from 39.4 to 2.9 years. The source bias was thus high for people dying close to the publication date of the source. Note that, by construction, the lifespan of persons in the first

\footnotetext{
${ }^{22}$ To make estimated dummies comparable across occupations in different occupational groups, the occupational category dummy (in the first row) has to be added to the occupation dummy.

${ }^{23}$ Mokyr (2005b) measured the mobility of 1185 "creative people" in Europe over 1450-1750 and showed it was large, with 3.72 mean moves per person. Longer living people, as expected, moved somewhat more.
} 


\begin{tabular}{lrlrlr} 
religious & -0.03 & military & -3.02 & education & 0.74 \\
\hline rabbi & 4.51 & admiral & 8.21 & dean & 4.07 \\
bishop & 3.87 & general & 7.04 & academician & 3.22 \\
archbishop & 3.47 & marshal & 6.74 & professor & 1.36 \\
abbot & 3.44 & colonel & 4.33 & rector & 1.22 \\
archdeacon & 2.38 & major & 2.17 & writer & 0.95 \\
cardinal & 1.58 & officer & 0.96 & teacher & 0.25 \\
theologian & 1.18 & commander & 0.73 & scholar & 0.15 \\
clergyman & 1.16 & military & -0.54 & lecturer & -0.86 \\
priest & 0.84 & captain & -0.77 & student & -10.03 \\
pastor & 0.82 & lieutenant & -1.23 & & \\
vicar & 0.13 & soldier & -2.40 & & \\
preacher & -0.27 & fighter & -4.23 & & \\
missionary & -1.26 & & & & \\
deacon & -4.98 & & & & \\
martyr & -14.62 & & & &
\end{tabular}

Table 3: Notoriety Bias for "religious", "military" and "education" Occupations.

group was between fifteen and thirty years; when added to the estimated dummy the sum was close to the longevity of the representative celebrity $(20+40=60)$.

To estimate the extent of the source bias, we ran the regression without the age at publication dummies, and then measured the source bias as the difference between the cohort dummy coefficients of the benchmark regression and the newly estimated coefficients. The solid line in Figure 7 represents the estimated source bias, and the dotted line is twice the standard deviation of the cohort dummies in the benchmark estimation. The source bias and the precision of the benchmark estimation -the inverse of the standard deviation- both clearly increased. The source bias is close to zero until the seventeenth century, then slowly increases but remaining small and non-significant until the cohort born in 1700; then, it increases to reach more than 4 years for the last cohort. Controlling for the source bias does not affect the main result that famous people longevity started increasing in 1640, as we have already observed in Figure 3. However, controlling for the source bias significantly increases the size of the improvement at the end of sample: it almost doubled the five year unconditional gain. Since most sources were published in the 19th and mainly 20th centuries, the number of observations included in the age at publication dummies increased from around $5 \%$ of the total observations in the first half of the eighteen century to $60 \%$ in the last decade. This factor explains why controlling for the source bias had such a large impact at the end of the sample. 


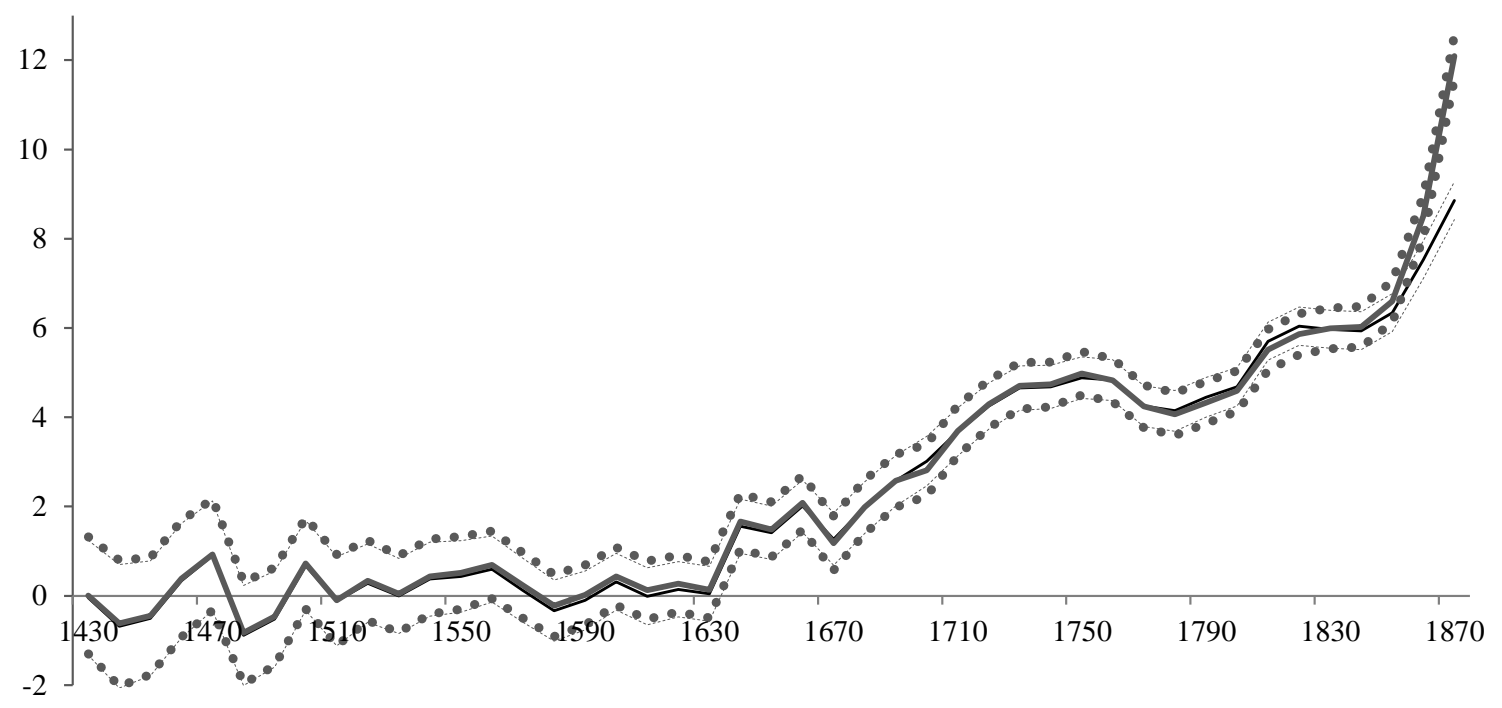

Figure 6: Conditional Longevity. Full sample: Cohort dummies and 95\% confidence interval (dashed). Restricted Sample: Cohort dummies and 95\% confidence interval (dots)

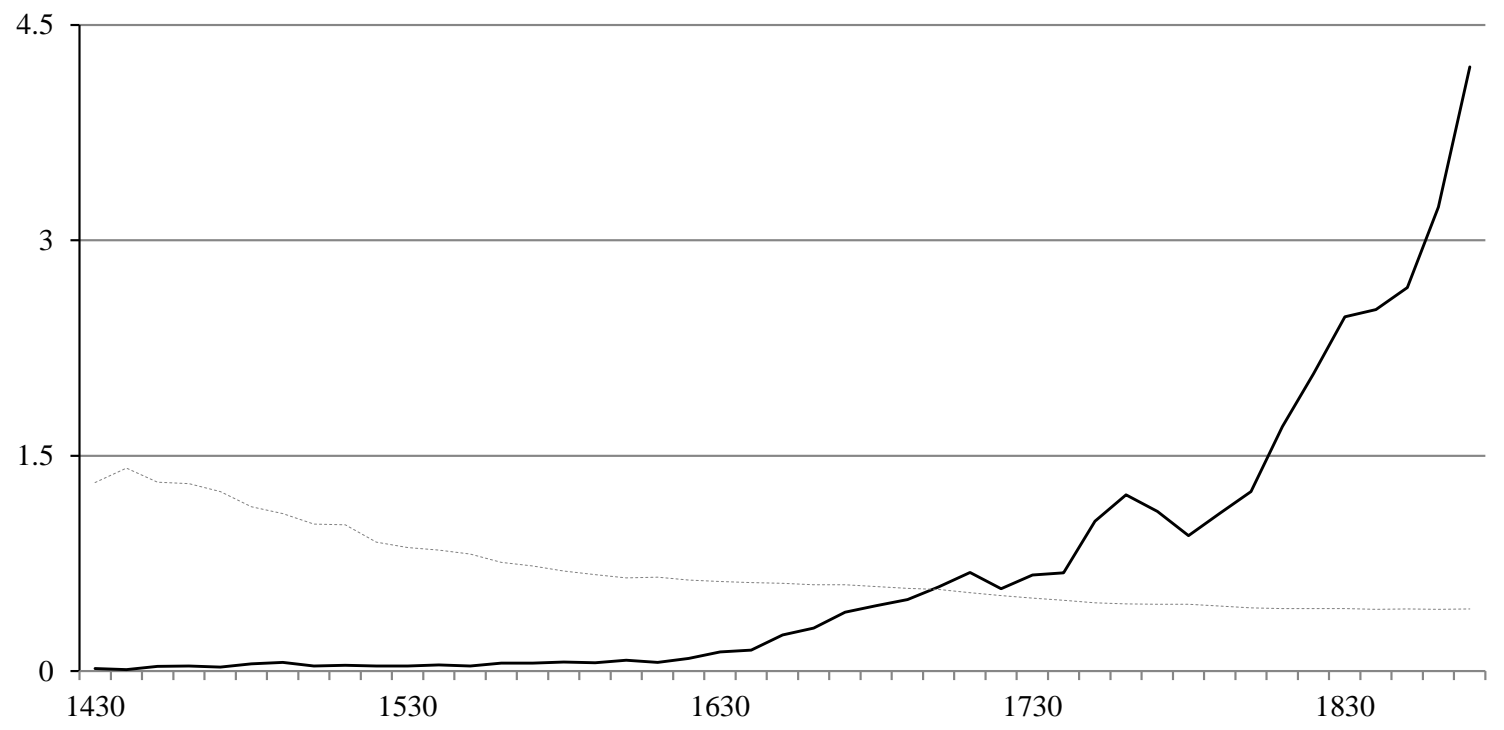

Figure 7: Source bias. Estimation (solid line), $2 \times$ std cohort dummies (dotted line) 


\subsection{Additional Robustness Checks}

An alternative procedure of controlling for the source bias consists in removing from the sample all individuals with a birth date close to the publication date of the source. This method is however much less efficient than the previous one, as we may loose a substantial number of observations. Still, to check the consistency of our benchmark estimation, we ran the same regression without the age at publication dummies on a restricted sample, excluding all individuals for which the source was published less than 100 years after their birth (i.e, all individuals for which one of the age at publication dummies takes value one). Results with this restricted sample are shows in Figure 6. Significant differences occur at the very end of the sample (where the restricted sample looses a lot of observations): for these cohorts, the gains in longevity are significantly for the restricted sample. This reinforces our view that the age at publication dummies do not artificially inflate the longevity gains.

To check that our results are not dominated by the lifespan of people from a few sources, we have also controlled for the 20 and the 60 largest sources, by including source dummies that take value one only if the individual is cited by the source. They include 110,745 and 177,983 observations, respectively. The cohort dummies estimated with these additional controls stay in the confidence interval of the benchmark estimation. ${ }^{24}$

To further assess the validity of our approach, we looked at some characteristics of the residuals $\varepsilon_{i, t}$. First, we estimated their density function, see Figure A.4: it appears to be unimodal and negatively skewed, a well-known result for the lifespan distribution of adult humans (Robertson and Allison 2012).

Second, looking at Figure 5, we observe that the confidence interval gets narrower as time passes. We checked whether this could be attributed to the increasing number of observations or to some heteroscedasticity in the error term. Accordingly, we computed the standard deviations of the residuals by decade, with confidence bounds around them, see Figure A.5. The only permanent large change was for the last six decades, for which the standard deviation displayed a downward trend. The reason is that, at the end of the sample, there are few people with an advanced age because of the source bias, reducing variability in longevity. Correcting for the source bias as we did does not fully correct the problem. Such heteroscedasticity is an artifact of the selection bias, not a change in the variance of the underlying population. Furthermore, we also computed the confidence interval of Figure 5

\footnotetext{
${ }^{24}$ The source with the largest (in absolute value) dummy coefficient is a book citing British soldiers who died in Bengali between 1758 and 1834. This source belongs to the 60 largest but not to the 20 largest. It covers 1396 people in the sample. The estimated coefficient is -16.96 (se 0.88). Interestingly, the coefficient of the dummy bengali moves up from -13.89 in the benchmark regression to 0.52 (se 0.86 ) in the regression with the 60 source dummies.
} 
with robust standard errors, and the changes are negligible.

Third, we checked for the effect of exceptional events on our estimation. We computed the longevity for each year of death, trying to identify particularly deadly events -see Figure A.6. By far the biggest event happened in 1794, which corresponds to the Reign of Terror during the French Revolution. Introducing a dummy variable "dead in 1794" into the regression, however, did not greatly modify the estimation. The biggest change was in the coefficient for the dummy "martyr" which went from -14.62 to -13.21 . The next biggest change was for decade 1730-9, with the coefficient going from 4.65 to 5.04. Coefficients, such as those for French, Bordeaux, and Toulouse, were affected, but to a very small extent. We conclude from this exercise that trying to model certain unusual events from European history would add little to our estimation.

Finally, we performed a median regression (the median regression is a particular case of a quantile regression where the coefficients are estimated by minimizing the absolute deviations from the median) to check that the rise in longevity was not driven by the right tail of the distribution. Results are very similar. The median lifespan of our famous people was 61.75 years until 1420. Cohort dummies are not significantly different from zero until cohort 1640-49, with median longevity reaching 72.05 for Einstein's cohort. If something, gains in longevity are larger for the median than for the mean celebrity.

\subsection{Is the Early Increase in Longevity General?}

Model (2) states that the longevity of celebrities in all occupations, cities and nationalities has moved jointly over time. Any gain in longevity is then assumed to be common. However, it may be that a particular occupational group or a particular region were behind the observed increase from 1640, and that the longevity of other occupations or regions did not improve at all or started to improve later. Perhaps income started increasing before the Industrial Revolution in the regions or for the occupations that led it, not in the others, making the longevity of famous people increase only in these regions or occupations. For this propose, we identified potential characteristics for early improvement in life expectancy, created dummies and ran new regressions interacting these dummies with the cohort dummies. The model to be estimated became:

$$
m_{i, t}=m+d_{t}+\tilde{d}_{t}+\alpha x_{i, t}+\varepsilon_{i, t}
$$

where $\tilde{d}_{t}$ measuring the difference between the conditional longevity of the selected group and the whole cohort $t$. 


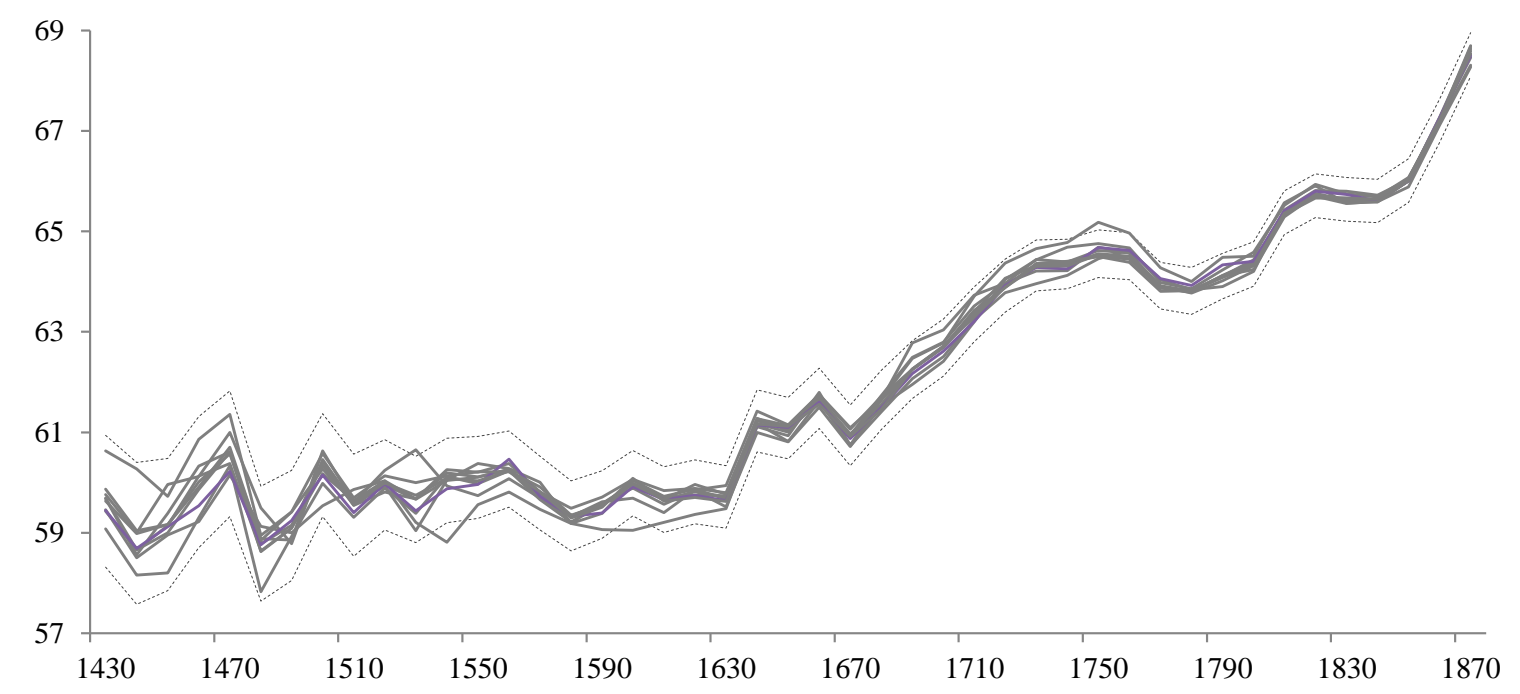

Figure 8: Longevity Excluding Each Occupational Group in Turn

\subsubsection{Occupations}

Could some occupations, because they profited from early improvements in income, or from some specific conditions, such as the military revolution, have led the reduction in mortality? To answer this question, we interacted the cohort dummies with occupational groups (arts and métiers, business, religious, education, humanities, law and government, military, nobility and sciences), one at a time, according to equation (3). We found that none of these groups was individually driving the main result. Figure 8 shows the estimated coefficients of the cohort dummies, $d_{t}$ in equation (3), i.e., after controlling for changes in the longevity of each occupational group separately. In each case, the cohort dummy coefficients represent the cohort longevity of famous people not belonging to each of the specified occupations. As can be observed in Figure 8, all of the coefficients were within the confidence interval of the cohort dummies in the benchmark estimation (the upper and lower dotted lines). Moreover, for each of the nine occupational groups, the interaction terms $\tilde{d}$ were always in the $(-2,2)$ years interval, without showing any particular pattern. Hence, it cannot be that our result were driven by any of the occupational groups alone.

\subsubsection{Nationalities and Cities}

Did celebrities' longevity increase first in those regions that led the industrial revolution, Great Britain in particular, or was it a more general phenomenon? With this hypothesis 


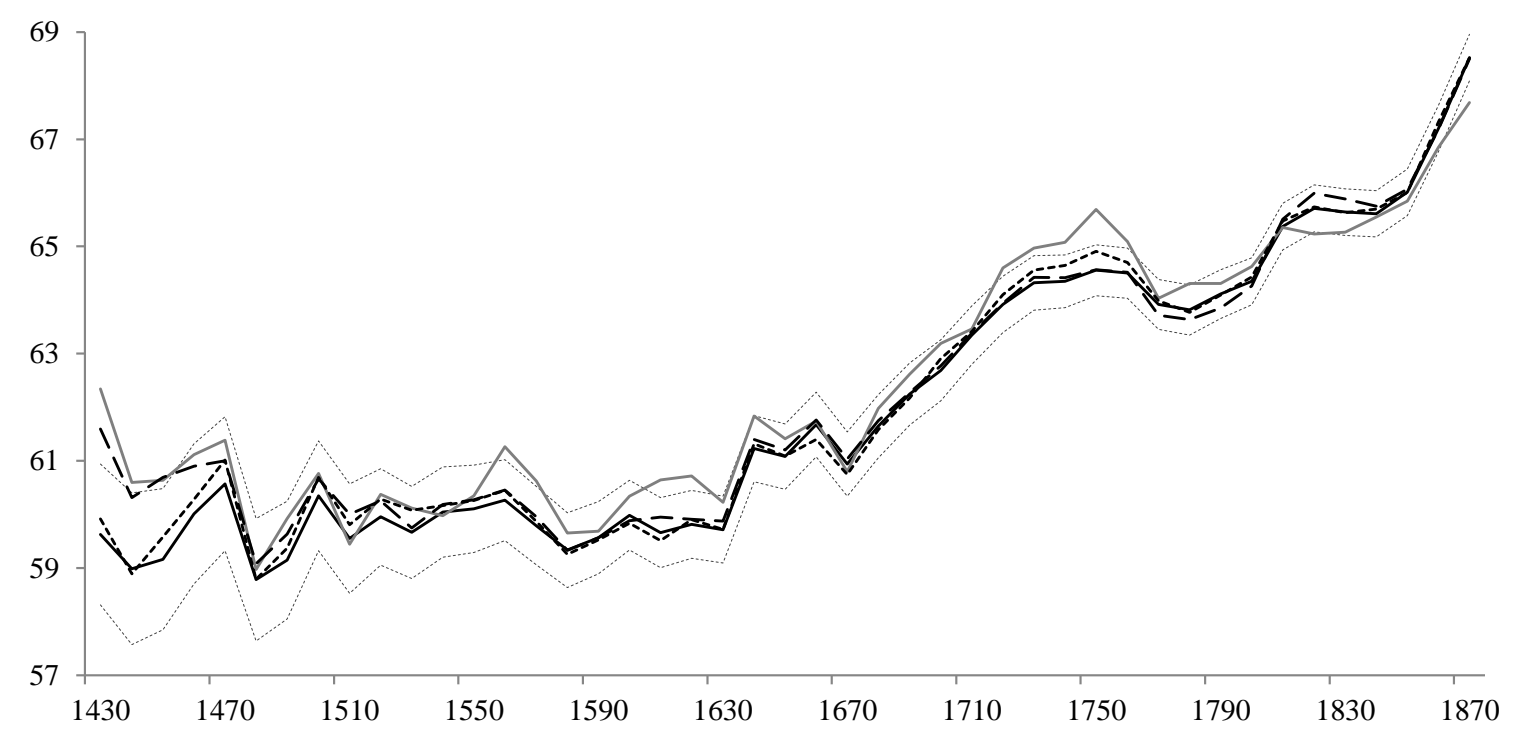

Figure 9: Longevity Excluding British, Leading Nations and Leading Cities

in mind, we created three dummies. First, a leading cities dummy including the largest cities in the sample, i.e., those with the largest number of observations (Amsterdam, Berlin, Copenhagen, London, Paris, Rome, Stockholm, Wien). Second, a British dummy, including English and Scottish nationalities, as well as people born or dying in London and Edinburgh, the only two British cities among the retained 77 large cities. Third, a leading nations dummy allocating the value of one if an individual had the nationality of a selected group of countries, or was born or died in a city, among the 77 selected cities, in the actual territory of one of the leading nations. The set of selected countries included those that, according to Maddison (2010), in 1870 had an annual GDP per capita of at least 1800 dollars (Australia, Austria, Belgium, Denmark, France, Germany, Netherlands, Switzerland, UK and US). As in the previous subsection, we added to the benchmark regression new terms interacting the cohort dummies with the three leading dummies above, one at a time. Figure 9 shows the cohort dummy coefficients estimated when the interactive terms were included (the dotted upper and lower lines correspond to the confidence intervals of the benchmark estimation). As can be observed, including the leading dummies did not significantly affect the estimation of the longevity of the whole population, meaning that neither leading cities, Britain nor leading nations were behind our main result that the longevity of famous people started increasing as early as in 1640 after millennia of stagnation. 


\section{Survival Laws}

To better characterize the forces responsible for the increase in famous people longevity, this section studies the shifts in the survival law underlying it. In particular, we investigate whether these shifts came from a change in the process of aging, or, on the contrary, they were related to improvements in health conditions independently of age. For this purpose, we grouped individuals into 150 cohorts of at least 1600 members and measured survival laws for these cohorts, then, following Gavrilov and Gavrilova (1991), we estimated the Gompertz-Makeham mortality law for each cohort and used the estimated coefficients to test the Compensation Effect of Mortality. We found that the changes in mortality observed since the middle of the seventieth century were mainly due to changes in the Gompertz parameters consistent with the Compensation Effect, and showing an early tendency for the survival law to rectangularize. Rectangularization implies a shift of age specific mortality rates away from young persons, without changing the lifespan. As death becomes more concentrated among the older persons, it implies a decreasing variability in the distribution of ages at death. (See Wilmoth and Horiuchi (1999) for various measures of rectangularization.)

\subsection{Conditional Survival and Mortality Rates}

Cohort dummies and residual terms of equation (2), as estimated in Section 4.1, were used to measure conditional survival laws for all individuals in the sample. For each individual $i$ belonging to cohort $t$, let us define $\hat{r}_{i, t} \equiv \hat{m}+\hat{d}_{t}+\hat{\varepsilon}_{i, t}$, where $\hat{m}$ was the estimated constant, $\hat{d}_{t}$ the estimated cohort dummy parameter and $\hat{\varepsilon}_{i, t}$ the estimated residual. We denoted by $r_{i, t}$ the conditional lifespan of individual $i$ belonging to cohort $t$, where $r_{i, t}$ was the integer part of $\hat{r}_{i, t}{ }^{25}$ This measure represents the lifespan of individual $i$ after controlling for all observed characteristics.

For cohort $t$, let $n_{t}$ be the total number of observations belonging to this cohort and let $s_{t, h}$ be the number of observations with conditional lifespan equal or larger than $h$. Cohort $t$ conditional survival probabilities are then measured by computing the ratios $s_{t, h} / n_{t}$ for all $h .^{26}$

In this section, following the argument developed in Section 2 concerning confidence intervals, we created cohorts of at least 1600 individuals; individuals born the same year always belong

\footnotetext{
${ }^{25}$ When the fractional part is less than 0.5 , we take the largest previous integer; otherwise we take the smallest following integer. Notice that conditional lifespans are not bounded between ages 15 and 100 , as unconditional lifespans are by construction.

${ }^{26}$ Contrary to their usual definition, survival probabilities are here computed vis a vis the whole population instead of the population at risk. We propose a correction for this in Section 5.3.
} 


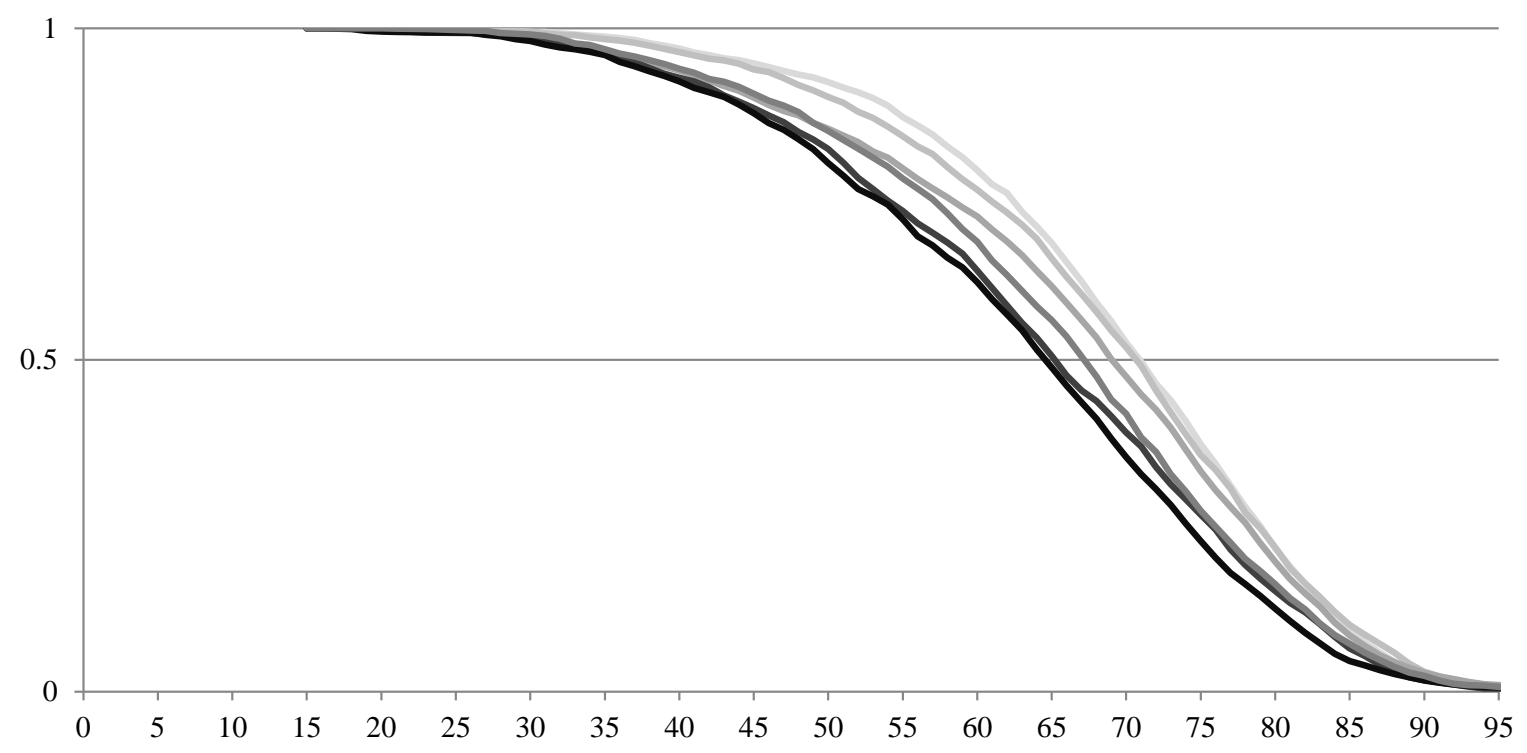

Figure 10: Conditional Survivals for some 1600-cohorts. From deep black to clear gray are cohorts 1535-1546, 1665-1669, 1787-1788, 1807-1808, 1816, 1879.

to the same cohort; we refer to them as the 1600-cohorts. Following this criterion, we detected 150 1600-cohorts. ${ }^{27}$ Figure 10 shows the survival laws of some selected 1600-cohorts; they are ordered from black, the oldest, to light gray, the youngest. The first survival law precedes 1640. As can be observed, the survival law moves to the right from the 17th century onward in a tendency to rectangularize.

\subsection{Gompertz-Makeham Law and Compensation Effect}

We followed Gavrilov and Gavrilova (1991) to estimate and interpret the evolution of the survival law. The main argument was based on two observations: the Gompertz-Makeham law of mortality and the Compensation Effect. Let death rates be denoted by $\delta(a)$, an age dependent function, where $a$ denotes individuals' age. The Gompertz-Makeham law of mortality, as suggested by Gompertz (1825) and Makeham (1860), asserts that death rates follow

$$
\delta(a)=A+e^{\rho+\alpha a} .
$$

\footnotetext{
${ }^{27}$ Individuals in the sample are ordered by their year of birth and cohorts were created following the position of individuals in the sample; for example, the first 1600 individuals belong to the first cohort. Because individuals born the same year belong to the same cohort, cohort sizes are in general larger than 1600 individuals. Indeed, the mode was very close to 1600 and $50 \%$ of the cohorts had less than 1900 observations. Details are provided in Appendix F.
} 
Death rates depend on an age-dependent component, the Gompertz function $e^{\rho+\alpha a}$, and an age-independent component, the Makeham constant $A, A>0$. In the Gompertz function, parameter $\rho$ measures the mortality of young generations while parameter $\alpha, \alpha>0$, represents the rate at which mortality increases with age. The corresponding survival law is

$$
S(a)=\exp \left\{-A a-\left(e^{\alpha a}-1\right) e^{\rho} / \alpha\right\}
$$

To assess whether the observed shifts in the survival law were related to age-dependent or age-independent factors, we estimated, by non-linear least squares, the Gompertz-Makeham law (4) (in $\operatorname{logs}$ ) for each of the 1600-cohorts. As usual in this literature, the estimation only considered the observed mortality rates between 30 and 90 years, since the GomperzMakeham law mainly applies to this age bracket.

Consistent with the main findings in Gavrilov and Gavrilova (1991), the estimated Gompertz parameter $\rho$ decreased over time whereas the estimated Gompertz parameter $\alpha$ increased, as can be observed in Figures A.8 and A.7 -the dotted lines correspond to the $95 \%$ confidence intervals. These parameter changes took place as early as for the cohort born in 1640, i.e., earlier than in Gavrilov and Gavrilova (1991). Contrary to the estimations in Gavrilov and Gavrilova (1991), the age-independent parameter $A$ was systematically non-significantly different from zero -see Figure A.9. This last observation relies on the fact that the mortality rates of famous people are close to zero for ages below 40. We develop this argument in Section 5.3 below.

The Compensation Effect of Mortality states that any observed reduction in the mortality of the young, $\rho$, has to be compensated by an increase in the mortality of the old, $\alpha$, following the relation

$$
\rho=M-T \alpha
$$

where $M$ and $T, T>0$, are constant parameters, the same for all human populations. While parameters $\rho$ and $\alpha$ in equations (4) and (5) may be dissimilar for different human populations, parameters $M$ and $T$ in equation (6) are common for humanity.

For $A=0$, it is easy to see that under the Compensation Effect, survival tends to rectangularize when $\alpha$ goes to infinity; in this case, the maximum lifespan of humanity is $T .{ }^{28}$ Following (6), any reduction in $\rho$ compensated by an increase in $\alpha$ rectangularizes the survival and increases longevity. Such an improvement in longevity is however bounded by the maximum lifespan $T$.

\footnotetext{
${ }^{28}$ For this purpose, take $\rho$ in (6) and substitute it in (4). Then, let $\alpha$ go to infinity, which implies that the death rates tend to zero for $a<T$ and to infinity when $a>T$.
} 
Figure 11 (left) represents the point estimates $\{\rho, \alpha\}$ for the 1501600 -cohorts retained in this section. They clearly move around a straight line. Indeed, the Compensation Effect of Mortality holds for famous people during the sample period. This finding is also in line with Gavrilov and Gavrilova (1991). ${ }^{29}$ Since $\rho$ decreased and $\alpha$ increased consistently with the Compensation Effect, the survival law of famous people tends to rectangularize as observed in Section 5.1. The Compensation Effect equation (6) was estimated by OLS on the 150 pairs $\{\rho, \alpha\}$ previously estimated. The lifespan parameter $T$ was estimated at 80.2 years -with a standard deviation of 0.58 years.
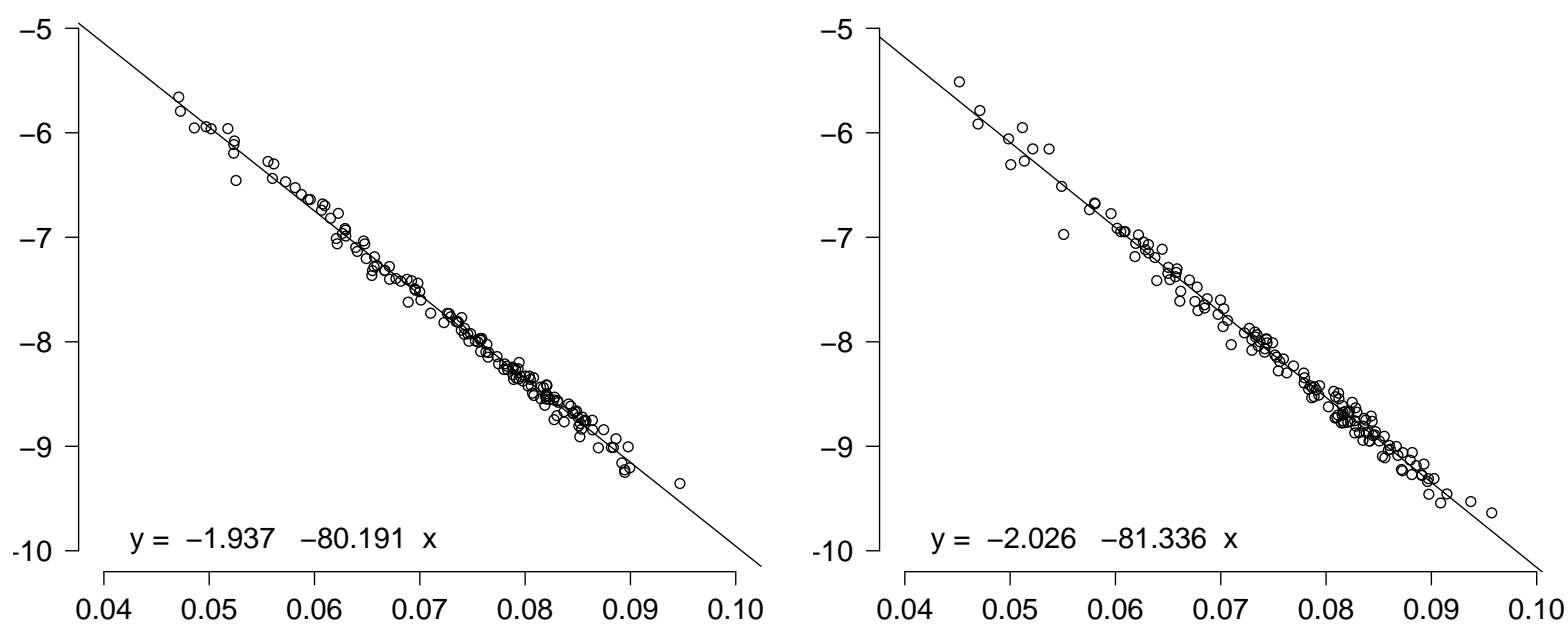

Figure 11: The two parameters of the Gomperz function $\rho$ (Y-axis), $\alpha$ (X-axis). Benchmark (left) and Notoriety Bias Corrected (right)

\subsection{Mortality of Potentially Famous People}

As explained in Section 3, the IBN suffers from the notoriety bias. The correction we implemented by introducing occupation dummies in the regression captures the difference in notoriety across famous people occupations, but might not be totally satisfactory, as it follows a very reduced form approach.

An alternative way to fully control for the notoriety bias is to estimate a structural model of this bias. Let us make the following assumptions. First, let us denote by $\delta_{p}(a)$ the mortality rates of the population of potentially famous people, which includes not only those observed in the IBN but also those that had the potential to be included but died before achieving the required prestige and fame. Let us then assume that the Gompertz-Makeham mortality law holds for the population of potential celebrities. For the sake of simplicity, let us assume that

\footnotetext{
${ }^{29}$ Strulik and Vollmer (2013) found changes in the Compensation Law in the last half of the 20th Century, with a corresponding increase in human lifespan $T$.
} 
$\delta_{p}(a)$ follows equation (4). Let us denote by $\Phi(a)$ the probability that potentially famous people achieve notoriety before age $a$. Consequently, death rates of (observed) famous people are

$$
\delta(a)=\Phi(a) \delta_{p}(a)
$$

the probability of dying at age $a$ conditional on being already famous.

Different theories may be elaborated to predict the age at which a potentially notorious person acquires the needed reputation to become famous. In this section, we build a simple theory based on the assumption that potentially famous people belong to dynasties, each one undertaking a single prominent job. Potentially famous members of the dynasty are sitting in a queue waiting for the death of the dynasty member currently holding the job. This is clearly the case for hereditary occupations like nobility where, for example, a prince has to wait for the death of the king to accede to the throne. It is also the case of ranked occupations, such as religious or military occupations, in which people move up in a grade scale and then hold the position until death. In occupations such as arts and sciences, things are more complex, since the number of jobs is somewhat endogenous. However, some form of congestion may also operate, making it more difficult to become famous when the pool of famous people is large.

Let us take the case of princes and kings as our benchmark. A prince has to wait until his father's death to become king. The probability of becoming king as a function of his age thus depends on the probability of death of his father. Given that both belong to the same population, the probability of a prince's accession depends on the death of the reigning king, i.e.,

$$
\Phi(a)=\frac{1-S_{p}(a+b)}{S_{p}(b)},
$$

where $a$ is the age of the prince and $b$ is the age of the king at the princes birth. Of course, $S_{p}(a+b)$ depends on the same parameters as the Gompertz-Makeham function $\delta_{p}(a)$-see equation (5). We can then use non-linear least square methods to estimate parameters $A$, $\rho$ and $\alpha$ for the population of potentially famous people on the death rates of observed celebrities by estimating:

$$
\delta(a)=\underbrace{\frac{1-\exp \left\{-A(a+b)-\left(e^{\alpha(a+b)}-1\right) e^{\rho} / \alpha\right\}}{\exp \left\{-A b-\left(e^{\alpha b}-1\right) e^{\rho} / \alpha\right\}}}_{\Phi(a)} \underbrace{\left(A+e^{\rho+\alpha a}\right)}_{\delta_{p}(a)}
$$

for some given $b$. We estimated the parameters of $\delta(a)$ for the 1600-cohorts, under the assumption that $b=26$. The Makeham constant becomes positive and significant; it displays no particular trend over the whole sample, except for a (non significant) decrease in the 
nineteenth century, which is consistent with the observations in Gavrilov and Gavrilova (1991). More interestingly, the new estimated parameters $\rho$ and $\alpha$-right panel of Figure 11follow a similar pattern as the parameters estimated in the benchmark. ${ }^{30}$ The estimated lifespan is 80.2 years, as in the benchmark estimation.

One can conclude that the rectangularization of the survival laws initiated in 1640, as well as the estimation of the lifespan $T$, are both robust to the proposed correction of the notoriety bias. The changes in longevity measured in Section 4 are then related to changes in the agedependent Gompertz parameters $\rho$ and $\alpha$, and these changes occur by leaving the lifespan $T$ unchanged (Compensation Effect).

\section{Comparisons with Previous Studies}

At least two questions are still open. First, to what extent is famous people longevity informative about the life expectancy of the whole population? To address this issue, we compared our estimates with existing estimates using English data based on family reconstruction (1550-1820), Swedish census data (1750-), and data for the city of Geneva (1625-1825). Second, to what extent do we provide a different message from the few studies about specific groups of famous people, such as English aristocrats and the Knights of the Golden Fleece?

\subsection{Comparison with Ordinary People}

\subsubsection{English Family Reconstitution Data, 1580-1820}

A global comparison between famous people and ordinary people even in Europe cannot be performed over the past, as data for the whole population are usually not available. England is an exception in this respect, thanks to the work of Wrigley et al. (1997), who provide life tables for the English population from 1550 to 1820. We can compare their data for males with a subsample of our database that includes famous people with English nationality and/or London as city of birth or death. Remember that our survival probabilities were computed from a measure of conditional lifespan for each individual, as described in Section 5.1, which results from adding the estimated constant term, the corresponding cohort dummy and individual error. Taking long periods, as in Wrigley et al. (1997), our subsample had a large enough number of observations to compute sensible survival laws: from 2184 individuals for 1550-1649 to 7935 individuals for 1800-1849.

\footnotetext{
${ }^{30}$ We have obtained similar results by simply assuming that the probability $\Phi(a)$ follows the uniform law rather than a survival probability.
} 


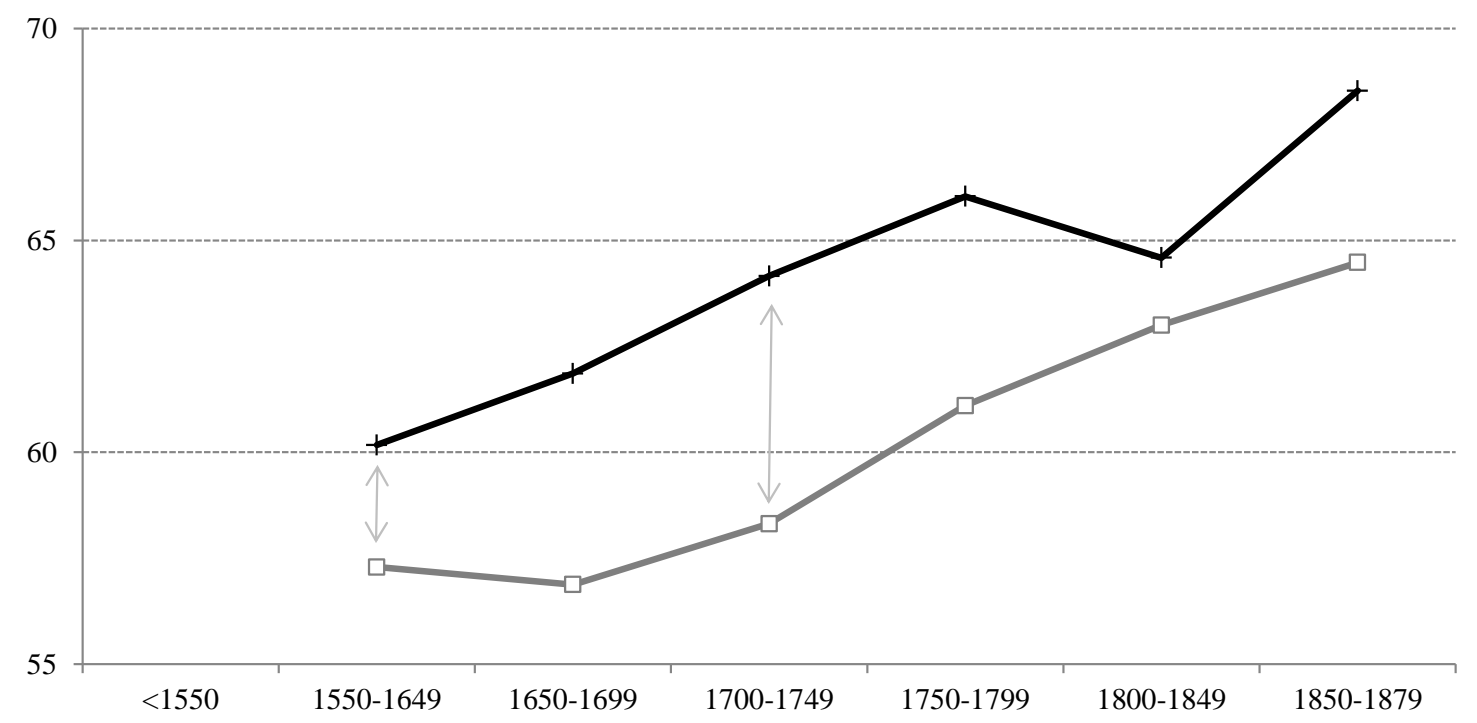

Figure 12: England: Life Expectancy at 25 (Wrigley's data, gray) vs Longevity at 25 (IBN, black)

Two main conclusions emerged when we compare the data of Wrigley et al. (1997) with ours, as can be seen in Figure 12. First, longevity of famous Englishmen in the IBN is systematically above the life expectancy of normal English males, consistently with the previous discussion in Section 3.2. Second, famous adult people were forerunners in declining mortality. Their longevity started increasing for cohorts born the second half of the 17th century creating an increasing gap from ordinary adults, who started catching-up with generations born the second half of the 18th century.

\subsubsection{Swedish Records, 1750-1879}

As early as 1749, Sweden established a public agency responsible for producing population statistics. These statistics were based on population records kept by the Swedish Lutheran church. These data are available from the Human Mortality Database (HMD) and show that the demographic transition in Sweden followed the standard pattern. Adult life expectancy started to increase around 1825 (see e.g. de la Croix, Lindh, and Malmberg (2008)).

The survival probabilities of the whole Swedish population and IBN Swedish famous people are compared in Figure 13. The Swedish population in the IBN is large enough to make the comparison in Figure 13 meaningful: 2444 individuals born in 1750-1799, to 4458 individuals born in 1800-1849. As for England, we observed that longevity is above life expectancy. We also observe a catching-up taking place at the beginning of the 19th century, 50 years later 


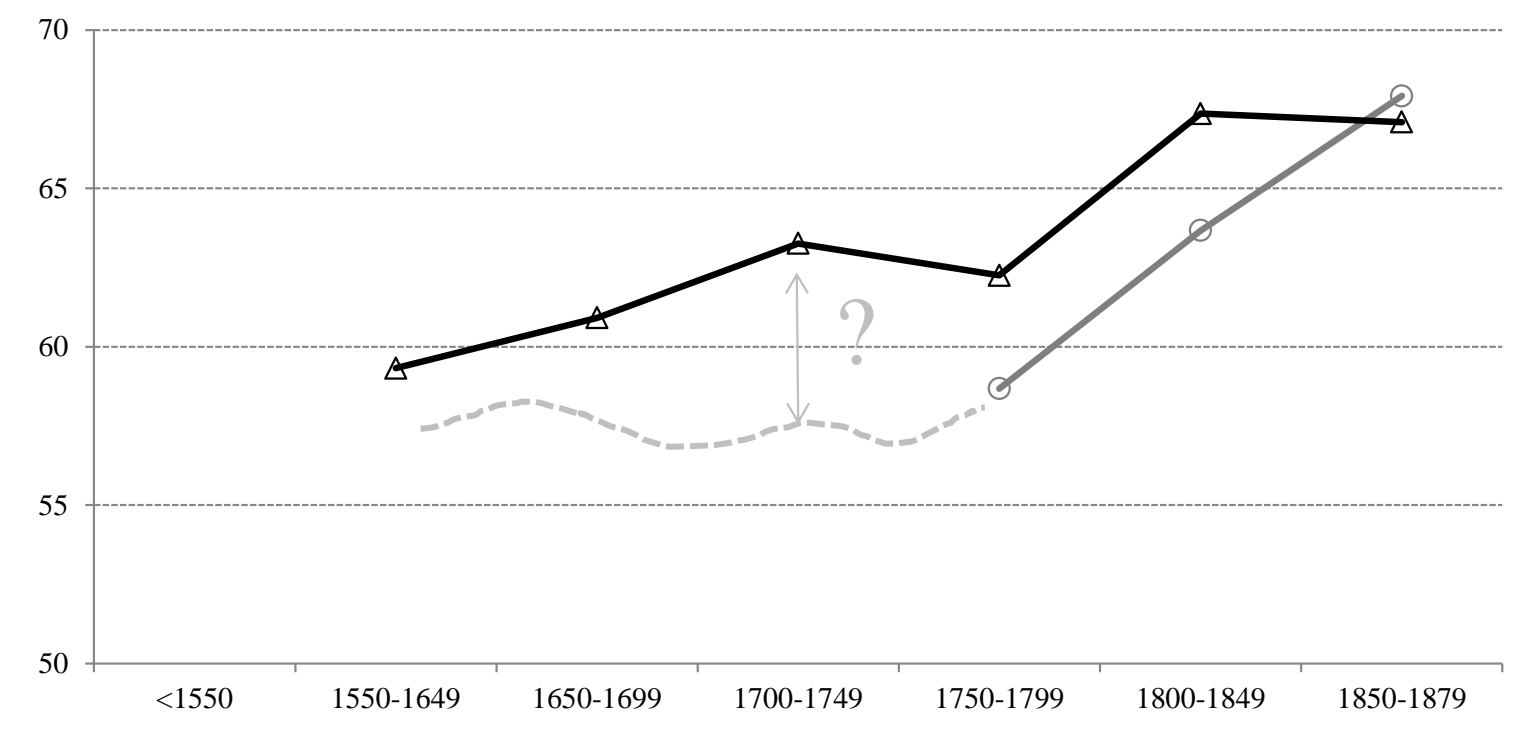

Figure 13: Sweden: Life Expectancy at 25 (HMD, gray) vs Longevity at 25 (IBN, black)

than in England. Of course, we do not know the life expectancy of the whole population before 1750. If what we measure in 1750 is representative of the level that prevailed before (assumption with light gray curve), then the pattern looks very much like the one we have for England, with an initial gap between life expectancy of ordinary people and longevity of famous people around five years, then a widening of the gap, because famous people started to benefit from longer lives, then a closing of the gap at the end of the period considered.

\subsubsection{Geneva, 1625-1825}

Perrenoud (1978) provided very detailed demographic data for the city of Geneva (Switzerland) over two centuries. If we consider periods of 50 years covering the Perrenoud sample, we have about 200 famous persons born or dying in Geneva per subperiod. Results are presented in Figure 14. We first remark that Perrenoud's data display an upward trend as early as in the seventeenth century. This fact was already stressed by Boucekkine, de la Croix, and Licandro (2003) who used that evidence to claim that improvements in adult longevity preceded the industrial revolution, at least in some cities, and may have increased the incentives to acquire education. Comparing Perrenoud to IBN, we do not retrieve the pattern seen for Britain and Sweden of early improvement for famous people, followed by a catching-up phenomenon; here the people of the city seem to have the same global trend as the IBN famous people, one of improvement in longevity through 1650-1799. This raises the question whether the trend we observe for famous people is in fact a urban phenomenon in 


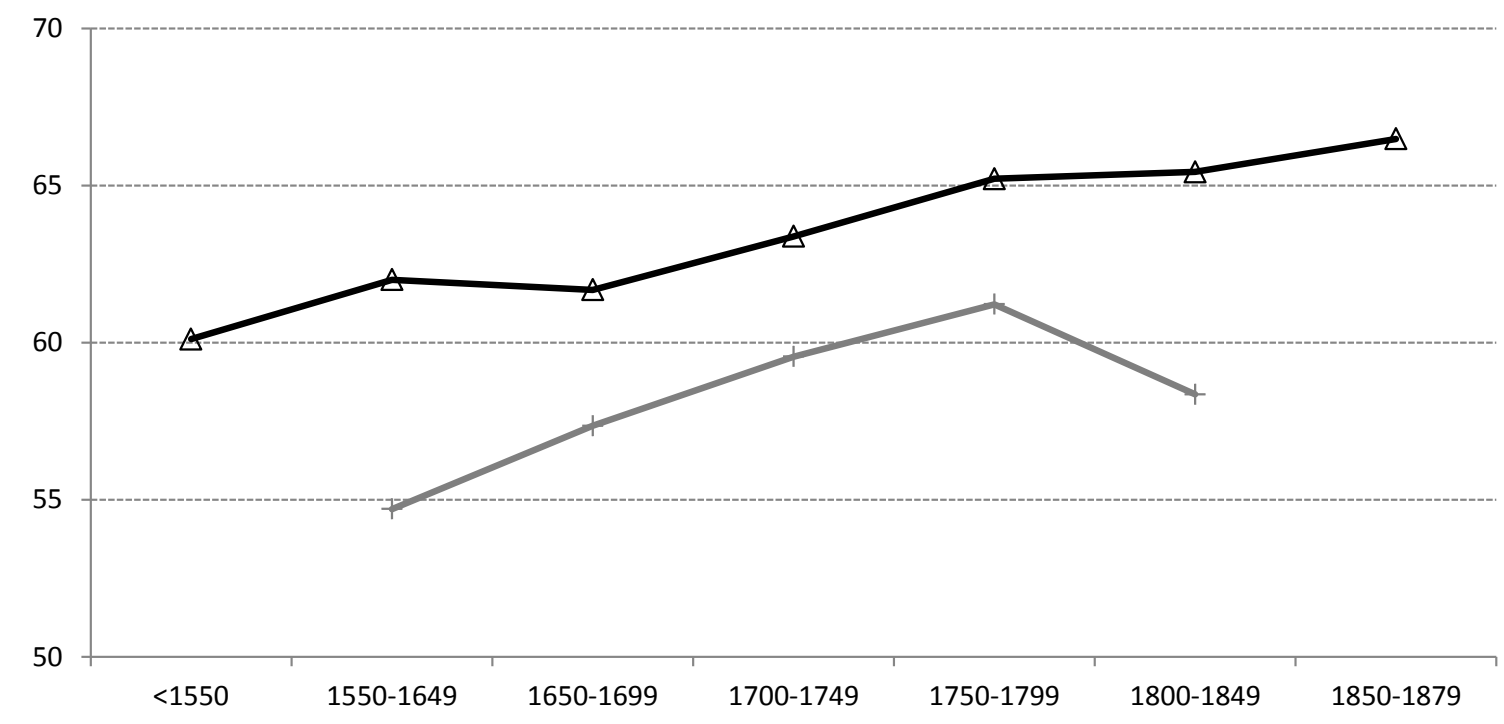

Figure 14: Geneva: Life Expectancy at 25 (Perrenoud's data, gray) vs Longevity at 25 (IBN, black)

Europe (beyond Geneva). ${ }^{31}$

\subsection{Comparison with Nobility}

In order to study long-term trends in the mortality rates of adults of a given population, several others have used various types of records, usually available for high social classes, such as genealogical data or monographs about military or religious orders. These social classes are closer to our famous people than to the rest of the population. Comparing these studies with similar subsamples extracted from the IBN dataset is an interesting robustness check.

We use two datasets covering the period 1500 to 1900, which overlaps the period where longevity of famous people starts increasing. First, the mortality tables for British peers, published by Hollingsworth (1977), dying between 1603 and 1938 and their offsprings. ${ }^{32}$ A comparable subsample from our IBN database consists of British Nobles. We have many such individuals, from 577 for the 16th century to 3,324 for the 19th century. Second, Vandenbroucke (1985) provides vital statistics for the Knights of the Golden Fleece, an

\footnotetext{
${ }^{31}$ There are not many cities for which we have longevity data prior to 1750 . Beltrami (1951) provided demographic data for the city of Venice (Italy) over 1600-1750. As in Geneva, Beltrami's data display a drop in mortality through the seventeenth century. Again, people from the cities seem to have the same global trend as IBN famous people, in particular as far as survival up to age 50 is concerned.

${ }^{32}$ The original data were sampled from genealogical data by Hollingsworth (1964).
} 


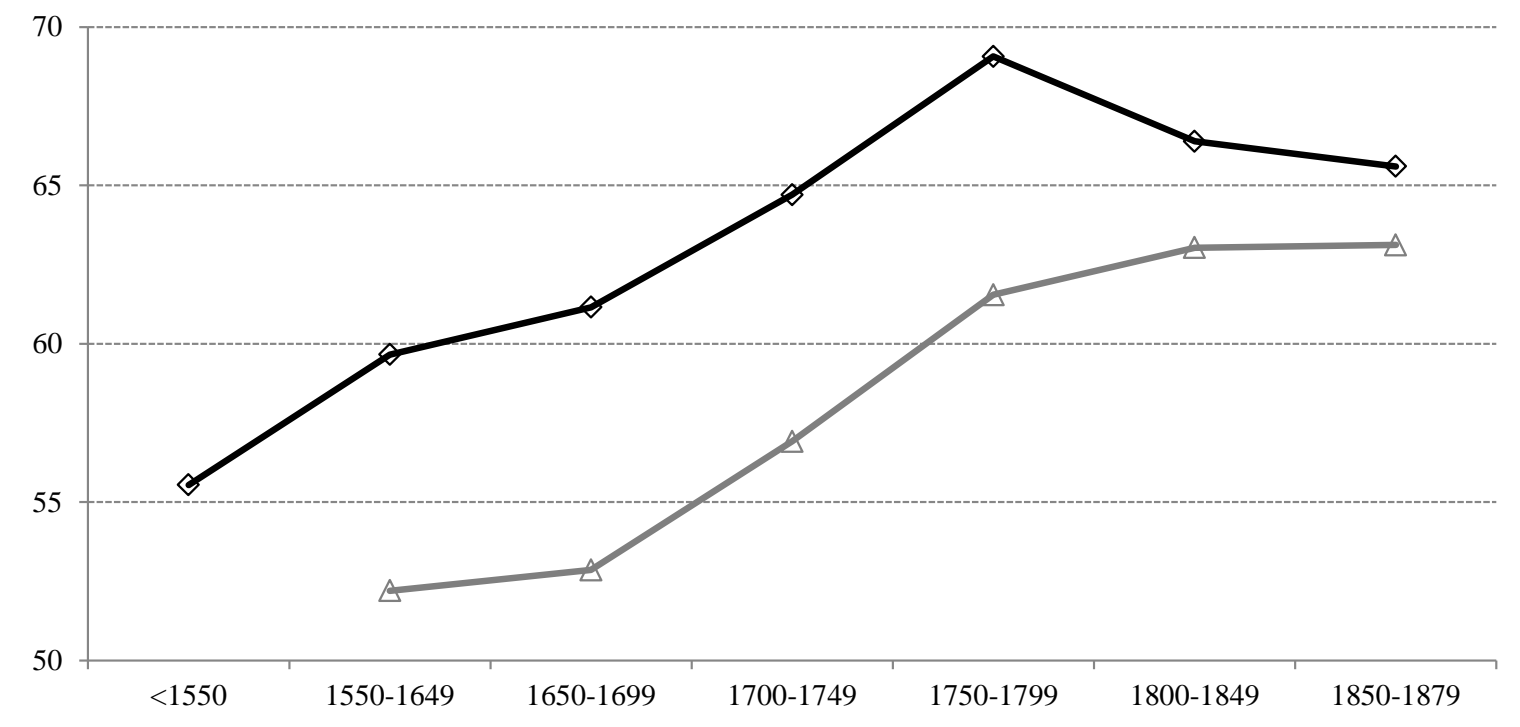

Figure 15: British Nobles: Life Expectancy at 25 (Hollingsworth's data, gray) vs Longevity at 25 (IBN, black)

order started in 1430 with the Dukes of Burgundy and continued with the Hapsburg rulers, the kings of Spain and the Austrian emperors. A comparable subsample from our database consists of people with a nobility occupation and Austrian, Belgian, Dutch, German or Spanish nationality (all belonging to the former Hapsburg empire): 2,349 persons fall in this category in the 16 th century, and 17,334 in the 19 th century.

Several lessons can be drawn from Figures 15 and 16. First, the life expectancy of both groups of nobles and the longevity of the corresponding IBN nobles share a common trend, supporting the claim that is around 1650 that adult mortality of famous people started reducing. Second, the gap between the two series is larger before 1700 than after; if something, our measure of longevity underestimates the improvements in life expectancy. This means that the results derived in Section 4, in particular the one that longevity increased by 5 years between 1640 and 1740, should in fact be interpreted as a lower bound on the actual increase in life expectancy. Third, mortality reductions for nobility take place in the 17th century in the three databases, reinforcing the observation that improvements in longevity of famous people anticipate those of ordinary people by at least one hundred years. 


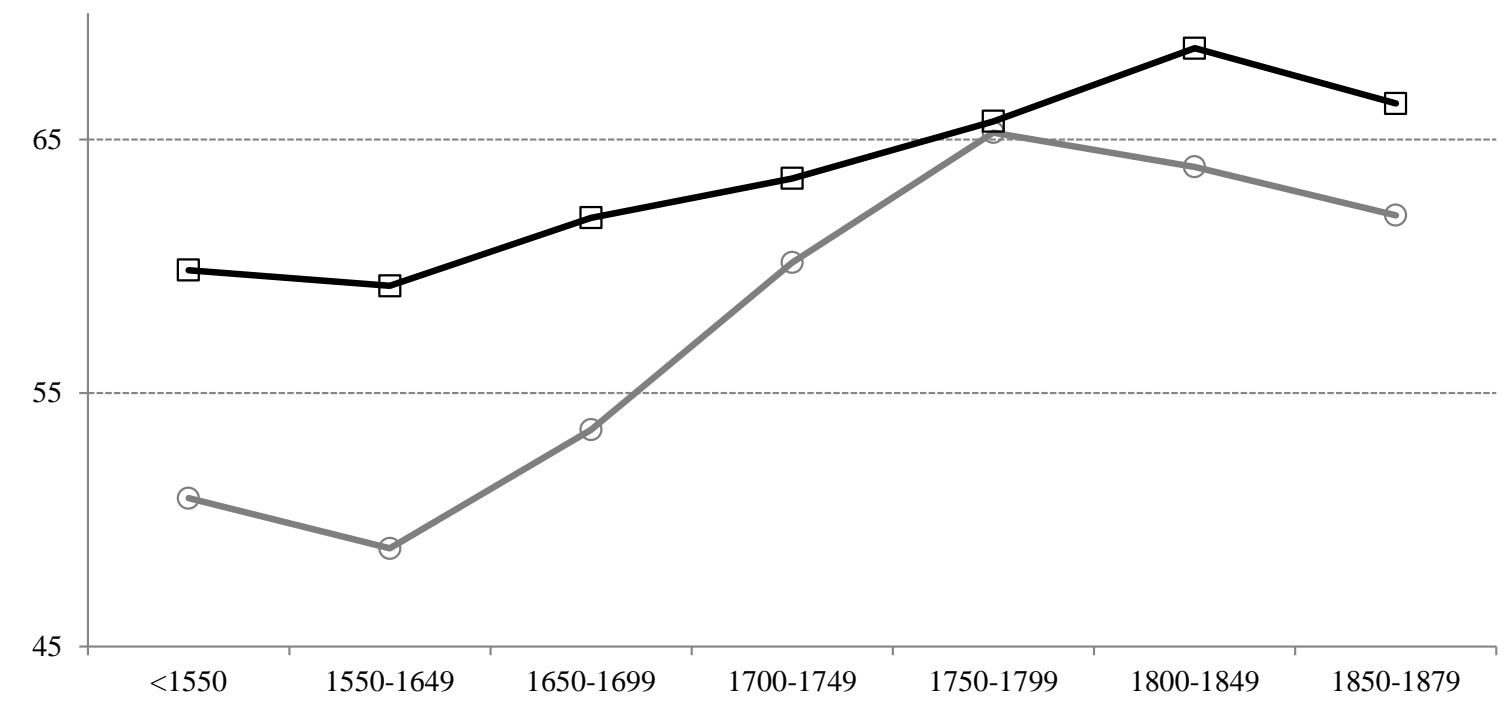

Figure 16: Habsburg Nobles: Life Expectancy at 25 (Knights of the Golden Fleece data, gray) vs Longevity at 25 (IBN, black)

\section{Interpretations and Conclusion}

It is generally accepted that survival of ordinary adults started to increase permanently in the nineteenth century, with scattered evidence showing that in some places it started some decades before. The main causes of this observation are still under debate, but include higher income, better nutrition, better hygiene habits and sanitization of cities, more efficient medicine and public health. ${ }^{33}$

This paper uses for the first time the Index Bio-bibliographicus Notorum Hominum (IBN), a dataset containing information about vital dates, occupations, nationality and other relevant characteristics of hundreds of thousands of famous individuals from all around the world. Exploiting observed individual characteristics to control for potential biases, we showed that the conditional longevity of all cohorts of famous people born before 1640 fluctuated around sixty years. We dated the beginning of the steady improvements in longevity to the cohorts born in 1640-9, clearly preceding the Industrial Revolution by one and a half centuries. We found that improvements in longevity involved most countries in Europe, as well as all types of skilled occupations. Finally, the reasons for this early increase in longevity were mainly

\footnotetext{
${ }^{33}$ For a general view on the main causes see Wilmoth (2007) and Cutler, Deaton, and Lleras-Muney (2006). The fundamental role of nutritional improvements on the reduction of mortality during the Industrial Revolution has been stressed by McKeown and Record (1962). Landes (1999), referring to the first half of the 19th century, argues that much of the increased life expectancy of these years came from gains in prevention, cleaner living rather than better medicine.
} 
related to an early rectangularization of the survival law.

The objective of the paper is to establish the above facts. But it is tempting to ask what could be the reasons for the reduction of famous people mortality rates in the seventeenth century. From the analysis above, a good explanation of this early improvement in longevity needs to fulfill the following conditions:

Selectivity. Reductions in mortality rates have to be restricted to people with some fame, not affecting the longevity of the general population.

Regional Independence. The reductions should not be related to a particular location, since the improvements in longevity took place throughout Europe.

Occupational Independence. They have to affect similarly almost all skilled occupations. Age Dependence. They should not affect all adult ages in the same way, but mainly reduce the mortality rates of working age adults.

Urban Character. They may affect ordinary people living in cities.

The Age dependence criterion implies that the cause of increased longevity should fundamentally generate a rectangularization of the human survival law without affecting the life span of human populations. We see four possible candidate reasons, detailed below. We are not going to select one of them, but rather check that they can fulfill the necessary conditions suggested above.

The first candidate is the early empowerment of the bourgeoisie. We formulate this hypothesis in the following way. A major accumulation of capital, skills and technology has preceded the industrial revolution; a sort of necessary condition. From the seventeenth century onward, famous people directly or indirectly benefited from this change, through a substantial increase in their income. However, the rest of the population continued living under the same conditions as in the Malthusian era, generating a notorious increase in income inequality. ${ }^{34}$ This hypothesis, by assumption, fulfills the Selectivity requirement. As long as the emergence of the bourgeoisie is a European phenomenon, it also fulfills the Regional Independency requirement. Occupational Independence is also met because the increase in the

\footnotetext{
${ }^{34}$ Hoffman et al. (2002) studied inequality in Europe from 1500 onward. They looked at the purchasing powers of different income classes based on changes in relative prices. They concluded that luxury goods, especially servants, became cheaper, greatly widening the inequality of lifestyles before the Industrial Revolution. The evidence they provide on relative prices offers another rationale for an early increase in inequality over Europe. Inequality is also at the core of the natural selection story proposed by Galor and Moav (2002). In their model, there are two kinds of parents, distinguished by their taste for the quality of children. Before the takeoff from the Malthusian regime the income of the "quality type" increases (the type from which one would draw our celebrities). Though in their model life expectancy is constant, one could claim that the increase in income of the "quality type" should lead to higher life expectancy. Hence their model is consistent with our findings of a takeoff of the life expectancy the high Human Capital people before the industrial revolution.
} 
surplus diffuses among the famous (e.g., even if the artists or the priests were not directly affected, the richest would buy more from them or make them larger transfers).

Receding pandemics is the second candidate. The last plague in England was clearly identified in 1666-1667 (see Creighton (1891)). After this date, Europe could have been free of plagues by chance (Lagerlöf (2003), for example), or because of the natural evolution of the disease itself. Famous people belong to the upper social classes and are, therefore, shielded from certain diseases that are the prime cause of mortality for the rest of the population, such as infectious diseases, but cannot escape plagues. If plagues are receding, as was shown to be the case after 1640 by Biraben (1975), then one should observe an improvement in the longevity of the upper classes, without much effect on the rest of the population, which remains primarily affected by other types of diseases. This type of explanation would fit Regional Independence, as plagues know no borders. The Urban Character of this explanation is also likely, as contagion is amplified by the high density of population. However, it is not clear how receding pandemics could satisfy the Age Dependence criterion; one would indeed a priori expect that pandemics are included in the (age-independent) Makeham constant, rather than in the Gompertz parameters.

The third candidate is medical progress. According to some authors (e.g. Omran (1971)), the influence of medical factors was largely inadvertent until the twentieth century, by which time pandemics of infection had already receded significantly. However, in the period 15001800, medicine showed an increasingly experimental attitude: no improvement was effected on the grounds of the disease theory (which was still mainly based on traditional ideas), but significant advances were made based on practice and empirical observations. For example, although the theoretical understanding of how drugs work only developed progressively in the nineteenth century with the development of chemistry (Weatherall 1996), the effectiveness of treatment of some important diseases was improved thanks to the practical use of new drugs coming from the New World. ${ }^{35}$ Another example is the use of the condom as a way to prevent spread of sexually transmitted diseases. ${ }^{36}$ Note that the benefits of better medical practice could fit Selectivity if it was affordable and/or known only to the rich -see Johansson (1999). Regional Independence would be satisfied if medical knowledge spread easily across

\footnotetext{
${ }^{35}$ For example, according to Hawkins (1829) leprosy, plague, sweating sickness, ague, typhus, smallpox, syphilis and scurvy were leading causes of death in the past but could be treated effectively at the time he wrote his book.

${ }^{36}$ According to Collier (2007), In "1666, the year of the Great Fire of London, the English Birth Rate Commission officially documented the condom's popular use throughout the country by explaining that the significant decrease in births at the time was due to the use of "condons." This is the first time that spelling, or anything close to it, was used in an official government document." In the same book it is also noted that promiscuous aristocrats used the condom invented under Charles II (1630-1685) and officers of his army using it during the English Revolution of the 1640s.
} 


\section{Europe.}

A variation of the medical progress theory would be the Enlightenment hypothesis. The decrease in superstition that emerged from the new approach to the world promoted by the Enlightenment could have led the elite to consider that they indeed had some hold on their length of life, and that diseases were not necessarily sent by god. The Enlightenment might also have pushed the upper classes to give up bad medical habits, such as bathing in mercury to cure syphilis, or considering the KingâĂŹs powdered feces as medicinal, implying that the advantage of a higher income in purchasing better food and shelter became more prominent. The enlightened view of the world could have easily spread among the upper classes in Europe through the network effect highlighted in Mokyr (2005b) but taken centuries to percolate into the rest of the population.

The fourth possible candidate is the drop in overall violence affecting famous people in the society. In his famous book, Pinker (2011) argues that there is an overall trend towards less violence; data from Europe seem to show an acceleration in the trend in the seventeenth century (see homicide rates, Figure 3-3, p63). Pinker also notices that "The European decline of violence was spearheaded by a decline in elite violence. (...) The historical Civilizing Process, in other words, did not eliminate violence, but it did relegate it to the socioeconomic margins." This view would be in line with our Selectivity criterion. Along the same line, Eisner (2011) builds a database of 1500 European monarchs, 22\% of them dying from a violent death, and documents that the rate of regicide dropped steadily after $1200 \mathrm{CE}$.

Our criteria could also be used to reject explanations, as shown in the following two examples. First, the introduction and diffusion of the potato across Europe (widespread cultivation beginning in the late seventeenth and early eighteenth centuries) improved nutritional standards, increased population size and urbanization (Nunn and Qian 2011), and may have increased longevity, but such an explanation would violate the Selectivity criterion. Second, one can wonder whether the rise in longevity we observe in 1640 is related to the military revolution and, in particular, to the declining role of noblemen in armies. ${ }^{37}$ This would however violate the occupation independence criterion. Moreover, nobles and military are only $15 \%$ of our sample. Further research may try to use the criteria highlighted here to discriminate among possible explanations.

\footnotetext{
${ }^{37}$ Until the seventeenth century noblemen assumed positions of command (regardless of their competence) in European armies. Over 1600-1700, armies grew considerably in size, requiring a better organization. For instance, in 1675, Louis XIV made power dependent on merit and seniority (rather than on social class or birth).
} 


\section{References}

A'Hearn, Brian, Joerg Baten, and Dorothee Crayen. 2009. "Quantifying quantitative literacy: age heaping and the history of human capital." Journal of Economic History 69:783-808.

Bar, Michael, and Oksana Leukhina. 2010. "The role of mortality in the transmission of knowledge." Journal of Economic Growth 15 (4): 291-321.

Beltrami, Daniele. 1951. "Lineamenti di storia della popolazione di Venezia nei secoli XVI, XVII e XVIII." Atti dell'Istituto Veneto di Scienze, Lettere ed Arti, vol. 109.

Biraben, Jean-Noël. 1975. Les hommes et la peste en France et dans les pays européens et méditerranéens. La Haye, Paris: Mouton.

Bongaarts, John, and Griffith Feeney. 2003. "Estimating Mean Lifetime." Proceedings of the National Academy of Sciences of the United States of America 100:13127-13133.

Boucekkine, Raouf, David de la Croix, and Omar Licandro. 2002. "Vintage Human Capital, Demographic Trends, and Endogenous Growth." Journal of Economic Theory 104 (2): $340-75$.

- 2003. "Early mortality declines at the dawn of modern growth." Scandinavian Journal of Economics 105 (3): 401-418.

Cervellati, Matteo, and Uwe Sunde. 2014. "The Economic and Demographic Transition, Mortality, and Comparative Development." American Economic Journal Macroeconomics. forthcoming.

Cipolla, Carlo. 1993. Before the Industrial Revolution, European Society and Economy 1000-1700. New York: Norton.

Clark, Gregory. 2007. A Farewell to Alms: A Brief Economic History of the World. Princeton: Princeton University Press.

Collier, Aine. 2007. The Humble Little Condom: A History. New York: Prometheus Books.

Condorcet, Marie-Jean-Antoine-Nicolas de Caritat, marquis de. 1795. Esquisse d'un tableau historique des progrès de l'esprit humain. Paris: Agasse.

Creighton, Charles. 1891. A history of epidemics in Britain. Cambridge: Cambridge University Press.

Cummins, Neil. 2014, September. "Longevity and the Rise of the West: Lifespans of the European Elite, 800-1800." Working papers 0064, European Historical Economics Society (EHES).

Cutler, David, Angus Deaton, and Adriana Lleras-Muney. 2006. "The Determinants of Mortality." Journal of Economic Perspectives 20 (3): 97-120.

de la Croix, David, and Omar Licandro. 2013. "The Child is Father of the Man: Implications for the Demographic Transition." The Economic Journal 123:236-261.

de la Croix, David, Thomas Lindh, and Bo Malmberg. 2008. "Swedish economic growth and education since 1800." Canadian Journal of Economics / Revue canadienne d'Economique 41 (1): 166-185. 
De Moor, Tine, and Jaco Zuijderduijn. 2013. "The Art of Counting: Reconstructing Numeracy of the Middle and Upper Classes on the Basis of Portraits in the Early Modern Low Countries." Historical Methods: A Journal of Quantitative and Interdisciplinary History 46 (1): 41-56.

Desmet, Klaus, Ignacio Ortuño-Ortín, and Romain Wacziarg. 2014. "Culture, Ethnicity and Diversity." Unpublished, UCLA.

Eisner, Manuel. 2011. "Killing Kings - Patterns of Regicide in Europe." British Journal of Criminology, AD 600-1800 51:556-577.

Fogel, Robert. 1994. "Economic growth, population theory and physiology: the bearing of long-term processes on the making of economic policy." American Economic Review 84:369Ü395.

Fornasin, Alessio, Marco Breschi, and Matteo Manfredini. 2010. "Mortality Patterns of Cardinals (Sixteenth - Twentieth Centuries)." Population (English Edition) 65:631-652.

Galor, Oded, and Omer Moav. 2002. "Natural Selection And The Origin Of Economic Growth." The Quarterly Journal of Economics 117 (4): 1133-1191 (November).

Galor, Oded, and David Weil. 1999. "From Malthusian Stagnation to Modern Growth." American Economic Review 89 (2): 150-154.

Gavrilov, Leonid, and Natalia Gavrilova. 1991. The Biology of Human Life Span: A Quantitative Approach. London: Harwood Academic Publishers.

Gompertz, Benjamin. 1825. "On the nature of the function expressive of the law of human mortality, and on a new mode of determining the value of life contingencies." Philosophical Transactions of the Royal Society of London 115:513-583.

Graunt, John. 1661. Natural and Political Observations Mentioned in a Following Index and Made upon the Bills of Mortality. London: Roycroft.

Halley, Edmond. 1693. "An estimate of the degrees of the mortality of mankind, drawn from curious tables of the births and funerals at the city of Breslaw; with an attempt to ascertain the price of annuities upon lives." Philosophical Transactions of the Royal Society 17:596-610.

Hawkins, Francis. 1829. Elements of Medical Statistics. London: Longman, Rees, Orme, Brown, and Green.

Hoffman, Philip T., David S. Jacks, Patricia A. Levin, and Peter H. Lindert. 2002. "Real Inequality in Europe since 1500." The Journal of Economic History 62 (02): 322-355.

Hollingsworth, Thomas. 1964. "The demography of the British peerage." Population Studies, vol. 18.

—. 1977. "Mortality in the British peerage families since 1600." Population 31:323-352.

Johansson, Ryan. 1999. "Death and the doctors: medicine and elite mortality in Britain from 1500 to 1800." Cambridge Group for the History of Population and Social Structure Working Paper Series.

Lagerlöf, Nils-Petter. 2003. "From Malthus to modern growth: can epidemics explain the three regimes ?" International Economic Review 44 (2): 755-777. 
Landes, David. 1999. The Wealth and Poverty of Nations: Why Some Are So Rich and Some So Poor. W. W. Norton \& Company.

Lucas, Robert E. 2009. "Ideas and Growth." Economica 76 (301): 1-19.

Maddison, Angus. 2010. "Historical Statistics of the World Economy: 1-2008 AD." http: //www.ggdc.net/MADDISON/.

Makeham, William. 1860. "On the law of mortality and the construction of annuity tables." Journal of the Institute of Actuaries 8:301-310.

Malanima, Paolo. 2009. Pre-Modern European Economy, One Thousand Years (10th-19th centuries). Leiden: Brill.

Malthus, Thomas. 1798. An Essay on the Principle of Population. London: Johnson.

McKeown, Thomas, and R. G. Record. 1962. "Reasons for the Decline of Mortality in England and Wales during the Nineteenth Century." Population Studies 16 (3): 94122.

Mokyr, Joel. 2005a. "The Intellectual Origin of Modern Economic Growth." Journal of Economic History 65 (2): 285 Ü351.

. 2005b. "Mobility, Creativity, and Technological Development: David Hume, Immanuel Kant and the Economic Development of Europe." Prepared for the session on "Creativity and the Economy", German Association of Philosophy, Berlin.

- 2011. The Enlightened Economy: An Economic History of Britain 1700-1850. Penguin Press.

Nunn, Nathan, and Nancy Qian. 2011. "The Potato's Contribution to Population and Urbanization: Evidence from a Historical Experiment." The Quarterly Journal of Economics 126:593-650.

Omran, Abdel. 1971. "The Epidemiologic Transition: A Theory of the Epidemiology of Population Change." Milbank Memorial Fund Quarterly 49:509-538.

Perrenoud, Alfred. 1978. "La mortalité à Genève de 1625 à 1825." Annales de démographie historique, pp. 209-233.

Pinker, Steven. 2011. The Better Angels of Our Nature: Why Violence Has Declined. New York: Viking.

Robertson, Henry T., and David B. Allison. 2012. "A Novel Generalized Normal Distribution for Human Longevity and other Negatively Skewed Data." PLoS ONE 7 (5): e37025.

Soares, Rodrigo R. 2005. "Mortality Reductions, Educational Attainment, and Fertility Choice." American Economic Review 95 (3): 580-601.

Squicciarini, Mara P., and Nico Voigtländer. 2014. "Human Capital and Industrialization: Evidence from the Age of Enlightenment." unpublished.

Strulik, Holger, and Sebastian Vollmer. 2013. "Long-run trends of human aging and longevity." Journal of Population Economics 26 (4): 1303-1323. 
Vandenbroucke, Jan. 1985. "Survival and expectation of life from the 1400's to the present - A study of the knighthood order of the Golden Fleece." American Journal of Epidemiology 22 (6): 1007-1015.

van Poppel, Frans, Dirk J. van de Kaa, and Govert E. Bijwaard. 2013. "Life expectancy of artists in the Low Countries from the fifteenth to the twentieth century." Population Studies, 67 (3): 275-292.

Weatherall, Miles. 1996. "Drug treatment and the rise of pharmacology." In Cambridge Illustrated History: Medicine, edited by Porter R, 246-277. Cambridge: Cambridge University Press.

Wilmoth, John. 2007. "Human Longevity in Historical Perspective." Chapter 2 of Physiological Basis of Aging and Geriatrics, edited by Paola Timiras, Forth edition, 11-22. New York: Informa.

Wilmoth, John, and Shiro Horiuchi. 1999. "Rectangularization Revisited: Variability of Age at Death within Human Populations." Demography 36 (4): 475-495.

Wrigley, Edward, R S Davies, James Oeppen, and Roger Schofield. 1997. English Population History from Family Reconstitution: 1580-183\%. Cambridge: Cambridge University Press. 


\section{A Lifespan Precision (not for publication)}

To measure the quality of the individual lifespan data, in this section we show two different statistics: the frequency of observations with imprecise vital dates and the heaping index.

The IBN adds the indications "c.", for circa, or "?" to the vital dates when the years of birth or death are not known with certainty. It may also be that more than one date is reported. We retained all the imprecise observations (taking the mean if there was more than one date), but created a discrete variable called precision, allocating a value of one when the lifespan was imprecise, zero otherwise. Figure A.1 shows the fraction of imprecise observations by decade. Individual lifespans measured by the IBN were highly imprecise until the end of the Middle Ages; the degree of imprecision then moves to zero as the sample reaches the 19th century.

When vital data are not known with certainty, biographers (or concerned persons themselves) often approximate them by rounding the year of death or birth to a number finishing in 0 or 5. Moreover, in the particular case of famous people, for obvious reasons, years of birth are likely to be more uncertain than years of death. The heaping index measures the frequency of observations with vital dates finishing in 0 or 5 ; it is commonly normalized by multiplying the frequency by 5. A heaping index close to unity shows that the vital data are very precise. Figure A.2 shows birth and death heaping indexes by decades up to $1879 .{ }^{38}$ The death date heaping index is low, indicating that the dates of death of famous people were well known. Birth dates were much more uncertain, as the heaping index is about 2.5 before 1450, indicating that there are 2.5 times more dates finishing in 0 or 5 than there should be. Improvements in the birth year heaping index seem to start around 1450. This observation is consistent with the findings of De Moor and Zuijderduijn (2013) that numeracy levels among the well-to-do in the early modern period were very low (in the Netherlands). By 1700, the gap between birth and death heaping has decreased and both indexes fluctuate around one.

If, following A'Hearn, Baten, and Crayen (2009), we interpret the age heaping index as a measure of human capital (consistently with the robust correlation between age heaping and literacy at both the individual and aggregate level), our findings support the hypothesis that there was a major increase in human capital preceding the industrial revolution.

\footnotetext{
${ }^{38}$ Notice that heaping has no sense before 800 , when the dating system starting at the birth of Jesus of Nazareth became widely used.
} 


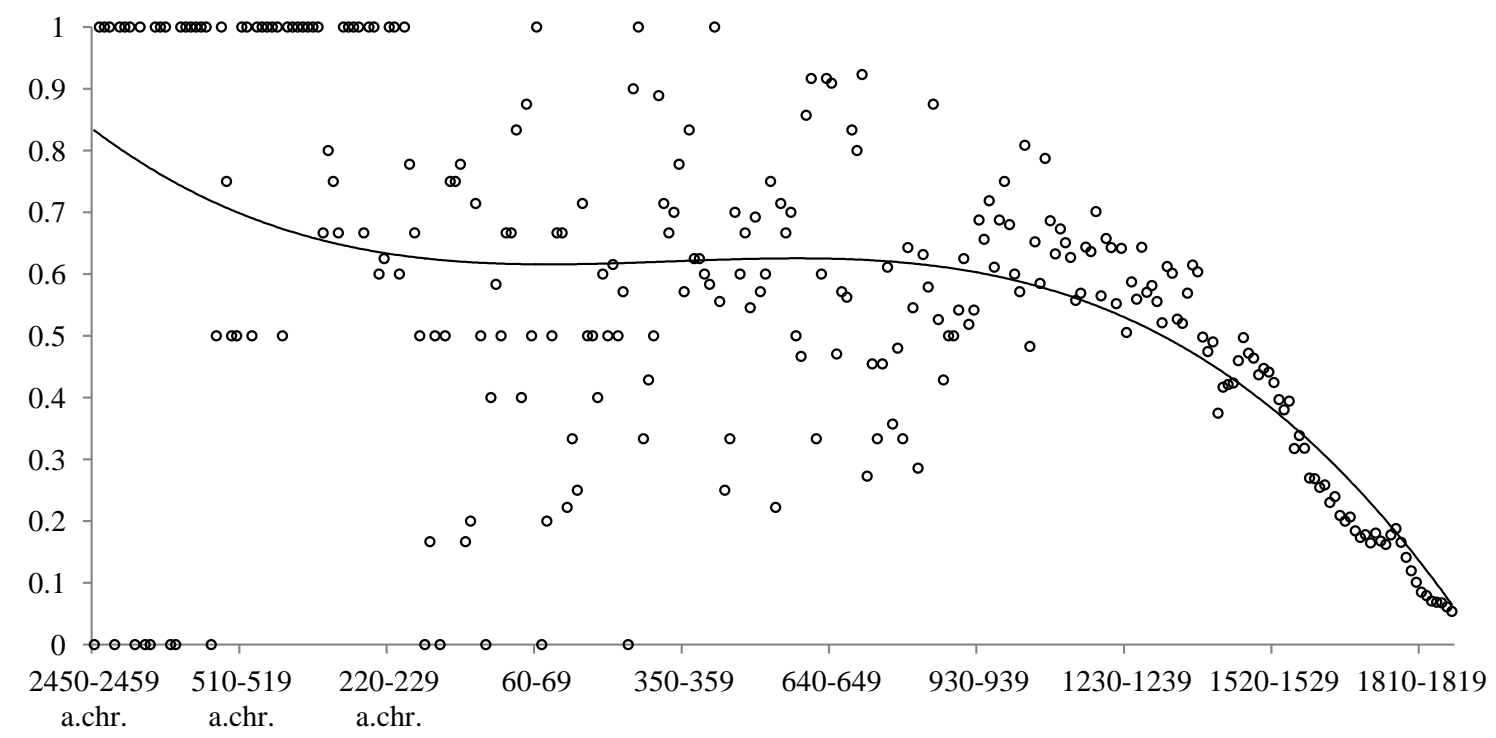

Figure A.1: Frequency of Imprecise Observations

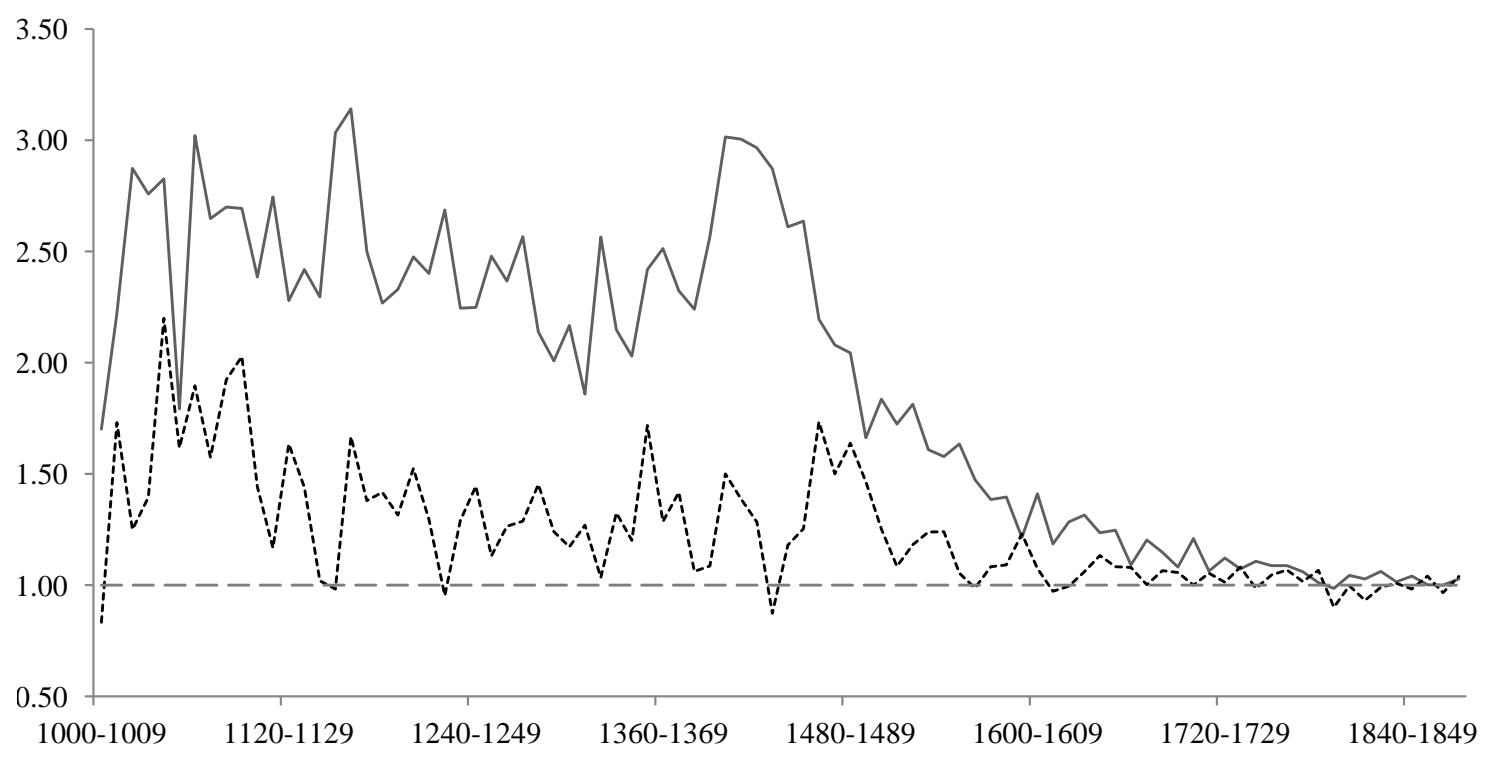

Figure A.2: Heaping Index. Birth year (solid line), death year (dashed line) 


\section{B Longevity vs Life Expectancy (nOt For PUblication)}

The population of currently famous people alive at the beginning to time $s, N_{s}$, evolves according to:

$$
N_{s+1}=N_{s}-d_{s}+I_{s+1}
$$

where $d_{s}$ is the number of deaths between age $s$ and age $s+1$, and $I_{s+1}$ is the number of new people gaining celebrity over the same age interval. When computing life expectancy, $N_{s}$ is the population at risk. Unfortunately, we do not observe $N_{s}$ since we do not know when people become famous (except in special cases for which a nomination is required) and $I_{s+1}$ is unobserved.

The life expectancy at age $a$ of this population is:

$$
E_{a}=\sum_{s=a}^{T}(s-a) m_{s, a}
$$

where $T$ is the maximum number of periods one can live, and $m_{s, a}$ is the true probability of dying at age $s$ conditionally on being alive at age $a$ :

$$
m_{s, a}=\frac{d_{s}}{N_{s}} \times S_{s, a}
$$

$S_{s, a}$ is the probability of reaching age $s$ if one has reached age $a$. It follows:

$$
S_{s+1, a}=S_{s, a} \times\left(1-\frac{d_{s}}{N_{s}}\right)=S_{a, a} \times \prod_{j=a}^{s}\left(1-\frac{d_{j}}{N_{j}}\right)=\prod_{j=a}^{s}\left(1-\frac{d_{j}}{N_{j}}\right)
$$

Notice that, contrary to the case where all individual belong to the population at age $a$ and can be followed until death, $m_{s, a} \neq d_{s} / N_{a}$.

One can rewrite the population at risk as:

$$
N_{s+1}=S_{s+1, a}\left(N_{a}+\sum_{j=a+1}^{s+1} \frac{I_{j}}{S_{j, a}}\right)
$$

We denote the population of all famous people aged $s$ by $\hat{N}_{s}$. This population includes everyone that is or will become famous. Contrary to $N_{s}$, we observe $\hat{N}_{s}$. Its dynamics are given by

$$
\hat{N}_{s+1}=\hat{N}_{s}-d_{s}
$$

Using equations (8) and (10), we can compute the gap between total population $\hat{N}$ and population at risk $N$ as

$$
\hat{N}_{s}-N_{s}=\hat{N}_{s+1}-N_{s+1}+I_{s+1}
$$


Iterating forward, we get

$$
\hat{N}_{s}-N_{s}=\hat{N}_{T}-N_{T}+\sum_{j=s+1}^{T} I_{j}=\sum_{j=s+1}^{T} I_{j}
$$

where $T$ is the date at which all famous people have been discovered, i.e., $I_{j}=0 \forall t>T$. It implies $\hat{N}_{T}=N_{T}$. The above equation reflects the idea that $\hat{N}_{s}$ incorporates all the people that are not yet famous but will be. We can define $\hat{m}_{s, a}$ as the observable probability of dying at age $s$ conditionally on being alive at age $a$ :

$$
\hat{m}_{s, a}=\frac{d_{s}}{\hat{N}_{a}}
$$

We have the following property:

$$
\sum_{s=a}^{T} d_{s}=\hat{N}_{a}, \quad \sum_{s=a}^{T} \hat{m}_{s, a}=1
$$

We can measure the mean lifetime conditionally on being alive at $a$ :

$$
L_{a}=\sum_{s=a}^{T} s \hat{m}_{s, a}
$$

which we call "longevity".

There is a gap $G_{a}$ between the expected length of life $a+E_{a}$ :

$$
G_{a}=L_{a}-E_{a}-a=\sum_{s=a}^{T}(s-a)\left(\hat{m}_{s, a}-m_{s, a}\right) .
$$

This gap comes from the fact that we cannot compute the correct mortality rates $m_{s, a}$ as we do not know the population at risk. Replacing $\hat{m}_{s, a}$ by its value, we obtain

$$
G_{a}=\sum_{s=a}^{T}(s-a)\left(\frac{d_{s}}{N_{s}} \frac{N_{s}}{\hat{N}_{a}}-m_{s, a}\right)=\sum_{s=a}^{T}(s-a) m_{s, a}\left(\frac{N_{s}}{\hat{N}_{a} S_{s, a}}-1\right)
$$

Using (9) we get:

$$
\begin{aligned}
G_{a}=\sum_{s=a}^{T}(s-a) m_{s, a}\left(\frac{S_{s, a}\left(N_{a}+\sum_{j=a+1}^{s} \frac{I_{j}}{S_{j, a}}\right)}{\hat{N}_{a} S_{s, a}}-1\right) & \\
& =\sum_{s=a}^{T}(s-a) m_{s, a}\left(\frac{N_{a}+\sum_{j=a+1}^{s} \frac{I_{j}}{S_{j, a}}}{\hat{N}_{a}}-1\right)
\end{aligned}
$$


Using (11) we get:

$$
\begin{aligned}
G_{a}=\sum_{s=a}^{T}(s-a) m_{s, a}\left(\frac{\hat{N}_{a}-\sum_{j=a+1}^{T} I_{j}+\sum_{j=a+1}^{s} \frac{I_{j}}{S_{j, a}}}{\hat{N}_{a}}-1\right) & \\
& =\sum_{s=a}^{T}(s-a) m_{s, a}\left(\sum_{j=a+1}^{s} \frac{I_{j}}{\hat{N}_{a} S_{j, a}}-\sum_{j=a+1}^{T} \frac{I_{j}}{\hat{N}_{a}}\right) .
\end{aligned}
$$

Here is how the gap depends on the process leading to notoriety $\left\{I_{j}\right\}_{j=a . . T}$ :

$$
G_{a}=\sum_{s=a}^{T}(s-a) m_{s, a}\left(\sum_{j=a+1}^{s} \frac{I_{j}\left(1-S_{j, a}\right)}{\hat{N}_{a} S_{j, a}}-\sum_{j=s+1}^{T} \frac{I_{j}}{\hat{N}_{a}}\right) .
$$

To illustrate the effect of a change in the age at which people become famous, suppose that a proportion $\mu$ of all famous people are already famous at age $a$ and that the proportion $1-\mu$ gets famous at age $f>a$. Then the bias is:

$$
B_{a}=\sum_{s=a}^{T}(s-a) m_{s, a}\left(\frac{(1-\mu) \hat{N}_{a}}{\hat{N}_{a} S_{f, a}}\right)=\frac{1-\mu}{S_{f, a}} E_{a} .
$$

The bias is therefore proportional to life expectancy, with the proportionality factor increasing in $f$ (as $S_{f, a}$ is decreasing in $\left.f\right)$ and decreasing in $\mu$. If age at notoriety $f$ changes, we have:

$$
\frac{\partial B_{a}}{\partial f}=-\frac{1-\mu}{S_{f, a}^{2}} E_{a} \frac{\partial S_{f, a}}{\partial f} .
$$

The derivatives depends on the slope of the survival function at age $f$. If it is not too decreasing at $f\left(\frac{\partial S_{f, a}}{\partial f}\right.$ is small), for example when $S$ is concave and $f$ is low enough, the effect on the bias will be small. 


\section{Occupation categories (NOT FOR PUBLICATION)}

Arts and métiers: actor, artist, cantor, collector, composer, designer, dramatist, engraver, goldsmith, illustrator, kapellmeister, lithograph, musician, organist, painter, pewterer, pianist, poet, regisseur, sculptor, singer, violinmaker and violinist.

Business: antiquary, bookseller, banker, printer, publicist, businessman, director, editor, farmer, librarian, industrialist, merchant, trader, manufacturer and wholesaler.

Education: author, academician, dean, lecturer, professor, rector, scholar, student, teacher and writer.

Humanities: archaeologist, classicist, economist, historian, journalist, orientalist, pedagogue, philologe, philosopher and translator.

Law and government: administrator, adviser, ambassador, bailiff, beamter, congressman, consul, councillor, deputy, diplomat, governor, inspector, judge, jurist, lawyer, magistrato, mayor, minister, notary, politician, prefect, president, procureur, secretary, senator and sheriff.

Military: admiral, brigadier-general, captain, colonel, commander, fighter, general, lieutenant, lieutenant-colonel, major, major-general, marshal, military, officer and soldier.

Nobility: baron, chamberlain, duke, earl, king, knight, lord, noble, prince and queen.

Religious: abbot, archbishop, archdeacon, capuchin, cardinal, clergyman, deacon, franciscan, jesuit, martyr, missionary, pastor, piarist, preacher, priest, rabbi, theologian and vicar.

Sciences: agronomist, architect, astronomer, botanist, builder, cartographer, chemist, doctor, engineer, geographer, geologist, inventor, mathematician,naturalist, pharmacist, physician, physicist, surgeon and zoologist.

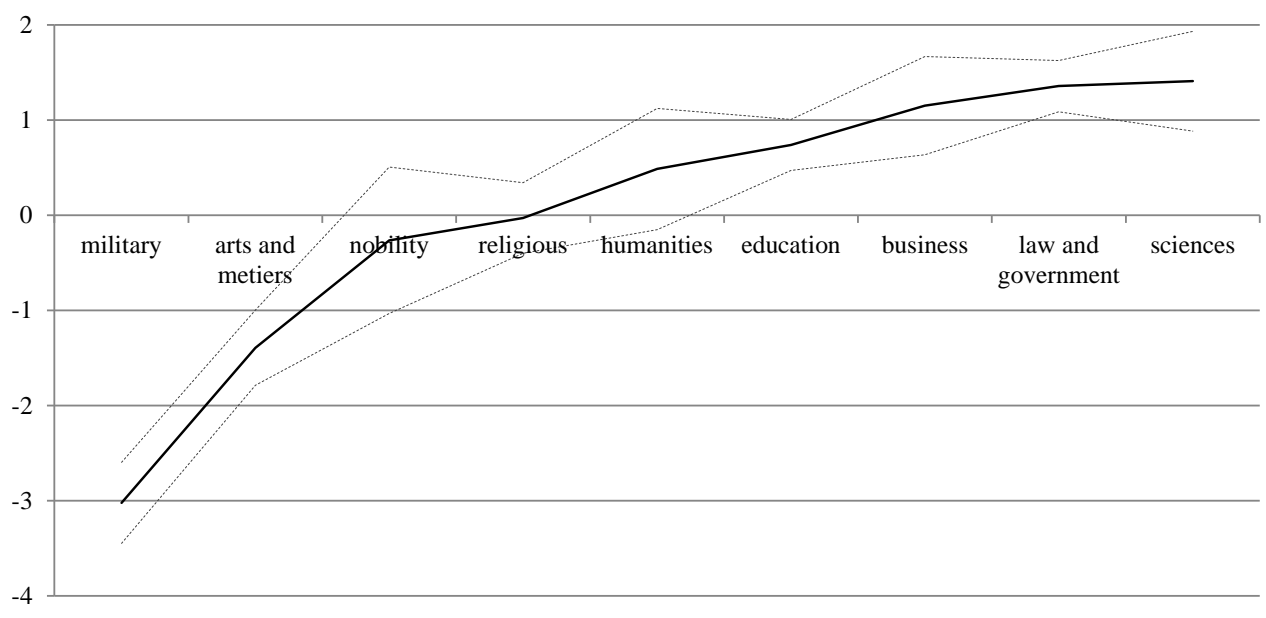

Figure A.3: Conditional Longevity. Main occupational groups 


\section{Analysis of the Residuals (NOT FOR PUBLICATION)}

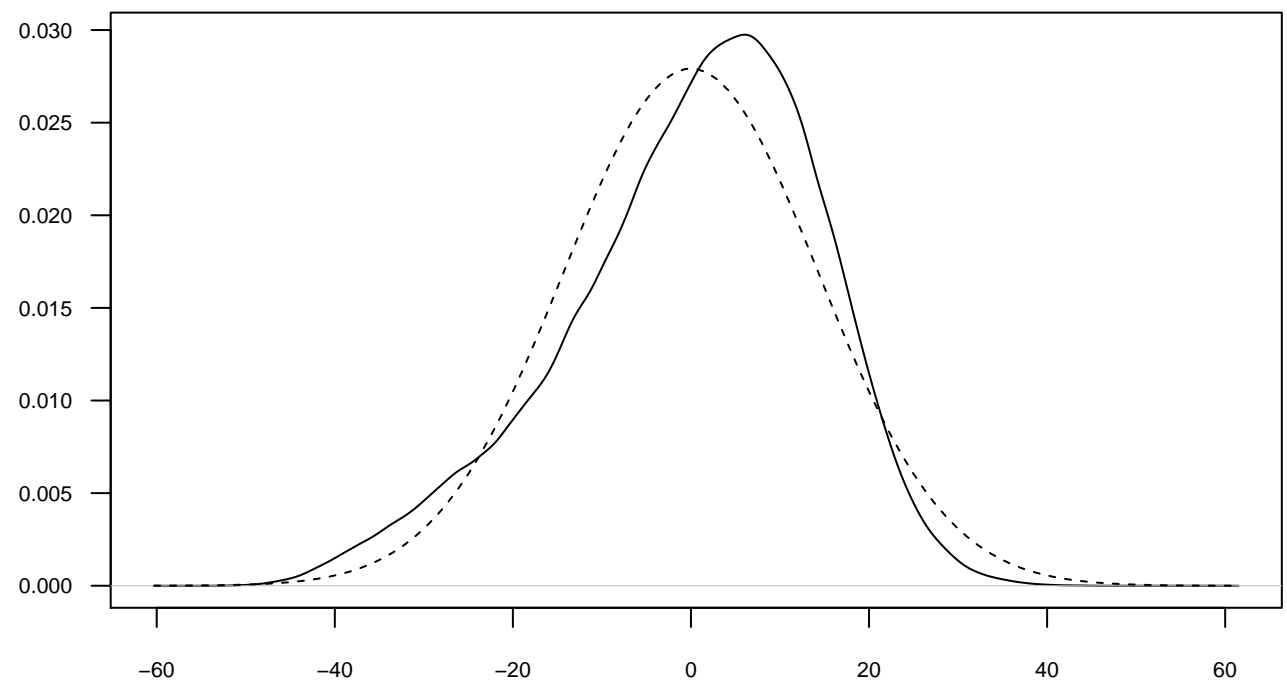

Figure A.4: Kernel Density of the Residuals (solid) and Normal density (dashes)

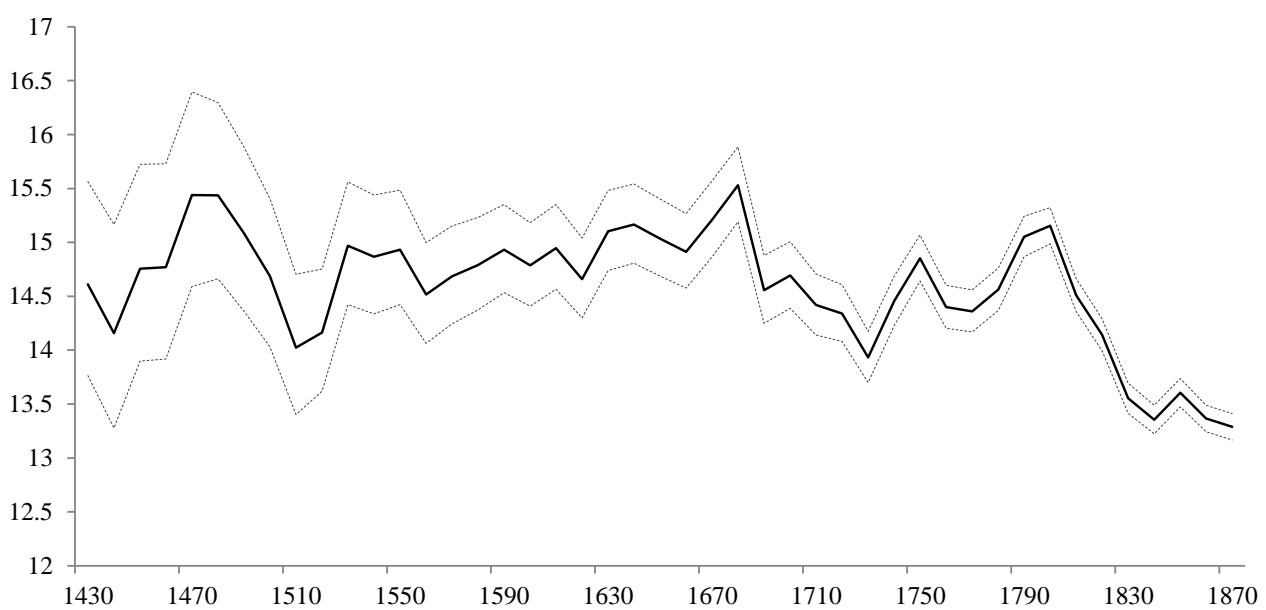

Figure A.5: Standard Deviation of Residuals by Decade, and 95\% confidence interval 


\section{E Longevity per Year of Death (NOT For PUblication)}

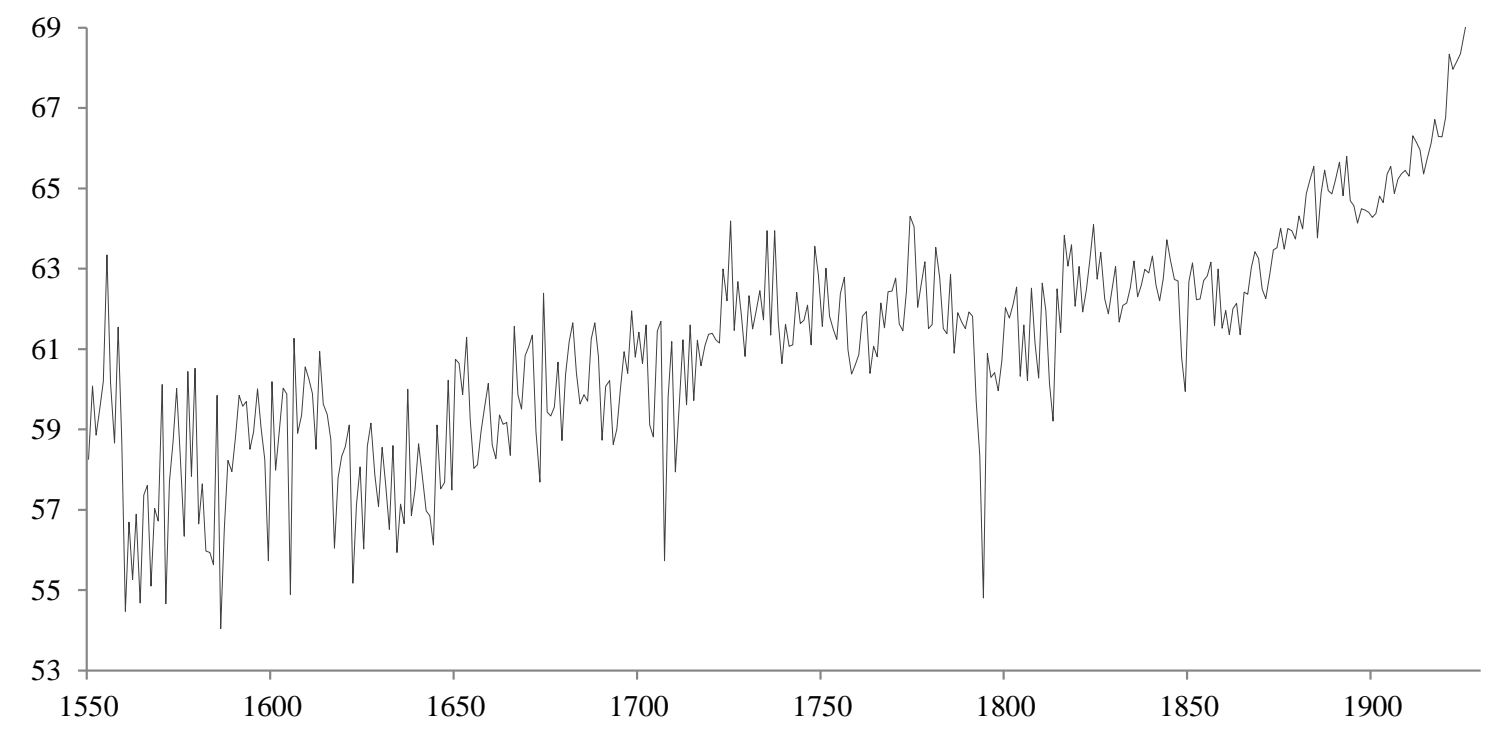

Figure A.6: Longevity per Year of Death 


\section{F 1600 cohorts (NOT FOR PUBLICATION)}

\begin{tabular}{|c|c|c|}
\hline cohort \# & years & \# obs \\
\hline 1 & $2450 \mathrm{BCE}-1040 \mathrm{CE}$ & 1,611 \\
\hline 2 & $1041-1254$ & 1,602 \\
\hline 3 & $1255-1360$ & 1,634 \\
\hline 4 & $1361-1415$ & 1,617 \\
\hline 5 & $1416-1450$ & 1,737 \\
\hline 6 & $1451-1481$ & 1,619 \\
\hline 7 & $1482-1502$ & 1,600 \\
\hline 8 & $1503-1520$ & 1,676 \\
\hline 9 & $1521-1534$ & 1,636 \\
\hline 10 & $1535-1546$ & 1,675 \\
\hline 11 & $1547-1557$ & 1,641 \\
\hline 12 & $1558-1566$ & 1,627 \\
\hline 13 & $1567-1575$ & 1,765 \\
\hline 14 & $1576-1583$ & 1,708 \\
\hline 15 & $1584-1590$ & 1,660 \\
\hline 16 & $1591-1597$ & 1,723 \\
\hline 17 & $1598-1603$ & 1,773 \\
\hline 18 & $1604-1610$ & 1,926 \\
\hline 19 & $1611-1616$ & 1,616 \\
\hline 20 & $1617-1622$ & 1,740 \\
\hline 21 & $1623-1628$ & 1,743 \\
\hline 22 & $1629-1633$ & 1,621 \\
\hline 23 & $1634-1639$ & 1,870 \\
\hline 24 & $1640-1644$ & 1,660 \\
\hline 25 & $1645-1649$ & 1,621 \\
\hline 26 & $1650-1654$ & 1,731 \\
\hline 27 & $1655-1659$ & 1,663 \\
\hline 28 & $1660-1664$ & 1,862 \\
\hline 29 & $1665-1669$ & 1,710 \\
\hline 30 & $1670-1674$ & 1,846 \\
\hline 31 & $1675-1679$ & 1,730 \\
\hline 32 & $1680-1683$ & 1,609 \\
\hline 33 & $1684-1688$ & 1,888 \\
\hline 34 & $1689-1693$ & 1,903 \\
\hline 35 & $1694-1697$ & 1,713 \\
\hline 36 & $1698-1701$ & 1,872 \\
\hline 37 & $1702-1705$ & 1,641 \\
\hline 38 & $1706-1709$ & 1,680 \\
\hline
\end{tabular}




\begin{tabular}{rcr}
\hline \hline cohort \# & years & \# obs \\
\hline 39 & $1710-1713$ & 1,946 \\
40 & $1714-1717$ & 2,023 \\
41 & $1718-1720$ & 1,662 \\
42 & $1721-1724$ & 2,106 \\
43 & $1725-1727$ & 1,763 \\
44 & $1728-1730$ & 1,879 \\
45 & $1731-1733$ & 1,892 \\
46 & $1734-1736$ & 2,046 \\
47 & $1737-1739$ & 1,994 \\
48 & $1740-1742$ & 2,208 \\
49 & $1743-1745$ & 2,298 \\
50 & $1746-1748$ & 2,284 \\
51 & $1749-1750$ & 1,874 \\
52 & $1751-1752$ & 1,795 \\
53 & $1753-1754$ & 1,793 \\
54 & $1755-1756$ & 1,901 \\
55 & $1757-1758$ & 1,834 \\
56 & $1759-1760$ & 1,907 \\
57 & $1761-1762$ & 1,840 \\
58 & $1763-1764$ & 2,042 \\
59 & $1765-1766$ & 2,125 \\
60 & $1767-1768$ & 1,978 \\
61 & $1769-1770$ & 2,231 \\
62 & $1771-1772$ & 2,054 \\
63 & $1773-1774$ & 2,074 \\
64 & $1775-1776$ & 2,041 \\
65 & $1777-1778$ & 2,060 \\
66 & $1779-1781$ & 2,039 \\
67 & $1781-1782$ & 1,867 \\
68 & $1783-1784$ & 1,997 \\
69 & $1785-1786$ & 2,146 \\
70 & $1787-1788$ & 2,255 \\
71 & $1789-1790$ & 2,390 \\
72 & $1791-1792$ & 2,240 \\
73 & $1793-1794$ & 2,436 \\
74 & $1795-1796$ & 2,485 \\
75 & $1797-1798$ & 2,620 \\
76 & $1799-1800$ & 2,950 \\
77 & $1801-1802$ & 3,061 \\
78 & $1803-1804$ & 3,017 \\
\hline & continued on next page \\
\hline \hline & & \\
\hline
\end{tabular}




\begin{tabular}{rcr}
\hline \hline cohort \# & years & \# obs \\
\hline 79 & $1805-1806$ & 3,152 \\
80 & $1807-1808$ & 3,161 \\
81 & $1809-1810$ & 3,322 \\
82 & 1811 & 1,688 \\
83 & 1812 & 1,743 \\
84 & 1813 & 1,611 \\
85 & 1814 & 1,642 \\
86 & 1815 & 1,795 \\
87 & 1816 & 1,624 \\
88 & 1817 & 1,849 \\
89 & 1818 & 1,838 \\
90 & 1819 & 1,805 \\
91 & 1820 & 1,863 \\
92 & 1821 & 1,705 \\
93 & 1822 & 1,731 \\
94 & 1823 & 1,770 \\
95 & 1824 & 1,709 \\
96 & 1825 & 1,845 \\
97 & 1826 & 1,685 \\
98 & 1827 & 1,760 \\
99 & 1828 & 1,746 \\
100 & 1829 & 1,795 \\
101 & 1830 & 1,890 \\
102 & 1831 & 1,692 \\
103 & 1832 & 1,693 \\
104 & 1833 & 1,786 \\
105 & 1834 & 1,775 \\
106 & 1835 & 1,785 \\
107 & 1836 & 1,835 \\
108 & 1837 & 1,873 \\
109 & 1838 & 1,860 \\
110 & 1839 & 1,931 \\
111 & 1840 & 2,069 \\
112 & 1841 & 1,958 \\
113 & 1842 & 2,001 \\
114 & 1843 & 1,972 \\
115 & 1844 & 1,951 \\
116 & 1845 & 2,048 \\
117 & 1846 & 1,953 \\
118 & 1847 & 1,966 \\
\hline & continued on next page \\
\hline & & \\
\hline
\end{tabular}




\begin{tabular}{rcr}
\hline \hline cohort \# & years & \# obs \\
\hline 119 & 1848 & 2,067 \\
120 & 1849 & 1,882 \\
121 & 1850 & 2,097 \\
122 & 1851 & 2,022 \\
123 & 1852 & 2,079 \\
124 & 1853 & 1,901 \\
125 & 1854 & 1,956 \\
126 & 1855 & 2,056 \\
127 & 1856 & 2,134 \\
128 & 1857 & 2,055 \\
129 & 1858 & 2,292 \\
130 & 1859 & 2,239 \\
131 & 1860 & 2,286 \\
132 & 1861 & 2,212 \\
133 & 1862 & 2,304 \\
134 & 1863 & 2,300 \\
135 & 1864 & 2,267 \\
136 & 1865 & 2,296 \\
137 & 1866 & 2,273 \\
138 & 1867 & 2,245 \\
139 & 1868 & 2,410 \\
140 & 1869 & 2,367 \\
141 & 1870 & 2,301 \\
142 & 1871 & 2,128 \\
143 & 1872 & 2,288 \\
144 & 1873 & 2,296 \\
145 & 1874 & 2,286 \\
146 & 1875 & 2,381 \\
147 & 1876 & 2,327 \\
148 & 1877 & 2,267 \\
149 & 1878 & 2,309 \\
150 & 1879 & 2,349 \\
Total & & 297,651 \\
\hline \hline & &
\end{tabular}




\section{G Estimation of the Gomperz-Makeham Law (Not For PUBLICATION)}

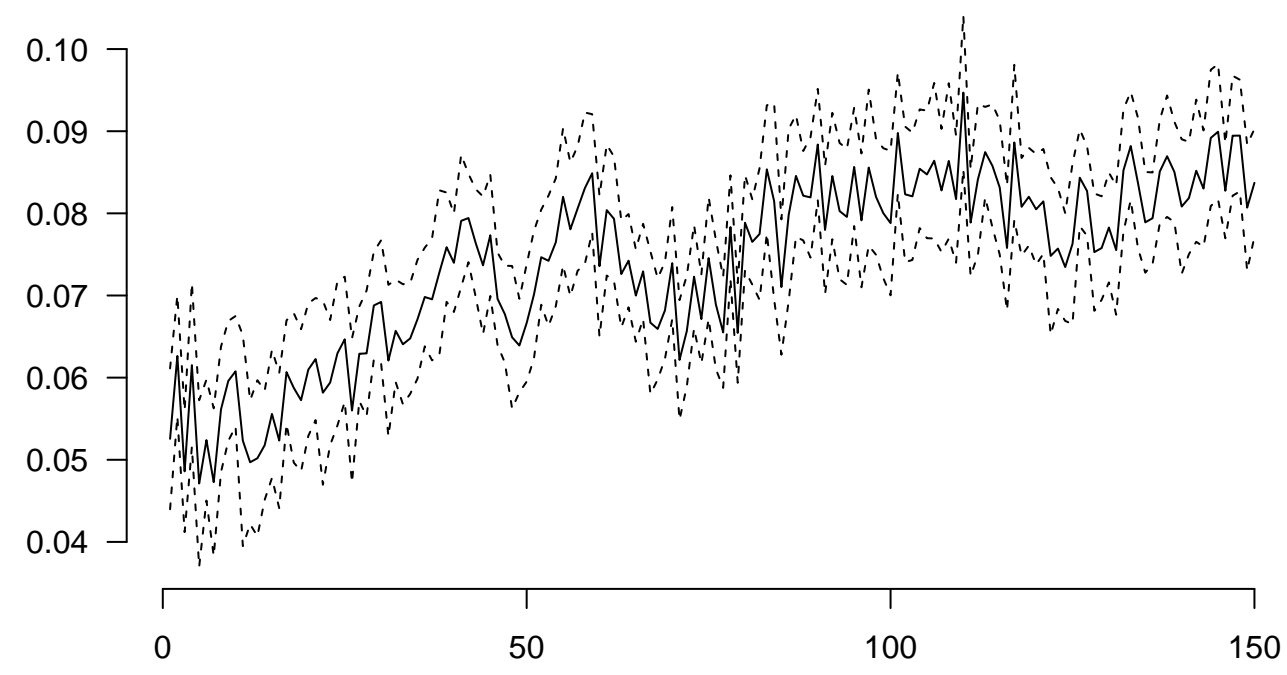

Figure A.7: Estimated $\hat{\alpha}$

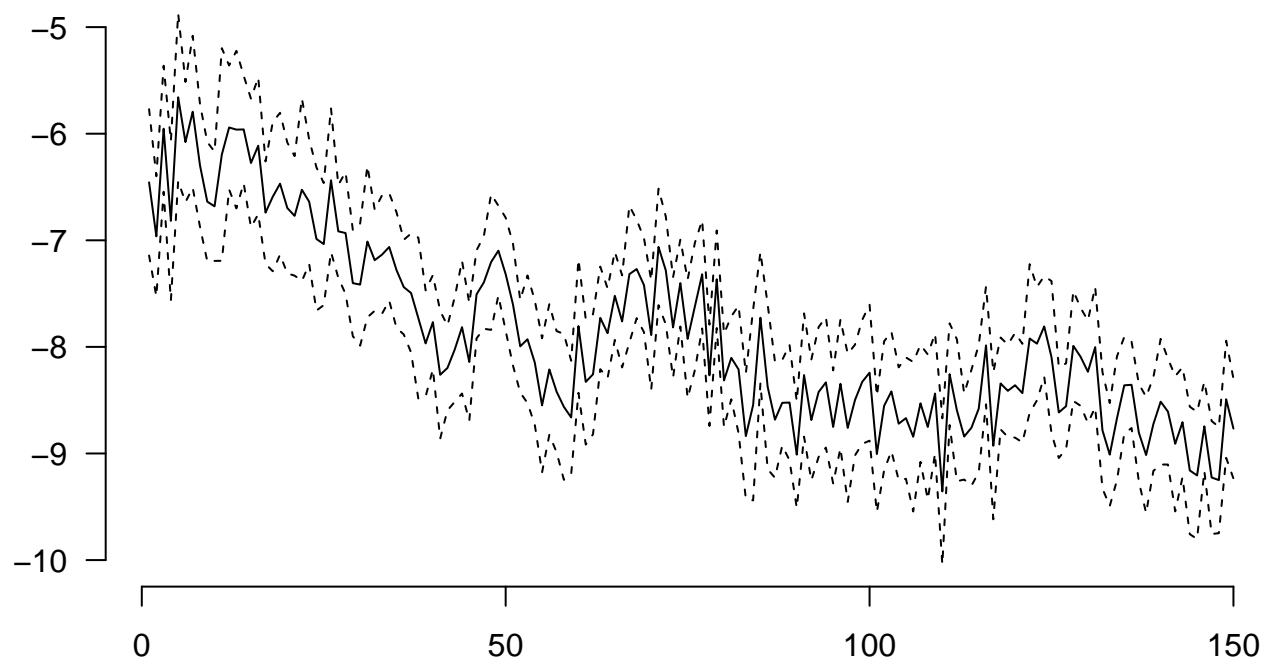

Figure A.8: Estimated $\hat{\rho}$ 

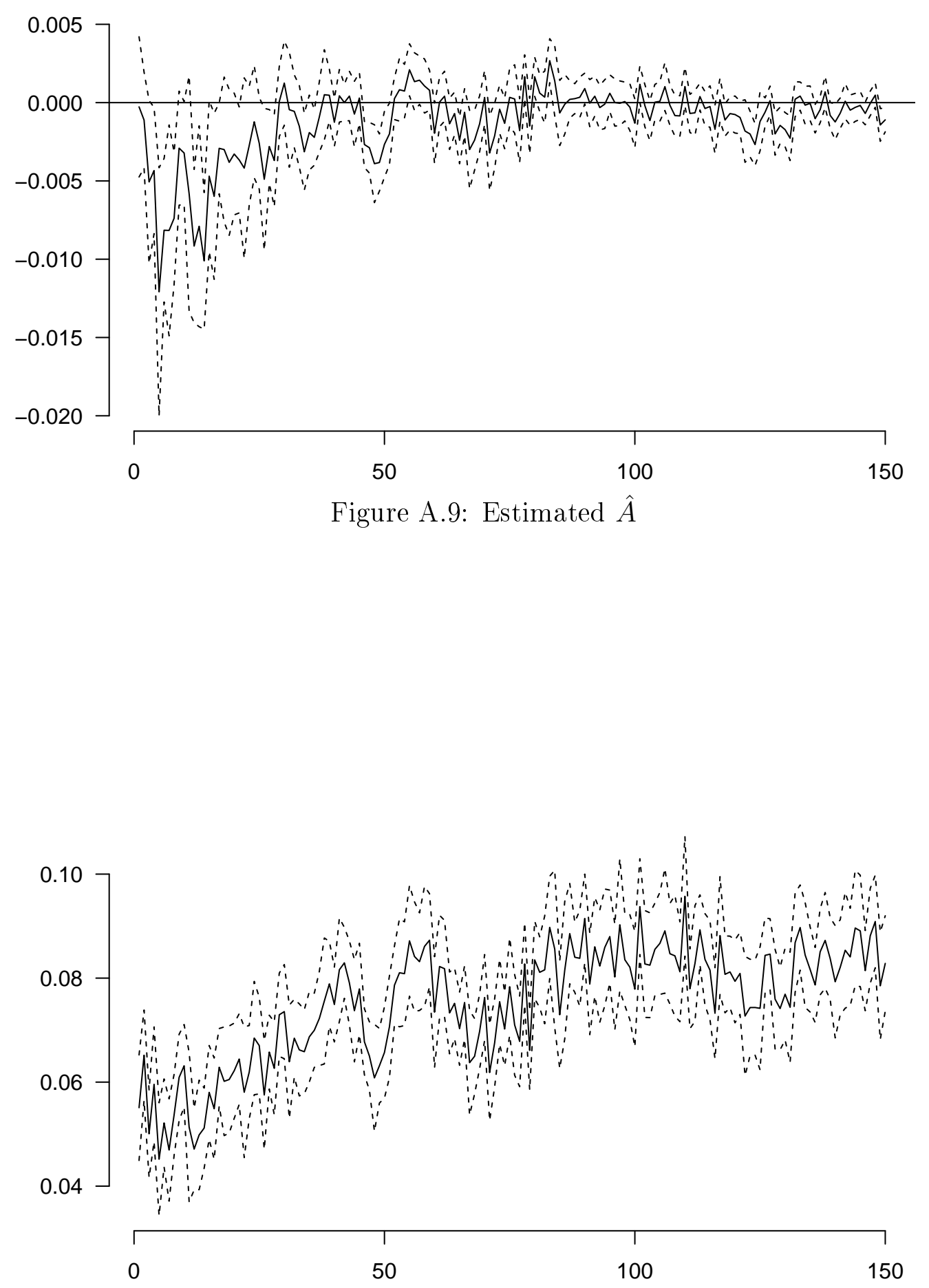

Figure A.10: Estimated $\hat{\alpha}$ - Notoriety Bias Corrected 


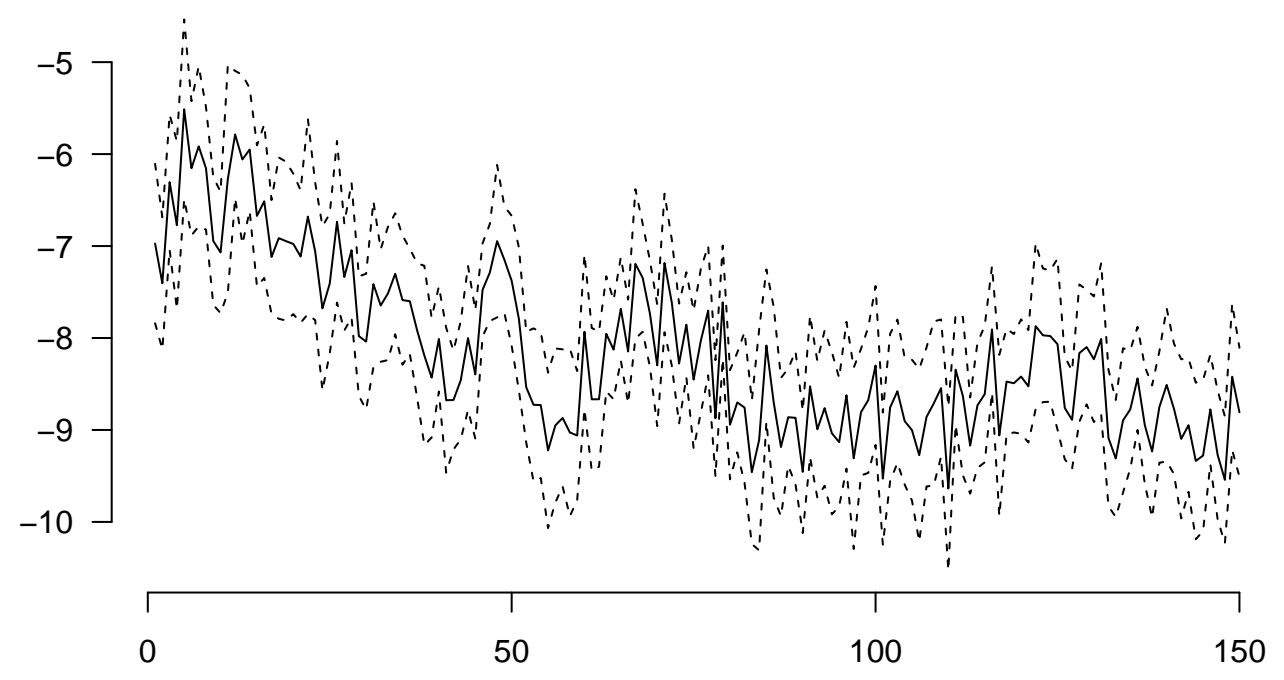

Figure A.11: Estimated $\hat{\rho}$ - Notoriety Bias Corrected

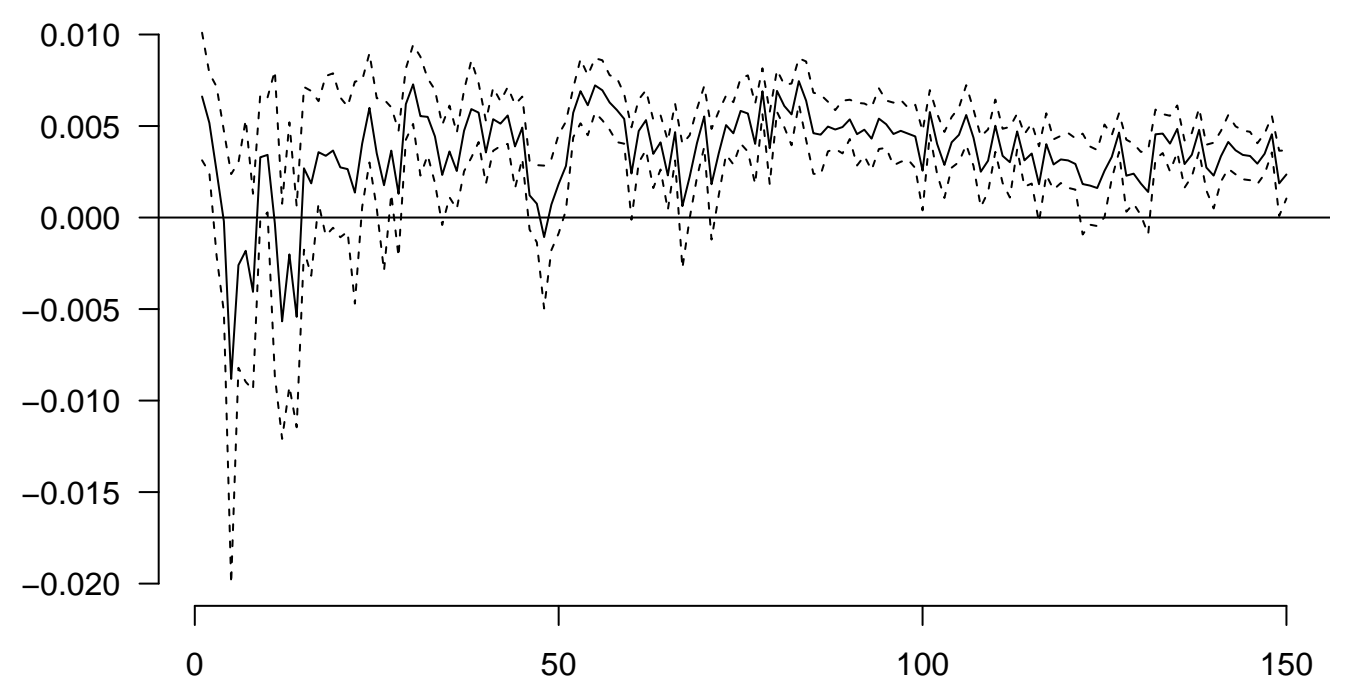

Figure A.12: Estimated $\hat{A}$ - Notoriety Bias Corrected 